\title{
MODELING AND VERIFICATION OF CUTTING TOOL TEMPERATURES IN ROTARY TOOL TURNING OF HARDENED STEEL
}

\author{
A Thesis \\ Presented to \\ The Academic Faculty \\ by \\ Vincent Dessoly \\ In Partial Fulfillment \\ of the Requirements for the Degree \\ Master of Science in Mechanical Engineering
}

Georgia Institute of Technology

April, 2004 
MODELING AND VERIFICATION OF CUTTING TOOL TEMPERATURES IN ROTARY TOOL TURNING OF HARDENED STEEL

Approved:

Dr. Shreyes Melkote, Chair

Dr. Thomas Kurfess

Dr. Steven Liang

Monday, April 9th 


\section{ACKNOWLEDGMENTS}

I acknowledge the support of Caterpillar Inc. and the Georgia Research Alliance for providing the research funds. I am also grateful to Mr. Peter Pasienza of Rotary Technologies Inc. for providing the rotary tool holder and cartridge used in the experiments.

Several individuals provided advice and additional resources that were instrumental in the success of this project. I would like to thank Sathyan Subbiah (Ph.D candidate) and Steven Sheffield (Machine tool specialist) for providing me with an opportunity to use the machines and measure the cutting forces. I thank John Graham for helping me with the hardness measurements. Many thanks are due to my father for giving me advices about the cutting forces analysis. Additionally, I acknowledge the support of Pierre-Emmanuel Deliou (former graduate student) for helping me with the temperature measurements. I would also like to thank Dr. Jonathan Colton for his assistance in using the furnace. I thank Xavier Brun (Ph.D candidate) for helping me with the camera calibration.

I would like to thank the faculty members of the Precision Machining Research Consortium at Georgia Tech including my committee and my advisor, Dr. Shreyes Melkote for providing an outstanding research environment. Dr. Christophe Lescalier is acknowledged for his advice about this project. Finally, I would also like to thank my fellow students. 


\section{TABLE OF CONTENTS}

ACKNOWLEDGMENTS

TABLE OF CONTENTS $\quad$ iv

LIST OF TABLES vii

LIST OF FIGURES viii

LIST OF SYMBOLS $\quad$ xii

SUMMARY $\quad$ XV

CHAPTER 1 INTRODUCTION 1

CHAPTER 2 LITERATURE REVIEW 5

2.1. Basic features of rotary tool processes 5

2.1.1. Generalities 5

2.1.2. Geometry 6

2.1.3. Kinematics 7

2.1.4. Mechanics 16

2.2. Previous studies on temperature modeling in a RT process 16

2.2.1. Study of Chen et al. (1992) 16

2.2.2. Study of Kishawy et al. (2001) 19

$\begin{array}{ll}\text { 2.3. Summary } & 27\end{array}$

CHAPTER 3 TOOL TEMPERATURE MODELING IN SPRT PROCESS 28

3.1. Modeling basics 28

3.2. Model development 31

3.2.1. Governing equation 31 
3.2.3. Heat flux at the tool-chip interface 33

3.2.4. Heat partitioning coefficient, $R_{2} \quad 34$

3.2.5. Boundary conditions 36

3.2.6. Implementation of the model in FEMLAB 38

3.3. Summary 46

$\begin{array}{lll}\text { CHAPTER } 4 & \text { EXPERIMENTAL WORK } & 47\end{array}$

4.1. Machining a hardened AISI 52100 steel 47

4.1.1. Experimental conditions 47

4.1.2. Cutting forces and chip geometry 52

4.2. Temperature measurements 66

4.2.1. Set-up $\quad 66$

4.2.2. Camera calibration $\quad 70$

$\begin{array}{lll}\text { 4.2.3. Sample results } & 71\end{array}$

$\begin{array}{ll}\text { 4.3. Summary } & 72\end{array}$

$\begin{array}{lll}\text { CHAPTER } 5 & \text { RESULTS AND DISCUSSION }\end{array}$

5.1. Tool temperature distribution in rotary tool turning 73

5.2. Tool temperature along the cutting edge in rotary tool turning 76

5.3. Comparison between rotary and fixed tools 81

5.4. Summary 83

$\begin{array}{lll}\text { CHAPTER } 6 & \text { CONCLUSIONS AND RECOMMENDATIONS } & 84\end{array}$

6.1. Model performance 84

6.2. Temperature measurement limitations 84 
APPENDIX A MECHANICS OF ROTARY TOOL PROCESSES

APPENDIX B DISCUSSION ABOUT CHEN'S MODEL

APPENDIX C DISCUSSION ABOUT KISHAWY'S MODEL

APPENDIX D INPUT PARAMETERS

REFERENCES

110 


\section{LIST OF TABLES}

Table 2-1 Rotary tool and corresponding equivalent classical processes. 15

Table 3-1 Thermal and physical properties of tool and workpiece materials. 31

Table 3-2 Mesh settings. $\quad 41$

$\begin{array}{lll}\text { Table 4-1 Hardness measurements } & 48\end{array}$

Table 4-2 Influence on the cutting speed on the forces. 54

Table 4-3 Influence of cutting speed on chip geometry (1). 56

Table 4-4 Influence of cutting speed on chip geometry (2). 57

Table 4-5 Influence of cutting speed on the forces. 64

Table 4-6 Cutting conditions used for temperature measurements. 69

Table 5-1 Average forces and average chip dimensions. $\quad 74$

$\begin{array}{lll}\text { Table 5-2 Model sensitivity. } & 77\end{array}$

$\begin{array}{lll}\text { Table 5-3 Maximum measured chip temperature } & 77\end{array}$

Table A-1 Rotary tool and corresponding perfectly equivalent classical $\quad 98$

Table C-1 Geometric and kinematics parameters in rotary tool turning. 109

Table C-2 Mechanical and thermal parameters in rotary tool turning. 109 


\section{LIST OF FIGURES}

Figure 1-1 Three basic types of cutting tools, (a) orthogonal tool, (b) oblique tool, 2 (c) tool with moving edge-slicing action (Shaw et al., 1952).

Figure 1-2 Schematic of the self-propelled rotary tool process. 2

Figure 2-1 Rotary cutting process as observed from fixed point (a) in space, (b) on tool (Armarego et al., 1994).

Figure 2-2 Tool on centre, orthogonal driven rotary tool cutting process

(Armarego et al., 1994).

Figure 2-3 Tool above and below centre, driven or self-propelled oblique rotary tool processes (Armarego et al., 1994).

Figure 2-4 Tilted tool, self-propelled oblique rotary tool process (Armarego et al, 1994.).

Figure 2-5 Driven oblique rotary tool and corresponding equivalent

"classical" processes (Armarego et al., 1994).

Figure 2-6 Driven orthogonal rotary tool and corresponding equivalent "classical" processes (Armarego et al., 1994).

Figure 2-7 Rotating friction zone (Chen et al., 1992).

Figure 2-8 Moving heat source model (Chen et al., 1992).

Figure 2-9 (a) Physical domain (rotary tool),

(b) Computational domain (parallelepiped).

Figure 2-10 Representation of a control-volume.

Figure 2-11 Simplified model for the tool, the chip and the chip-tool interface (Kishawy et al., 2001).

Figure 3-1 Energy partitioning diagram.

Figure 3-2 Simplified energy partitioning diagram.

Figure 3-3 Simplified tool-chip interface.

Figure 3-4 Equivalent heat sources. 
Figure 3-5 Tool surfaces subjected to convection.

$\begin{array}{lll}\text { Figure 3-6 Insulated tool surfaces. } & 37\end{array}$

Figure 3-7 Tool-chip interface subjected to a heat- flux. 38

Figure 3-8 Tool in draw mode. 39

Figure 3-9 Tool-chip interface in boundary mode. 40

Figure 3-10 Tool in mesh mode. $\quad 41$

$\begin{array}{lll}\text { Figure 3-11 Rotary tool in post mode. } & 42\end{array}$

Figure 3-12 Fixed tool in post mode. 43

Figure 3-13 Preliminary comparison of predicted trends with published data 44

Figure 3-14 Temperature distribution along the cutting edge in rotary tool turning. 45

$\begin{array}{lll}\text { Figure 4-1 Tool holder, rotary and fixed tool cartridges. } & 48\end{array}$

Figure 4-2 Actual self-propelled rotary tool process. 49

Figure 4-3 Analog filter and charge amplifier. 51

Figure 4-4 Fixed tool, $\mathrm{V}_{\mathrm{w}}=20 \mathrm{~m} / \mathrm{min}, \mathrm{f}=0.1 \mathrm{~mm} / \mathrm{rev}, \mathrm{a}_{\mathrm{p}}=0.2 \mathrm{~mm}$.

Figure 4-5 Rotary tool, $\mathrm{V}_{\mathrm{w}}=20 \mathrm{~m} / \mathrm{min}, \mathrm{f}=0.1 \mathrm{~mm} / \mathrm{rev}, \mathrm{a}_{\mathrm{p}}=0.2 \mathrm{~mm}$.

Figure 4-6 Influence of cutting speed on cutting force. 54

Figure 4-7 Influence of cutting speed on thrust force. 55

Figure 4-8 Influence of cutting speed on feed force. 55

Figure 4-9 Influence of cutting speed on the average deformed chip thickness. 57

Figure 4-10 Influence of cutting speed on the average chip width. 58

Figure 4-11 Rotary tool, $\mathrm{V}_{\mathrm{w}}=20 \mathrm{~m} / \mathrm{min}, \mathrm{f}=01 \mathrm{~mm} / \mathrm{rev}, \mathrm{a}_{\mathrm{p}}=0.05 \mathrm{~mm} . \quad 60$

Figure 4-12 Fixed tool, $\mathrm{V}_{\mathrm{w}}=20 \mathrm{~m} / \mathrm{min}, \mathrm{f}=0.1 \mathrm{~mm} / \mathrm{rev}, \mathrm{a}_{\mathrm{p}}=0.05 \mathrm{~mm}$, first cut. 61

Figure 4-13 Fixed tool, $\mathrm{V}_{\mathrm{w}}=20 \mathrm{~m} / \mathrm{min}, \mathrm{f}=0.1 \mathrm{~mm} / \mathrm{rev}, \mathrm{a}_{\mathrm{p}}=0.05 \mathrm{~mm}$, second cut. $\quad 61$ 
Figure 4-14 Fixed tool, $\mathrm{V}_{\mathrm{w}}=20 \mathrm{~m} / \mathrm{min}, \mathrm{f}=0.1 \mathrm{~mm} / \mathrm{rev}, \mathrm{a}_{\mathrm{p}}=0.05 \mathrm{~mm}$, third cut. 62

Figure 4-15 Measurement of the displacement of the fixed tool. 62

Figure 4-16 Fixed tool, flank wear, $V_{w}=20 \mathrm{~m} / \mathrm{min}, \mathrm{f}=0.1 \mathrm{~mm} / \mathrm{rev}, \mathrm{a}_{\mathrm{p}}=0.05 \mathrm{~mm} . \quad 63$

Figure 4-17 Rotary tool, flank wear, $\mathrm{V}_{\mathrm{w}}=20 \mathrm{~m} / \mathrm{min}, \mathrm{f}=0.1 \mathrm{~mm} / \mathrm{rev}, \mathrm{a}_{\mathrm{p}}=0.05 \mathrm{~mm} .63$

Figure 4-18 Influence of cutting speed on cutting force. 64

Figure 4-19 Influence of cutting speed on thrust force. 65

Figure 4-20 Influence of cutting speed on feed force. 65

Figure 4-21 Temperature measurement set-up. $\quad 69$

Figure 4-22 Camera calibration for the tool material. 70

Figure 4-23 Camera calibration for the workpiece material. 71

Figure 4-24 Rotary tool temperature distribution using 72 an IR thermal imaging camera.

Figure 5-1 Rotary tool predicted temperature distribution (in ${ }^{\circ} \mathrm{K}$ ), $\quad 74$ $\mathrm{Vw}=10 \mathrm{~m} / \mathrm{min}, \mathrm{f}=0.1 \mathrm{~mm} / \mathrm{rev}$, ap $=0.05 \mathrm{~mm}$.

Figure 5-2 Rotary tool-chip interface predicted temperature distribution (in ${ }^{\circ} \mathrm{K}$ ), $\quad 75$ $\mathrm{Vw}=10 \mathrm{~m} / \mathrm{min}, \mathrm{f}=0.1 \mathrm{~mm} / \mathrm{rev}$, ap $=0.05 \mathrm{~mm}$.

Figure 5-3 Rotary tool measured temperature distribution (in ${ }^{\circ} \mathrm{K}$ ), $\mathrm{Vw}=10 \mathrm{~m} / \mathrm{min}, \mathrm{f}=0.1 \mathrm{~mm} / \mathrm{rev}$, ap $=0.05 \mathrm{~mm}$.

Figure 5-4 Cutting temperature along the cutting edge, $\mathrm{Vw}_{\mathrm{w}}=10 \mathrm{~m} / \mathrm{min} . \quad 78$

Figure 5-5 Cutting temperature along the cutting edge, $\mathrm{Vw}=15 \mathrm{~m} / \mathrm{min} . \quad 78$

Figure 5-6 Cutting temperature along the cutting edge, $\mathrm{Vw}=20 \mathrm{~m} / \mathrm{min}$. 79

Figure 5-7 Cutting temperature along the cutting edge, $\mathrm{Vw}=25 \mathrm{~m} / \mathrm{min}$. 79

Figure 5-8 Predicted and measured temperature comparison at a given point $\quad 80$ on the tool rake face.

Figure 5-9 Fixed tool measured temperature distribution $\left(\right.$ in $\left.{ }^{\circ} \mathrm{C}\right)$, $\mathrm{Vw}=10 \mathrm{~m} / \mathrm{min}, \mathrm{f}=0.1 \mathrm{~mm} / \mathrm{rev}$, ap $=0.05 \mathrm{~mm}$. 
Figure 5-10 Rotary and fixed tools temperatures along the cutting edge, $\mathrm{Vw}=10 \mathrm{~m} / \mathrm{min}$.

Figure 5-11 Rotary and fixed tools temperatures along the cutting edge, $\mathrm{Vw}=15 \mathrm{~m} / \mathrm{min}$.

Figure A-1 Driven oblique rotary tool cutting model (Armarego et al., 1994). 88

Figure A-2 Driven orthogonal rotary tool cutting model (Armarego et al., 1994). 95

Figure A-3 Self-propelled oblique rotary tool cutting model 96 (Armarego et al., 1994). 


\section{LIST OF SYMBOLS}

Note:

- Vectors are in bold type and their magnitudes are in normal type.

- The units follow the SI system.
$a_{c} a_{t}$
chip and tool diffusivity respectively
$\mathrm{B}, \mathrm{B}_{\mathrm{c}}$
workpiece and chip width in rotary tool process for Armarego et al.
B
width of cut in "classical" oblique cutting and equivalent width of
cut for Armarego et al.
$\mathrm{b}, \mathrm{b}_{\mathrm{c}} \quad$ width of cut and chip width
$\mathrm{c}_{\mathrm{t}} \quad$ tool heat capacity
F friction force on rake face
$\mathbf{F}_{\mathbf{P}} \quad$ cutting force component in the $\mathbf{V}$ direction
$\mathbf{F}_{\mathbf{Q}} \quad$ cutting force component in the $\mathrm{P}_{\mathrm{n}}$ normal to $\mathbf{F}_{\mathbf{P}}$
$\mathbf{F}_{\mathbf{R}} \quad$ cutting force component mutually perpendicular to $\mathbf{F}_{\mathbf{P}}$ and $\mathbf{F}_{\mathbf{Q}}$
$\mathbf{F}_{\mathrm{s}} \quad$ shear force in the shear plane
$\mathbf{F}_{\mathbf{P t}} \quad$ total cutting force component in the $\mathbf{V}$ direction
$\mathbf{F}_{\mathbf{Q t}} \quad$ total cutting force component in the $\mathrm{P}_{\mathrm{n}}$ normal to $\mathbf{F}_{\mathbf{P}}$
$\mathbf{F}_{\mathbf{R t}} \quad$ total cutting force component mutually perpendicular to $\mathbf{F}_{\mathbf{P}}$ and $\mathbf{F}_{\mathbf{Q}}$
i inclination angle between $\mathbf{V}$ and $\mathrm{P}_{\mathrm{n}}$
$\mathrm{i}_{\mathrm{s}} \quad$ static inclination angle between $\mathbf{V}_{\mathrm{w}}$ and $\mathrm{P}_{\mathrm{n}}$
$\mathrm{K} 1_{\mathrm{P}}, \mathrm{K} 1_{\mathrm{Q}}, \mathrm{K} 1_{\mathrm{R}} \quad$ edge force per unit width in $\mathbf{F}_{\mathbf{P}}, \mathbf{F}_{\mathbf{Q}}$ and $\mathbf{F}_{\mathbf{R}}$ directions 


\begin{tabular}{|c|c|}
\hline $1,1_{c}$ & length of "workpiece" and chip respectively \\
\hline$l_{\mathrm{f}}$ & tool-chip contact length \\
\hline$P_{n}$ & normal plane, the plane normal to the cutting edge \\
\hline $\mathrm{P}$ & total cutting power $=\mathrm{F}_{\mathrm{Pt}} \mathrm{V}$ \\
\hline $\mathrm{Q}_{1}, \mathrm{Q}_{2}, \mathrm{Q}_{3}$ & heat dissipated at the primary, secondary and tertiary zone \\
\hline & respectively \\
\hline$r_{b}, r_{t}$ & chip width and chip thickness ratio \\
\hline$r_{1}$ & absolute chip length ratio \\
\hline$r_{l r}$ & relative chip length ratio \\
\hline $\mathrm{R}_{1}, \mathrm{R}_{2}, \mathrm{R}_{3}$ & heat partitioning coefficients of the primary, secondary and tertiary \\
\hline & zones respectively \\
\hline $\mathrm{t}$ & undeformed chip thickness \\
\hline$t_{c}$ & deformed chip thickness \\
\hline $\mathrm{U}$ & total specific cutting power or total specific cutting energy \\
\hline $\mathbf{V}$ & resultant or relative cutting velocity \\
\hline $\mathbf{V}_{\mathbf{c}}$ & absolute chip velocity \\
\hline $\mathbf{V}_{\mathrm{cr}}$ & relative chip velocity \\
\hline $\mathbf{V}_{\mathbf{f}}$ & feed rate \\
\hline $\mathbf{V}_{\mathbf{r}}$ & rotary tool peripheral velocity \\
\hline $\mathbf{V}_{\mathrm{s}}$ & velocity in shear plane \\
\hline $\mathbf{V}_{\mathbf{w}}$ & absolute workpiece or cutting velocity \\
\hline
\end{tabular}




$\begin{array}{ll}\text { GREEK } & \\ \alpha_{\mathrm{n}} & \text { normal rake angle in } \mathrm{P}_{\mathrm{n}} \\ \beta, \beta_{\mathrm{n}} & \left.\text { friction angle and normal friction (in } \mathrm{P}_{\mathrm{n}}\right) \\ \eta_{\mathrm{c}} & \text { relative chip flow angle (between } \mathrm{V}_{\mathrm{cr}} \text { and } \mathrm{P}_{\mathrm{n}} \text { ) } \\ \eta_{\mathrm{c}}, & \left.\text { friction force angle (between } \mathrm{F} \text { and } \mathrm{P}_{\mathrm{n}}\right) \\ \eta_{\mathrm{s}} & \left.\text { shear flow angle (between } \mathrm{V}_{\mathrm{s}} \text { and } \mathrm{P}_{\mathrm{n}}\right) \\ \eta_{\mathrm{s}}, & \left.\text { shear force angle (between } \mathrm{F}_{\mathrm{s}} \text { and } \mathrm{P}_{\mathrm{n}}\right) \\ \tau & \text { shear stress in the shear plane } \\ \phi_{\mathrm{n}} & \text { normal shear angle in } \mathrm{P}_{\mathrm{n}} \\ \psi & \left.\text { absolute chip flow angle (between } \mathrm{V}_{\mathrm{c}} \text { and } \mathrm{P}_{\mathrm{n}}\right) \\ \rho_{\mathrm{t}} & \text { projected absolute chip flow angle } \\ \omega_{\mathrm{r}} & \text { rotational tool frequency } \\ & \begin{array}{l}\text { tool density } \\ \end{array}\end{array}$




\section{SUMMARY}

One of the main features of any material removal process is that a significant portion of the mechanical energy generated by the interaction of the tool and the workpiece is converted into heat. In metal cutting, this energy is mainly created by shearing and friction and is dissipated through conduction of heat into the tool, the workpiece and the chip. This results in an increase in tool temperature which accelerates the tool wear. Tool wear is not desirable because both tool life and the accuracy of the machined surface are adversely affected.

Several methods have been investigated by researchers in order to lower the tool temperature. In particular, the use of cutting fluids that serve as both a heat transport mechanism and as a lubricant at the tool-chip interface has been studied and used in practice today. However, in some cases, its effectiveness is limited by its inability to penetrate the tool-chip interface. Furthermore, these days, the use of cutting fluids is less desirable because of its adverse effect on the environment. Some investigations have reported that exposure to particles generated by evaporation of cutting fluids can cause breathing trouble and skin irritation.

A novel method to decrease the cutting temperature is to use a rotating cutting edge in the form of a disk. This type of device is known as a rotary tool and it provides a rest period for the cutting edge thereby allowing for the edge to be cooled and a continuously fresh portion of the edge to be engaged with the workpiece. This enables the tool wear to be distributed uniformly along the entire periphery of the cutting tool. 
In order to quantify the beneficial characteristics this type of tool, an analysis of the cutting temperatures involved in such a process is presented in this thesis. To do so, a predictive tool temperature model is developed using the finite element method. To determine the effectiveness of this model, tool rake face temperature measurements have been made with an infra-red thermal imaging camera. The thesis also presents a comparison of rotary tool temperatures and an equivalent circular fixed tool temperature and quantifies the influence of tool rotation. The analysis has been carried out for classical longitudinal turning of the outer diameter of a 52100 hardened steel (58 HRC) bar. Hard turning is investigated since tool wear is of particular concern to make this process viable compared to the well-established grinding process. Predicted and measured tool temperatures show good overall agreement along the cutting edge. The measured temperatures are found to be up to $50^{\circ} \mathrm{C}$ lower in rotary tool cutting than in fixed tool cutting under the same conditions.

The tool temperature distribution model can be used to obtain a good idea of the cutting temperatures occurring during a rotary tool cutting process. In addition, the results obtained in this work are encouraging in terms of tool wear and tool life enhancement. 


\section{CHAPTER 1 \\ INTRODUCTION}

The chip formation process in machining is accompanied by heat generation, which influences the mechanical and physical properties of both the workpiece and the cutting tool. High temperatures tend to accelerate thermal softening of the tool and subsequent tool wear, which are not desirable because they negatively impact the accuracy of the machined surface and tool life.

There are many approaches to minimize the impact of heat generation on tool life in metal cutting. A first approach is to use a cutting fluid but its effectiveness is limited by its ability to penetrate between the tool and the chip and the use of cutting fluids is now being questioned on health terms. One novel approach is to remove the heat generated through a cooling cycle as in interrupted cutting. The idea is to either translate a wide tool to the side as it moves forward relative to the workpiece, which allows for dissipation of heat throughout the body of the tool (Figure 1-1(c)), or to use a cutting edge in the form of a disk that rotates about its principal axis. The latter, known as a rotary tool (Figure 1-2), provides a rest period for the cutting edge, thus enabling the edge to be cooled and a continuously fresh portion of the edge to be engaged with the workpiece. Such a tool has the potential to enhance the tool life and lower the high cost of replacing the cutting tool in machining of hardened steels using the single point turning process. Insert rotation can be either externally driven (Driven Rotary Tool) or generated by a self-propelling action induced by chip formation (Self-Propelled Rotary Tool) (Armarego et al., 1994). 


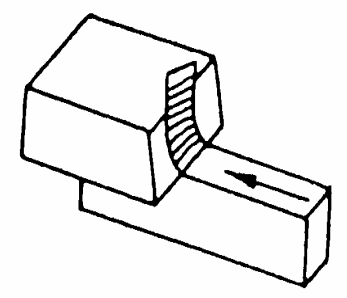

a
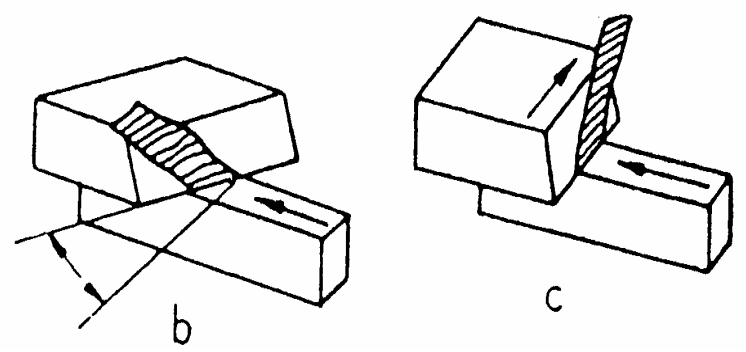

Figure 1-1: Three basic types of cutting tools, (a) orthogonal tool, (b) oblique tool, (c) tool with moving edge-slicing action (Shaw et al., 1952).

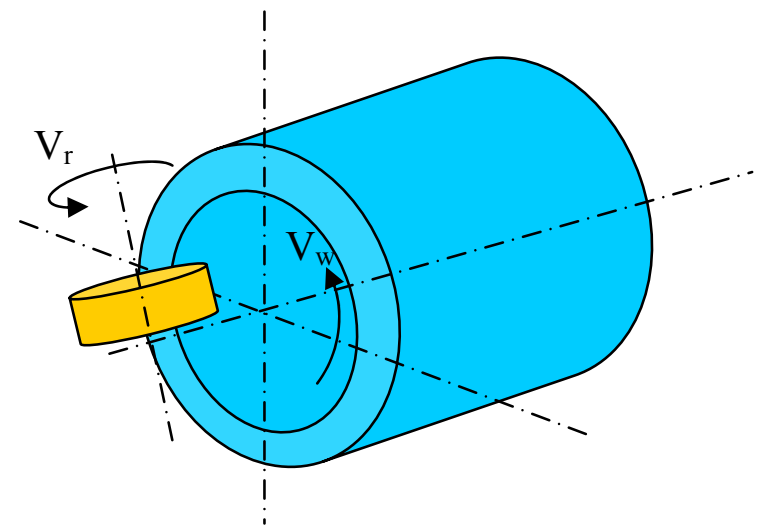

Figure 1-2: Schematic of the self-propelled rotary tool process.

Conventional methods of machining hardened materials usually involve rough machining of the annealed workpiece followed by heat treatment, grinding and superfinishing or honing. The main issues with this multi-step process are obviously its high cost and time. Also, this process requires several machines for each operation. Hard turning refers to single point machining of materials approximately $45 \mathrm{HRC}$ and higher using extremely hard, wear-resistant cutting tools such as polycrystalline cubic boron nitride (PCBN) or ceramics. This process can yield material removal rates close to rough 
machining and surface characteristics comparable to grinding, using a single machine tool. This provides an attractive alternative to the conventional machining sequence because the number of operations is reduced and the entire machining process can be performed after heat treatment. Moreover, machine tools used for hard turning are typically cheaper than those used for grinding and chips generated during hard turning are easier to recycle than grinding swarf. Therefore, hard turning provides cost savings and environmental advantages when used as a replacement for grinding operations.

Since very limited work has been reported in modeling and validating tool temperature in rotary tool based hard turning, this thesis addresses two major research objectives:

1. Modeling of the tool temperature distribution in self-propelled rotary tool (SPRT) in machining of hardened steel where tool life is of particular concern.

2. Experimental model validation through measurements of the cutting tool temperature distribution using an infra-red thermal imaging camera under different cutting conditions.

Since tool life is significantly influenced by cutting temperatures, a model is developed to analyze the heat transfer and temperature distribution in rotary tool turning of hardened 52100 steel (58 HRC). The model is based on the moving heat source theory of conduction and employs the Finite Element Method (FEM) for its solution. Moreover, both rotary and equivalent fixed tool cutting processes are compared in terms of cutting tool temperatures generated.

The thermal modeling and solution approach in this work is significantly simpler than in previous work (Chen 1992, Kishawy et al. 2001). Furthermore, unlike previous 
rotary tool temperature modeling and verification efforts, actual temperature distribution is experimentally verified.

\section{Thesis outline}

Chapter 2 provides an overview of prior work related to rotary tool turning, with an emphasis on investigations of the process itself and cutting temperatures. A description of predictive temperature model developed in this work is provided in Chapter 3. Chapter 4 provides a description of the experimental work on rotary tool temperature measurements. This chapter also discusses forces and chip formation

involved in the SPRT process. Chapter 5 provides results in terms of predicted and measured temperatures and pertinent discussion of the results. Finally, the conclusions and recommendations for future work are presented in Chapter 6. 


\section{CHAPTER 2}

\section{LITERATURE REVIEW}

This chapter provides a review of prior research related to rotary tool turning with an emphasis on investigations considering specific aspects of the process itself and cutting temperatures involved in this process. This chapter begins by providing the basics of the rotary tool process such as kinematics and mechanics. This chapter also provides an overview of influential work related to cutting temperatures in rotary tool turning. Finally, this chapter concludes by describing limitations of prior work and emphasizing the need for a study of factors largely ignored by these investigations.

\subsection{Basic features of rotary tool processes}

\subsubsection{Generalities}

Generally, rotary tool turning is a cutting process in which the cutting edge of a round insert rotates about its axis, so that a continuously indexed cutting edge is fed into the cutting zone. Compared to a conventional stationary tool or non-rotating circular tool, rotary tool allows each portion of the cutting edge to be cooled between engagements and makes use of the entire circumference of the edge which has a positive influence on lowering overall tool temperature.

Insert rotation can be either externally driven (Driven Rotary Tool) or generated by a self-propelling action induced by chip formation (Self-Propelled Rotary Tool). Venuvinod et al. (1981) studied the mechanics of the DRT process. Shaw et al. (1952) investigated the DRT process and measured the average tool-chip interface temperatures 
using the tool-work thermocouple technique. Armarego et al. (1997) investigated the mechanics of both DRT and SPRT processes theoretically and experimentally.

Like conventional cutting processes, the rotary tool cutting process is classified as orthogonal or oblique depending on whether the workpiece velocity is perpendicular to the rotary tool cutting edge or not, respectively. The DRT can be both, whereas the SPRT requires the cutting edge to be at an oblique angle to the cutting speed in order to derive its motion. The insert rotation about its axis is derived from the cutting force parallel to the workpiece velocity. Consequently, the static inclination angle $i_{s}$ must be non-zero for the tool to rotate.

In self-propelled tool cutting process, another way to explain the diminution of temperature could be given. Indeed, in metal cutting the temperature in the tool-chip interface depends on the balance between the generation and the dissipation of heat. In conventional cutting, the consumed power is largely converted into heat. In rotary tool cutting, some energy is required to drive the tool and is turned into kinetic energy. Thus, the heat generation is reduced (Wuyi et al., 1991).

\subsubsection{Geometry}

Geometrically, the DRT is a frustrum of a cone which may be inverted such that the base acts as the rake face or used upright with the periphery of the cone surface acting as the rake face. The SPRT is also a frustrum of a cone (because of the clearance angle) but is very thin. It looks like the conventional fixed circular insert. In both cases, the cutting edge is a circular. In most of studies, the tool rake face is supposed to be a plane normal to the insert rotation axis. Also, it is important to note that both orientation 
(inclinations) and position (with respect to the workpiece axis) of the tool are predominant parameters and will be discussed in the following section.

\subsubsection{Kinematics}

Like stationary tools, two motions are important in a rotary tool process:

- Cutting motion, rotational speed of the workpiece $\mathrm{N}_{\mathrm{w}}$.

- Feed motion of the tool into the piece $f$.

The main feature of a rotary tool is that the tool also rotates. Thus, a third motion, i.e. rotational speed of the tool, $\mathrm{N}_{\mathrm{r}}$ occurs in this process.

The consequences of this characteristic concern the kinematics and the mechanics

of the chip formation process. Indeed, it is obvious that the spin of the tool deviates the chip flow velocity vector.

Also, the effect of feed rate $V_{f}$ can be ignored because its value is much smaller than the cutting speed $V_{w}$ and $V_{r}$. Thus, the following relations between the different velocities can be derived.

$$
\begin{aligned}
& \vec{V}=\vec{V}_{w}-\vec{V}_{r} \\
& \vec{V}_{c r}=\vec{V}_{c}-\vec{V}_{r}
\end{aligned}
$$

Consequently, the mechanism is studied in the frame of the tool where the cutting edge is assumed to be a straight line since the tool radius is large compared to other geometric parameters (Figure 2-1). 


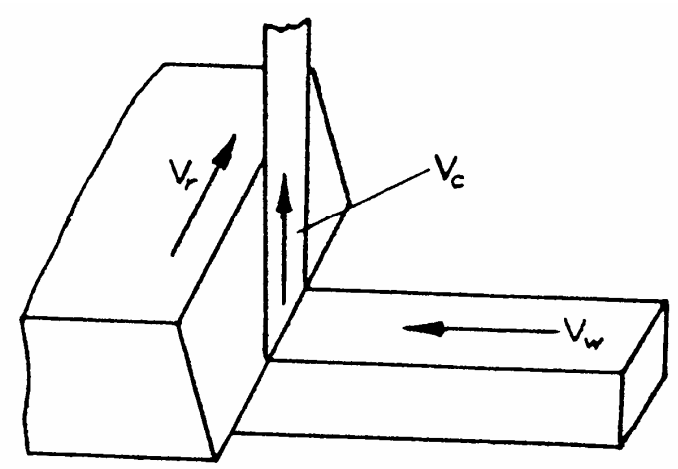

(a)

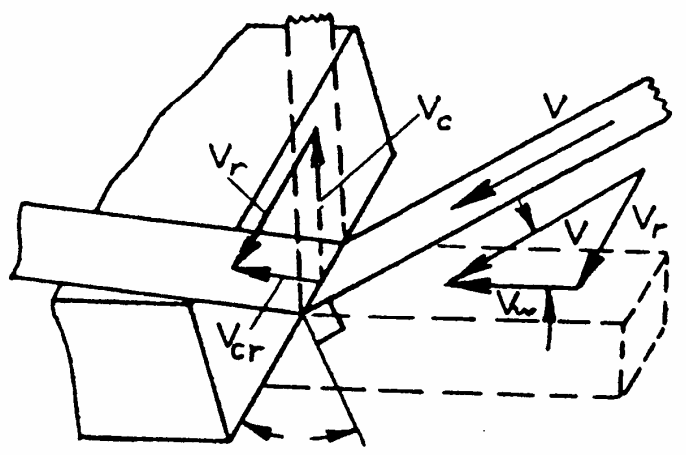

(b)

Figure 2-1: Rotary cutting process as observed from fixed point (a) in space, (b) on tool (Armarego et al., 1994).

Armarego et al. (1994) carried out investigations in order to understand the fundamentals of the rotary tool cutting processes. Studying operations for machining a tube, they related rotary tool processes to the better known orthogonal and oblique cutting processes and developed mechanics of cutting models for these new processes. They performed a theoretical investigation and validated their model trough experimental investigation. When the rotary tool and the tube diameters are large compared to the tube thickness and the feed speed is negligible compared to the cutting speed, the rotary tool can be represented by a straight cutting wedge tool of constant normal rake angle. 
As pointed out earlier, all rotary tool processes can be classified into three basic types: driven orthogonal rotary operation, driven oblique rotary operation and selfpropelled rotary operation. If the angle between the cutting velocity $\mathbf{V}_{\mathbf{w}}$ and the normal plane $P_{n}$ (called static inclination angle $i_{s}$ ) is equal to zero then it is called orthogonal; otherwise, it is called oblique.

Thus, there exists only one way to get a driven orthogonal rotary operation, i.e. the tool has to be on centre. For the self-propelled, there are two possibilities. On one hand, the tool can be tilted. On the other hand, it can be set above or below centre. For the driven oblique process, the tool is not inclined but is set above or below centre. The different cases are presented in Figure 2-2, through Figure 2-4.

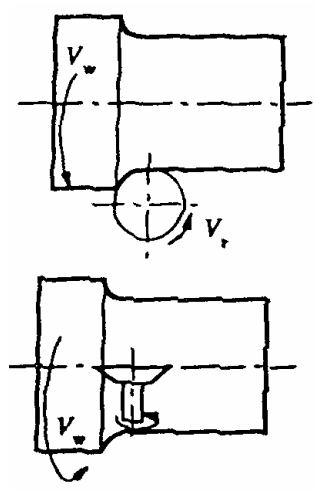

(a)

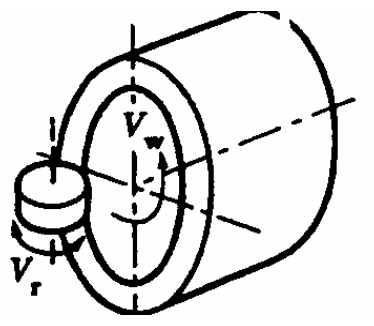

(b)

Figure 2-2: Tool on centre, orthogonal driven rotary tool cutting process (Armarego et al., 1994). 

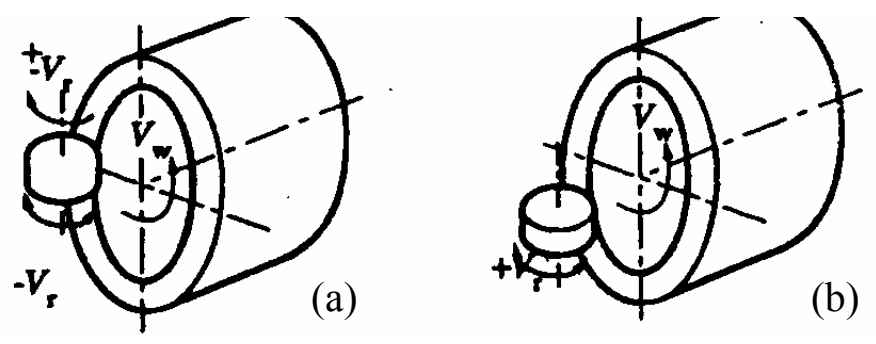

Figure 2-3: Tool above and below centre, driven or self-propelled oblique rotary tool processes (Armarego et al, 1994.).
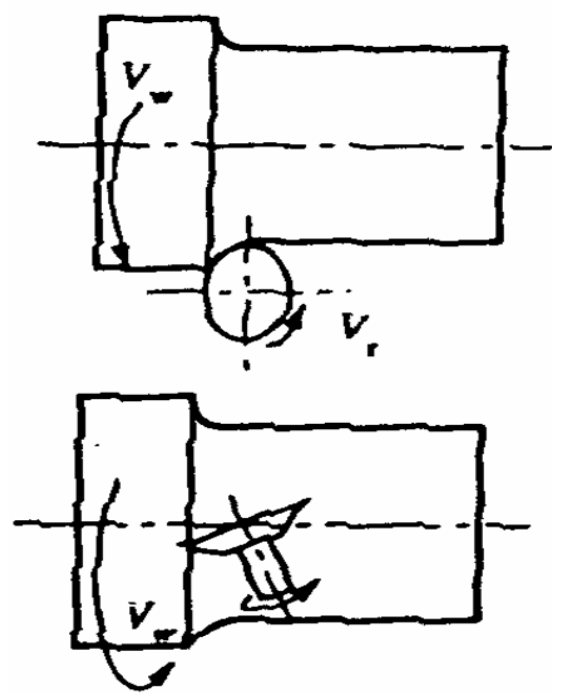

Figure 2-4: Tilted tool, self-propelled oblique rotary tool process (Armarego et al., 1994).

\subsubsection{Driven oblique rotary tool cutting process}

The kinematics of this process is studied first. Indeed, it may be considered as a general case for reasons explained later. As mentioned earlier, the mechanism has to be studied both in the absolute space and in the frame of the tool. In Figure 2-3(a), the tool is set above centre and driven in a clockwise direction as viewed from the top. In this case, 
$\mathrm{V}_{\mathrm{r}}$ is assumed to be positive. Thus, the workpiece velocity $\mathbf{V}_{\mathbf{w}}$ and the walls of the tube (assumed to be straight) are inclined to the normal plane $\mathrm{P}_{\mathrm{n}}$ by the static inclination angle $\mathrm{i}_{\mathrm{s}}$; the process is oblique rotary. The orientation of the relative or resultant workpiece velocity $\mathbf{V}$ is given by the inclination angle $i$ with respect to $P_{n}$. In Figure 2-5(a) to (e), configurations of the driven oblique rotary tool are simulated as $V_{r}$ varies from a positive value to a negative value (the spin of the tool is reversed). When $V_{r}$ is equal to zero, the rotary tool becomes a stationary tool as shown in Figure 2-5(b). Also, in this case, the driven oblique process is identical to the classical oblique cutting process as seen in Figure 2-5(b) and (g).

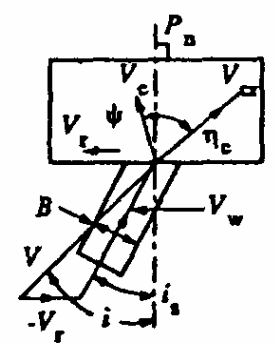

(a)

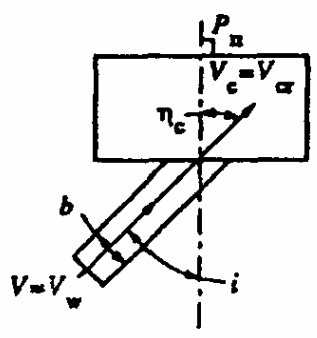

(f)

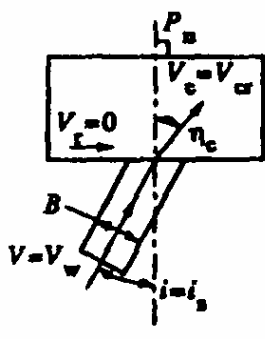

(b)

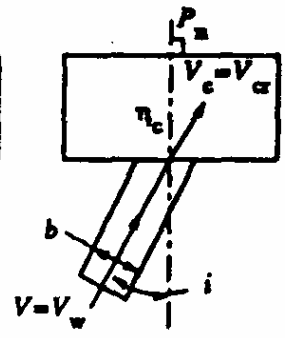

(8)

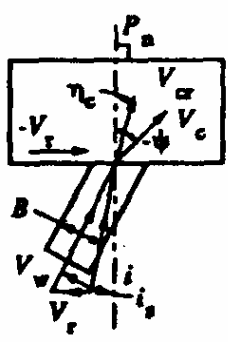

(c)

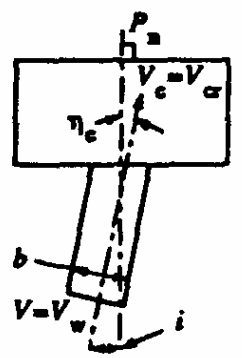

(h)

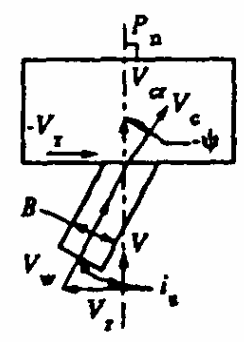

(d)

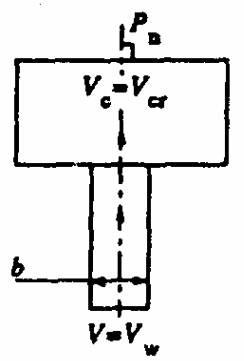

(i)

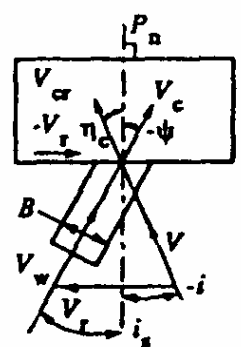

(e)

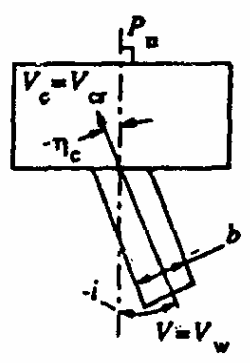

(j)

Figure 2-5: Driven oblique rotary tool and corresponding equivalent "classical" processes (Armarego et al., 1994). 
The following equations can be derived from the Figure 2-5:

$$
\begin{gathered}
V=\sqrt{\left(V_{w} \cos i_{s}\right)^{2}+\left(V_{r}+V_{w} \sin i_{s}\right)^{2}} \\
\tan i=\frac{V_{r}+V_{w} \sin i_{s}}{V_{w} \cos i_{s}} \\
V_{w}=V \frac{\cos i}{\cos i_{s}} \\
V_{r}=V \frac{\sin \left(i-i_{s}\right)}{\cos i_{s}}
\end{gathered}
$$

The driven oblique process is considered to be the most general case among all rotary tool processes. Indeed, this type of operation involves variables such as the static inclination angle $i_{\mathrm{s}}$ which is zero for the driven orthogonal rotary tool process, and the inclination angle $\mathrm{i}$ which is zero for the self-propelled oblique rotary tool.

Regarding Figure 2-5, driven oblique rotary tool process (Figure 2-5(a)-(e)) and classical oblique cutting process (Figure 2-5(f)-(j)) exhibit similarities. Considering Figure 2-5(a) and (f) it is noted that in both processes the resultant cutting velocity $\mathbf{V}$ is oriented at the inclination angle $i$ to the straight cutting edge. The main difference comes from the definitions of $i$ and $i_{s}$. Indeed, for the driven oblique process, $\mathbf{V}_{\mathbf{w}}$ is referenced by $i_{s}$ with respect to $P_{n}$ and by $\left(i-i_{s}\right)$ with respect to $\mathbf{V}$ whereas for the classical oblique process, $\mathbf{V}_{\mathbf{w}}=\mathbf{V}$ and is oriented at the inclination angle $\mathrm{i}=\mathrm{i}_{\mathrm{s}}$. For the former, the difference between the static inclination and inclination angles ensures that a different portion of the cutting tool engages the workpiece during cutting while for the latter, the same portion of the edge is engaged. 
Thus, from a kinematics point of view, the two corresponding processes could be considered "equivalent" if the volume removal rate is equal for the same $\mathrm{V}$ and thickness t so that:

$$
\begin{gathered}
V b t=V_{w} B t=V B t \frac{\cos i}{\cos i_{s}} \\
b=B \frac{\cos i}{\cos i_{s}}
\end{gathered}
$$

\subsubsection{Driven orthogonal rotary tool cutting process}

When the rotary tool is set on centre (i.e. static inclination angle $i_{s}$ equal to zero) and driven, the process is considered to be a driven orthogonal rotary tool process. The absolute velocity $\mathbf{V}_{\mathbf{w}}$ is parallel to $\mathrm{P}_{\mathrm{n}}$ but the relative velocity $\mathbf{V}$ is inclined to $\mathrm{P}_{\mathrm{n}}$ by the inclination angle $\mathrm{i}$ whose both magnitude and direction depend on those of the tool rotational velocity $\mathbf{V}_{\mathbf{r}}$. In Figure 2-6, both driven orthogonal rotary tool process and its equivalent classical orthogonal cutting process are shown as $V_{r}$ varies from a positive value to a negative value. Equations (3) to (8) for the driven oblique rotary tool also apply for the orthogonal one when $i_{s}=0$ is substituted. 


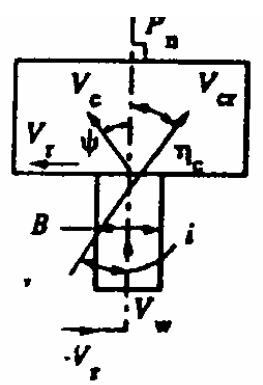

(a)

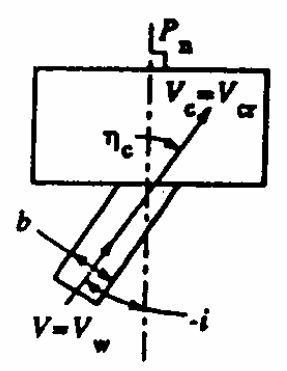

(d)

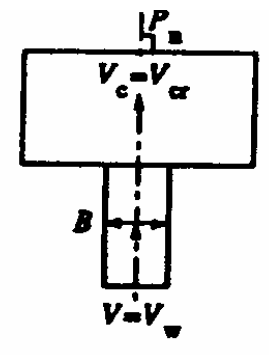

(b)

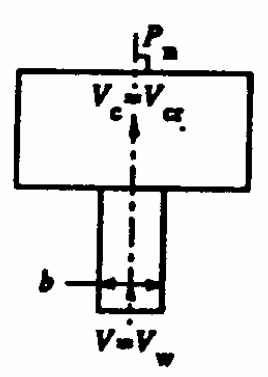

(e)

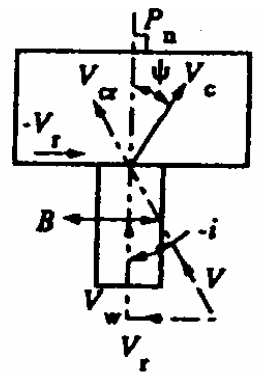

(c)

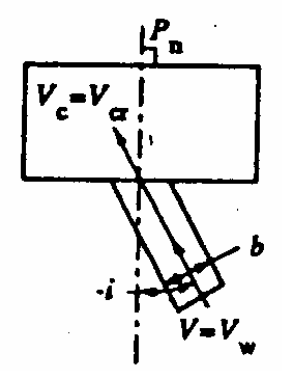

(f)

Figure 2-6: Driven orthogonal rotary tool and corresponding equivalent "classical" processes (Armarego et al., 1994).

When the tool is set on centre and not driven but free to rotate about its axis, the tool could be self-propelled. However, as shown in Figure 2-6(b) and (e), this phenomenon does not occur. Indeed, in this case, the driven orthogonal rotary process is perfectly equivalent to the classical orthogonal cutting process and the resultant force lies in the normal plane so that no side force along the cutting edge can propel the tool. Thus, the orthogonal rotary tool process must be driven by an external source.

\subsubsection{Self-propelled oblique rotary tool cutting process}

Contrary to the former process, this process has to be oblique in order to allow the rotation of the tool. As pointed out earlier, one way to get tool motion is to set it above or below centre. If the rotary tool is free to rotate and is set above centre so that $i_{s}$ is not 
equal to zero, the cutting action will result in a force along the cutting edge which will propel the tool counter-clockwise (negative $\mathrm{V}_{\mathrm{r}}$ ) until an equilibrium position is achieved where no side force acts along the tool edge (assuming the rotary tool axis can rotate freely with no friction and chip transportation requires no additional energy). This condition occurs when the relative velocity $\mathbf{V}$ lies in the normal plane (inclination angle is zero) as shown in Figure 2-5(d). Thus, the equivalent process is a classical orthogonal process. When the tool is set below centre, the static inclination angle $i_{s}$ becomes negative, the inclination angle $\mathrm{i}$ is zero, and the tool is propelled clockwise.

The other way to propel the tool is to give an effective negative rake angle to the tool. Thus, the tool is again driven by the chip in a counter-clockwise direction. This tilted position of the tool is similar to the one where it is set above centre. Also, some tools are inclined in two directions, around the workpiece axis and around the axis normal to the latter (effective negative rake angle). Equations (3) to (8) for the driven oblique rotary tool also apply for the self-propelled one when $\mathrm{i}=0$ is substituted.

\subsubsection{Summary of the different types of rotary tool processes}

Table 2-1: Rotary tool and corresponding equivalent classical processes.

\begin{tabular}{|c|c|c|c|}
\hline $\begin{array}{c}\text { Rotary tool } \\
\text { processes }\end{array}$ & Driven oblique & $\begin{array}{c}\text { Driven } \\
\text { orthogonal }\end{array}$ & $\begin{array}{c}\text { Self-propelled } \\
\text { (oblique) }\end{array}$ \\
\hline $\begin{array}{c}\text { Corresponding } \\
\text { equivalent classical } \\
\text { cutting processes }\end{array}$ & Oblique & $\begin{array}{c}\text { Oblique; } \\
\text { Orthogonal if } \\
\mathrm{Vr}=0\end{array}$ & Orthogonal \\
\hline
\end{tabular}




\subsubsection{Mechanics}

This work is presented in Appendix A.

\subsection{Previous studies on temperature modeling in a RT process}

\subsubsection{Studys of Chen et al. (1992)}

Note:

The notations used in this section are those used by Chen et al. (1992) and will not be used again here after.

In their study, Chen et al. derive a model to predict the cutting temperature in SPRT turning of high-performance materials such as the $\mathrm{SiC}$ reinforced aluminum composite and a titanium alloy $6 \mathrm{AL}-4 \mathrm{~V}$. He also presents experimental measures of both temperature and cutting forces. Temperature measurements are made using the tool-work thermocouple technique.

Tool temperature analysis is based on a model of a heat source moving cyclically along the cutting edge. The tool-chip interface is assumed to be a heat source of surface $\mathrm{S}_{\mathrm{t}}$ moving along the circular cutting edge.

The shape of this interface is one of the most important parameters because its area and the heat flux are closely linked. In rotary tool operation, it is quite difficult to define it very accurately. However, analyzing the worn rake face of a fixed circular tool, it appears to be a small "coma" shape region as shown in Figure 2-7. Chen et al. simplify this coma to be a right-angled triangle.

Provided that the rake and clearance angles are not too large, the circular cutting tool is treated as a quarter-infinite body. In the Figure 2-8, the cutting edge is in the $\mathrm{x}$ - 
axis direction and the rake face of the tool in the $\mathrm{x}-\mathrm{y}$ plane and the hatched triangle area represents the moving heat source. Further simplification by symmetry is made by assuming a heat source $2 \mathrm{~S}_{\mathrm{t}}$ moving along the $\mathrm{x}$-axis at the surface of a semi-infinite body, provided that the $x-z$ plane is a perfect insulator and the heat source $2 S_{t}$ expends the same flux, yet double symmetrical area of the original $\mathrm{S}_{\mathrm{t}}$.

With these simplifications, the heat source $S_{t}$ rotating along the circular edge is treated as a problem of $2 \mathrm{~S}_{\mathrm{t}}$ periodically entering at an end $0_{1}$, moving at speed $\mathrm{V}_{\mathrm{t}}$ along the $\mathrm{x}$-axis in the $\mathrm{x}-\mathrm{y}$ plane and exiting at another end $0_{2}$. The interval of time between $0_{1}$ and $0_{2}$ corresponds to one rotational period of the tool.

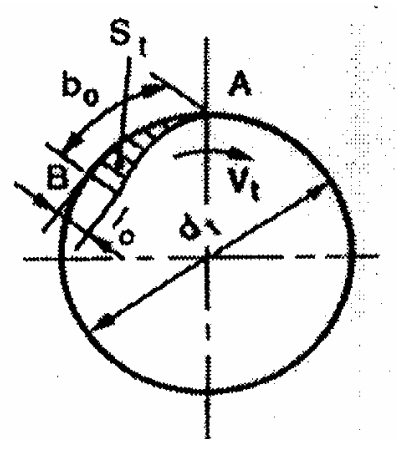

Figure 2-7: Rotating friction zone (Chen et al., 1992). 


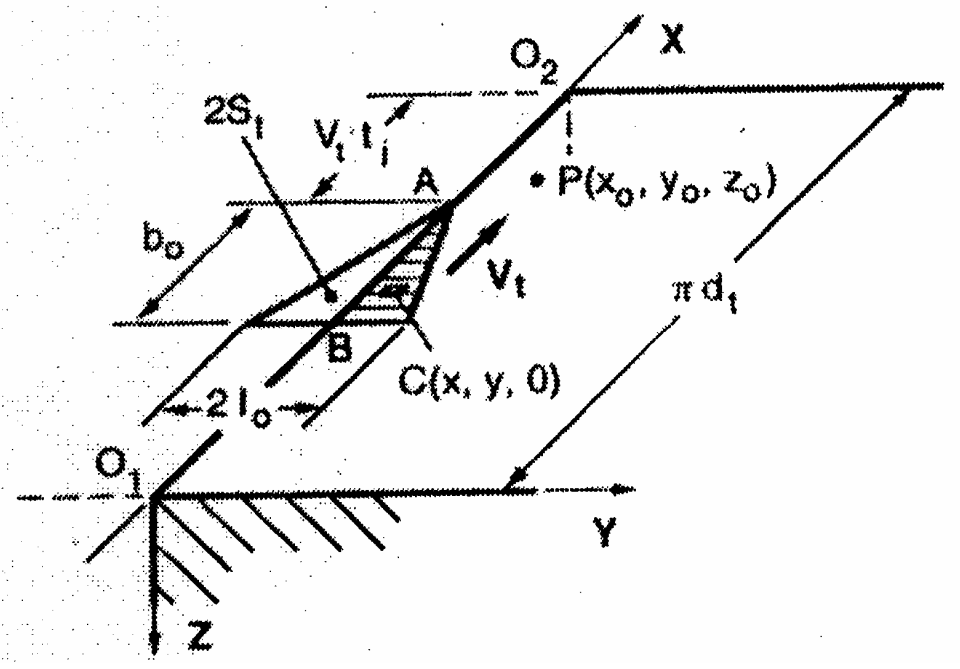

Figure 2-8: Moving heat source model (Chen et al., 1992).

According to Chen et al., the problem has to be solved using the approach of Carlsaw and Jaeger (1959) for moving heat sources. The starting point for Chen et al. (1992) analysis is the following equation of heat conduction:

$$
\frac{\partial \theta}{\partial t}=K \cdot\left(\frac{\partial^{2} \theta}{\partial x^{2}}+\frac{\partial^{2} \theta}{\partial y^{2}}+\frac{\partial^{2} \theta}{\partial z^{2}}\right)
$$

where $\theta$ is the temperature and $\mathrm{K}$ the diffusivity of the tool.

The temperature rise of the tool $\Delta \theta$ is derived for any point $\mathrm{P}\left(\mathrm{x}_{0}, \mathrm{y}_{0}, \mathrm{z}_{0}\right)$ in Figure 2-8 in a semi-infinite body (tool) at time $\mathrm{t}$ after a heat $\mathrm{Q}$ (in Joules) is liberated instantaneously at a point $\mathrm{C}(\mathrm{x}, \mathrm{y}, \mathrm{z})$ of the interface:

$$
\begin{gathered}
\Delta \theta=\frac{2 Q}{8 \rho . c .(\pi \cdot K \cdot t)^{3 / 2}} \exp \left(-\frac{\Delta r^{2}}{4 K t}\right) \\
\Delta r^{2}=\left(x_{0}-x\right)^{2}+\left(y_{0}-y\right)^{2}+\left(z_{0}-z\right)^{2}
\end{gathered}
$$


where $\mathrm{c}$ is the specific heat of the tool $\left(\mathrm{W} \cdot \mathrm{m}^{-2} \cdot \mathrm{K}^{-1}\right)$ and $\rho$ is the density of the tool $\left(\mathrm{kg} \cdot \mathrm{m}^{-}\right.$ ${ }^{3}$ ). The 2 in the numerator of Equation (10) comes from the fact that the body is semiinfinite and not infinite. Chen et al. assume that the heat source is uniformly distributed. The mean heat flux expended at the tool-chip interface is $\mathrm{q}_{\mathrm{t}}\left(\mathrm{W} \cdot \mathrm{m}^{-2}\right)$ and the fraction of energy going into the tool is R. Thus, the quantity of heat per unit time per unit area going into the tool is $\mathrm{Rq}_{\mathrm{t}}$.

Chen et al. use the analytical approach of Shaw (1984) to obtain the temperature of the chip at the chip-tool interface $\theta_{0}$ ':

$$
\theta_{0}{ }^{\prime}=\theta_{s}+\Delta \theta_{t}
$$

where $\theta_{\mathrm{s}}$ is the average shear-plane temperature and $\Delta \theta_{\mathrm{t}}$ the temperature rise in the tool chip interface with the partition coefficient $\mathrm{R}$.

By equating $\theta_{0}$ and $\theta_{0}$, the coefficient $\mathrm{R}$ is determined as well as the temperature distribution.

Additional discussion about this model is given in Appendix B.

\subsubsection{Study of Kishawy et al. (2001)}

Note:

The notations used in this section are those used by Kishawy et al. and will not be used again here after.

The model used by Kishawy et al. to obtain the tool temperature distribution in SPRT turning of plain carbon steel is based on a finite-volume discretization approach applied to a general conservation of energy statement for the tool and the chip. Their 
approach is divided into two parts. The first involves a 1D discrete model and gives the heat partition coefficient $R_{2}$ (fraction of heat at the tool-chip interface going to the chip), the interface temperature $T_{c t}$ and the average tool temperature $T_{t a}$. The second involves a 3D discrete model and is used to examine the temperature distribution in the tool.

According to Kishawy et al., the starting point is the conservation equation in generalized coordinates applied to bot the chip and the tool. Generalized coordinates are used due to geometric differences between the tool (cylindrical) and the chip (rectangular). Kishawy et al. use these coordinates to apply the same computer model to the tool and the chip geometry. Also, the control-volume/grid generation approach permits to transform a physical domain (which can have a complex shape) to a computational domain which is nothing but a parallelepiped (Patankar, 1980, Ozisik, 1994, Thompson et al., 1982), as shown in Figure 2-9 Generalized coordinates $(\varepsilon, \eta, \zeta)$ are orthogonal.

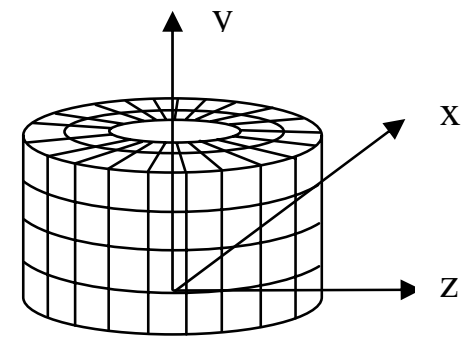

(a)

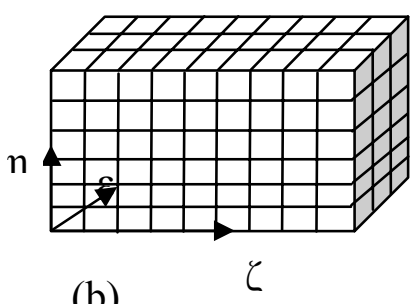

(b)

Figure 2-9: (a) Physical domain (rotary tool), (b) Computational domain (parallelepiped). 


$$
\begin{aligned}
& \frac{\partial}{\partial t}(\rho J h)_{c}+\frac{\partial}{\partial \varepsilon}(\rho J U h)_{c}+\frac{\partial}{\partial \eta}(\rho J V h)_{c}+\frac{\partial}{\partial \zeta}(\rho J W h)_{c}=\frac{\partial}{\partial \varepsilon}\left(J \frac{k_{c}}{c_{p c}}\left(g_{11} \frac{\partial h_{c}}{\partial \varepsilon}\right)\right)+ \\
& \frac{\partial}{\partial \eta}\left(J \frac{k_{c}}{c_{p c}}\left(g_{22} \frac{\partial h_{c}}{\partial \eta}\right)\right)+\frac{\partial}{\partial \zeta}\left(J \frac{k_{c}}{c_{p c}}\left(g_{33} \frac{\partial h_{t}}{\partial \zeta}\right)\right)+S_{c}
\end{aligned}
$$

where $h_{c}$ is the enthalpy of the chip and is nothing but $c_{p} T$ (T being the absolute temperature), $\rho$ is the density of the material, $\mathrm{k}_{\mathrm{c}}$ and $\mathrm{c}_{\mathrm{pc}}$ are the thermal conductivity and the heat capacity of the chip respectively, $S_{c}$ is the heat generation due to the shear plane and $\mathrm{J}$ is the Jacobian of the transformation as follows:

$$
J=\frac{1}{x_{\varepsilon}\left(y_{\eta} z_{\zeta}-y_{\zeta} z_{\eta}\right)-x_{\eta}\left(y_{\varepsilon} z_{\zeta}-y_{\zeta} z_{\varepsilon}\right)+x_{\zeta}\left(y_{\varepsilon} z_{\eta}-y_{\eta} z_{\varepsilon}\right)}
$$

where

$$
\frac{\partial x}{\partial \varepsilon}=x_{\varepsilon}, \text { etc. }
$$

The metrics with an orthogonal underlying grid are:

$$
\begin{aligned}
& g_{11}=\varepsilon_{x}^{2}+\varepsilon_{y}^{2}+\varepsilon_{z}^{2} \\
& g_{22}=\eta_{x}^{2}+\eta_{y}^{2}+\eta_{z}^{2} \\
& g_{33}=\zeta_{x}^{2}+\zeta_{y}^{2}+\zeta_{z}^{2}
\end{aligned}
$$

Orthogonal generalized coordinates impose:

$$
\begin{aligned}
& \varepsilon_{x} \eta_{x}+\varepsilon_{y} \eta_{y}+\varepsilon_{z} \eta_{z} \\
& \varepsilon_{x} \zeta_{x}+\varepsilon_{y} \zeta_{y}+\varepsilon_{z} \zeta_{z} \\
& \eta_{x} \zeta_{x}+\eta_{y} \zeta_{y}+\eta_{z} \zeta_{z}
\end{aligned}
$$

The contravariant velocities at the face of all control-volumes are:

$$
\begin{aligned}
& U=\varepsilon_{x} u+\varepsilon_{y} v+\varepsilon_{z} w \\
& V=\eta_{x} u+\eta_{y} v+\eta_{z} w \\
& W=\zeta_{x} u+\zeta_{y} v+\zeta_{z} w
\end{aligned}
$$

where $(\mathrm{u}, \mathrm{v}, \mathrm{w})$ is the velocity field in the physical domain 


$$
\begin{aligned}
& \frac{\partial}{\partial t}(\rho J h)_{t}+\frac{\partial}{\partial \varepsilon}(\rho J U h)_{t}+\frac{\partial}{\partial \eta}(\rho J V)_{t}+\frac{\partial}{\partial \zeta}(\rho J W h)_{t}=\frac{\partial}{\partial \varepsilon}\left(J \frac{k_{t}}{c_{p t}}\left(g_{11} \frac{\partial h_{t}}{\partial \varepsilon}\right)\right)+ \\
& \frac{\partial}{\partial \eta}\left(J \frac{k_{t}}{c_{p t}}\left(g_{22} \frac{\partial h_{t}}{\partial \eta}\right)\right)+\frac{\partial}{\partial \zeta}\left(J \frac{k_{t}}{c_{p t}}\left(g_{33} \frac{\partial h_{t}}{\partial \zeta}\right)\right)
\end{aligned}
$$

These energy equations used by Kishawy et al. take conduction and convection due to the moving mass (tool) into account.

The second equation which describes the problem is the continuity of flux at the tool-chip interface. If $\mathrm{S}_{\mathrm{ct}}$ is the heat flux $\left(\mathrm{W} \cdot \mathrm{m}^{-2}\right)$ extended at the interface and $\mathrm{A}_{\mathrm{ct}}$ is the interface area, Kishawy et al. derive:

$$
\begin{aligned}
\frac{k_{t}}{c_{t}}\left(J g_{22} \frac{\partial h_{t}}{\partial \eta}\right)+ & \frac{k_{c}}{c_{c}}\left(J g_{22} \frac{\partial h_{c}}{\partial \eta}\right)=J\left(\eta_{x}+\eta_{y}+\eta_{z}\right) S_{c t} \\
\left(\eta_{x}+\eta_{y}+\eta_{z}\right) S_{c t} & =A_{c t}
\end{aligned}
$$

Equations (16), (21) and (22) are discretized using a finite-volume discretization (Patankar, 1980, Ozisik, 1994, Thompson et al., 1982). In the Figure 2-10, the volumecontrol is in 2D for better understanding, but actually it is a parallelepiped with a top and a bottom called $\mathrm{T}$ and $\mathrm{B}$ like as $\mathrm{N}$ for North and so on.

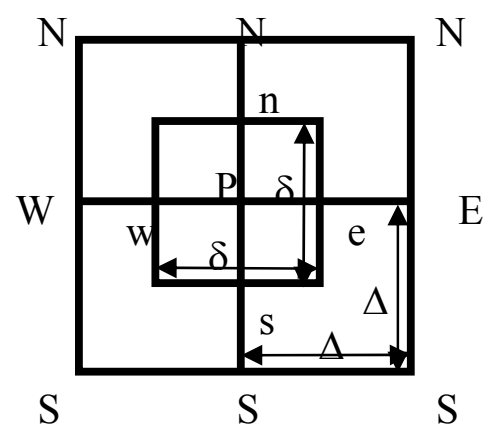

Figure 2-10: Representation of a control-volume. 
Kishawy et al. use the following notations: ijk for $\mathrm{P}, \mathrm{i}+1 \mathrm{jk}$ for $\mathrm{E}, \mathrm{i}-1 \mathrm{jk}$ for $\mathrm{W}$, $\mathrm{ij}+1 \mathrm{k}$ for $\mathrm{N}$ and so on to write the discritized energy equations. Also, each control-volume is a unit parallelepiped (i.e. $\Delta \varepsilon=\Delta \eta=\Delta \zeta=1$ ). He finds:

$$
\begin{aligned}
& \frac{(\rho J)_{c}}{\Delta t}\left(h_{i j k}-h_{i j k}^{\circ}\right)_{c}+\left(\Omega_{e}-\Omega_{w}\right)_{c}+\left(\Omega_{n}-\Omega_{s}\right)_{c}+\left(\Omega_{t}-\Omega_{b}\right)_{c}=S_{c} \\
& \frac{(\rho J)_{t}}{\Delta t}\left(h_{i j k}-h_{i j k}^{\circ}\right)_{t}+\left(\Omega_{e}-\Omega_{w}\right)_{t}+\left(\Omega_{n}-\Omega_{s}\right)_{t}+\left(\Omega_{t}-\Omega_{b}\right)_{t}=0
\end{aligned}
$$

where:

$$
\begin{aligned}
& \Omega_{e}=(\rho J U h)_{e}-\left(\frac{J k}{c_{p}} g_{11} \frac{\partial h}{\partial \varepsilon}\right)_{e} \\
& \Omega_{w}=\ldots
\end{aligned}
$$

Kishawy et al. use a power law function to approximate all the terms $\Omega$ (Patankar, 1980). The function is only written at the e-face for $\Omega_{\mathrm{e}}$ since other faces follow a similar development.

$$
\Omega_{e}=F_{e}\left(h_{i j k}+\frac{\left(1-0.5 P_{e}\right)^{5}}{P_{e}}\left(h_{i+1 j k}-h_{i j k}\right)\right)
$$

where:

$$
\begin{aligned}
P_{e} & =\frac{F_{e}}{D_{e}} \\
F_{e} & =(\rho J U)_{e} \Delta \eta \Delta \zeta=(\rho J U)_{e} \\
D_{e} & =\left(\frac{k}{c_{p}} J \frac{g_{11}}{\delta \varepsilon}\right)_{e}=\left(\frac{k}{c_{p}} J g_{11}\right)_{e}
\end{aligned}
$$

$\mathrm{P}_{\mathrm{e}}$ is the Peclet number at the east-face. 
For the 3D case, Equation (27) is substituted into Equation (24) with similar substitutions for the other faces to get an equation for the control-volume in terms of its enthalpy $h_{i j k}$ and the surrounding ones $h_{i+1 j k}, h_{i-1 j k}$ and so on. For the $1 D$ application, Kishawy et al. assume that temperatures vary only in one grid dimension, so, the practical enthalpies are only $\mathrm{h}_{\mathrm{i}}, \mathrm{h}_{\mathrm{i}-1}$ and $\mathrm{h}_{\mathrm{i}+1}$.

Kishawy et al. derive the discrete equation of continuity of flux at the chip-tool interface using a finite-difference approximation on each side of the interface with $\Delta \eta=$ $1 / 2$ :

$$
\left(\frac{k_{t}}{c_{p t}}+\frac{k_{c}}{c_{p c}}\right) h_{c t}-\left(\frac{k_{c}}{c_{p c}}\right) h_{j}-\left(\frac{k_{t}}{c_{p t}}\right) h_{i}=\frac{J}{2 g_{22}}\left(\eta_{x}+\eta_{y}+\eta_{z}\right) S_{c t}
$$

where $h_{c t}$ is the interface enthalpy, and $h_{i}$ and $h_{j}$ are the tool and the chip enthalpy respectively.

Equations (24), (25), (27) and (29) are used in both level one and two applications together with boundary conditions.

In the level one application, the rotary tool is divided into stationary controlvolumes as shown in Figure 2-11 and the chip is represented by a stationary controlvolume and connected to the tool by $\mathrm{S}_{1}$ (tool-chip interface) in the same figure. Kishawy et al. represent both conduction in the tool and convection of the chip by an effective thermal resistance $\mathrm{R}_{\mathrm{eff}}$. Also, the terms $\omega \mathrm{r}$ and $\mathrm{R}_{\mathrm{k}}$ are shown to represent energy transport due to the rotation of the tool and diffusion respectively. The other assumptions used for this model are:

- The tool is assumed to be sharp, the tertiary zone is not considered in his model. 
- The chip leaves the shear zone at a constant temperature equal to the shear plane temperature.

- The heat generated along the friction interface is uniformly distributed.

- The radial thickness of the tool is equal to the height of the chip-tool interface.

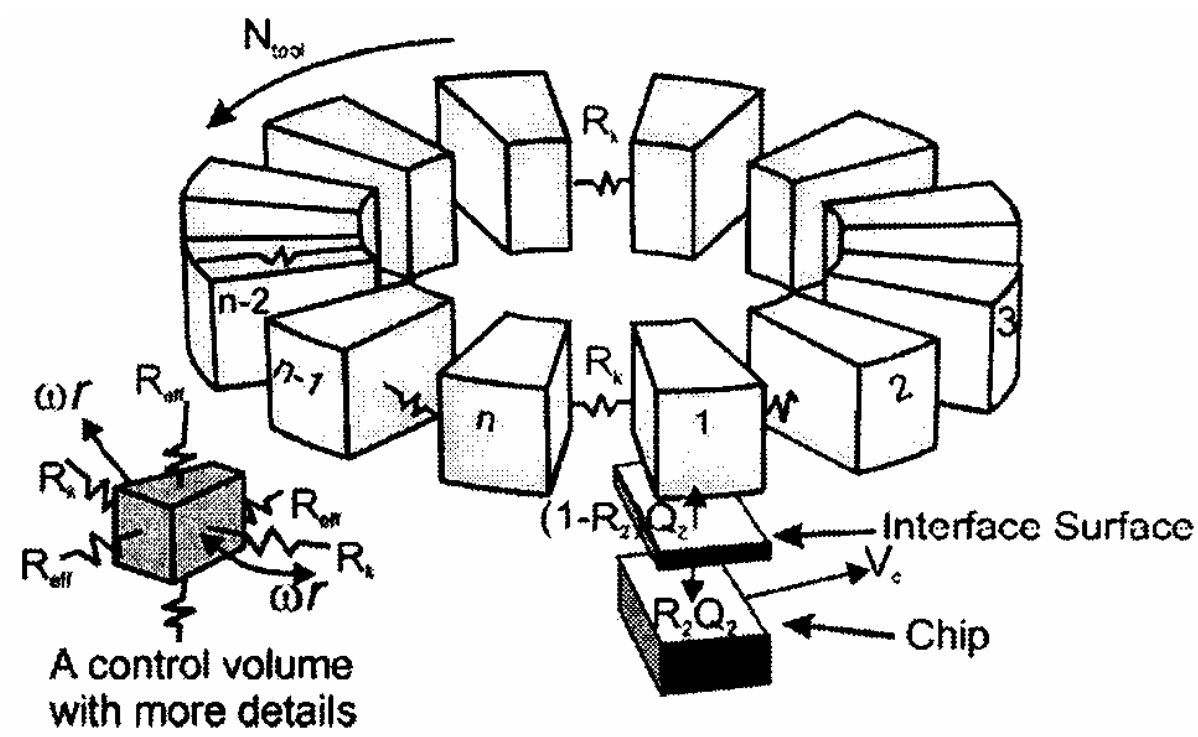

Figure 2-11: Simplified model for the tool, the chip and the chip-tool interface (Kishawy et al., 2001).

With these assumptions and simplifications, Kishawy et al. derive new conservation equations for both the tool and the chip and for every control-volume (zone 1 to $\mathrm{n}$ in the tool and zone 1 in the chip).

For zone 1: 


$$
\begin{aligned}
& \left(\Omega_{e}-\Omega_{w}\right)=A \frac{1}{R_{e f f} c_{p t}}\left(h_{i}-h_{\infty}\right)+2 J \frac{k_{t}}{c_{p t}} g_{22}\left(h_{c t}-h_{i}\right) \\
& \left(\Omega_{e}-\Omega_{w}\right)=A \frac{1}{R_{e f f} c_{p c}}\left(h_{j}-h_{\infty}\right)+2 J \frac{k_{c}}{c_{p c}} g_{22}\left(h_{c t}-h_{j}\right)
\end{aligned}
$$

For zones 2 to n:

$$
\left(\Omega_{e}-\Omega_{w}\right)=A \frac{1}{R_{e f f} C_{p t}}\left(h_{i}-h_{\infty}\right)
$$

For zone $\mathrm{S}_{1}$ (tool-chip interface), Equation (29) is applied without modification. Kishawy et al. solve the system of Equations (29), (30) and (31) directly when average properties are used. He mentions that it can be solved by iteration when variable properties are applied.

In the level two application, the object of this $3 \mathrm{D}$ model is to examine the influence of the rotational tool speed on the maximum temperature and the temperature distribution in the tool. Thus this model is applied only to the tool and uses the partitioning coefficient $\mathrm{R}_{2}$ obtained in the level one application. For numerical computation, Kishawy et al. use Equations (25) and (27). Convection conditions (using the heat transfer coefficient $\mathrm{h}=100 \mathrm{~W} \cdot \mathrm{m}^{-2} \cdot \mathrm{K}^{-1}$ ) are applied at all boundaries except near the tool-chip interface where the following assumptions apply:

- The shear plane temperature from the level one model is applied at the maximum radius of the tool.

- The total heat load (1- $\left.\mathrm{R}_{2}\right) \mathrm{S}_{\mathrm{ct}}$ is applied in a linear fashion (as a heat flux) from a maximum at the outer tool radius to zero at the point where the tool-chip interface ends. 
The predicted results were compared to temperature measurements reported by Shaw et al. (1952) for one cutting condition. The discussion about this model is presented in Appendix C.

\section{3. $\underline{\text { Summary }}$}

Prior research on modeling and measuring temperatures in rotary tool turning has been reported. Shaw et al. (1952) measured the average cutting tool temperature in driven rotary tool turning of plain carbon steel using the tool-work thermocouple technique. They reported that measured temperatures could be up to $200^{\circ} \mathrm{C}$ lower in rotary tool cutting than under fixed tool conditions. Wuyi et al. (1991) also reported lower cutting temperatures in machining hardened steel using a similar technique. Chen et al. (1992) adapted the sliding heat source method proposed by Carslaw and Jaeger (1959) and modified the heat source geometry to be closer to the rotary tool problem. However, as pointed out earlier, some parts of this work have to be considered carefully since some explanations are not very clear. They too measured cutting temperatures in machining of composite materials with self-propelled rotary tool using the tool-work thermocouple technique. Kishawy et al. (2001) used a control volume method to apply the heat conservation equation to both the chip and tool. But as with Chen et al.'s work, some results have to be analyzed carefully. They compared their model predictions to the average tool temperature measurements reported by Shaw et al. (1952). 


\section{CHAPTER 3}

\section{TOOL TEMPERATURE MODELING IN SPRT PROCESS}

In this investigation, a finite element modeling approach is presented to obtain the temperature distribution in the rotary tool during machining of hardened AISI 52100 steel. The thermal modeling and solution approach in this work are significantly simpler than in the previous work of Chen et al. (1992) and Kishawy et al. (2001).

\subsection{Modeling basics}

The model used for a rotary tool process is similar to that used for classical orthogonal and oblique cutting processes (Shaw, 1984).

The three main sources of thermal energy in metal cutting include the primary or shear zone $Z_{1}$, secondary or friction zone $Z_{2}$ and the tertiary or tool-work zone $Z_{3}$. Generally, the tertiary is ignored when a perfectly sharp tool is assumed. The temperature at the chip-tool interface (secondary zone) is one of the major causes of tool rake face wear. The three zones are depicted for an orthogonal cutting process in Figure 3-1 where:

- $\mathrm{Q}_{1}$ is the heat generated in the primary zone.

- $\mathrm{Q}_{2}$ is the heat generated in the secondary zone.

- $\mathrm{Q}_{2}$ is the heat generated in the tertiary zone.

- $\mathrm{R}_{1}$ is the fraction of heat from $Z_{1}$ going to the chip. Part of the heat at $Z_{1}$ is transported by the chip and part of it flows into the workpiece.

- $\mathrm{R}_{2}$ is the fraction of heat from $\mathrm{Z}_{2}$ going to the chip. Part of the heat at $\mathrm{Z}_{2}$ is transported by the chip and part of it flows into the tool. 
- $\mathrm{R}_{3}$ is the fraction of heat from $Z_{3}$ going to the tool. Part of the heat at $Z_{3}$ flows into the tool and part of it flows into the workpiece.

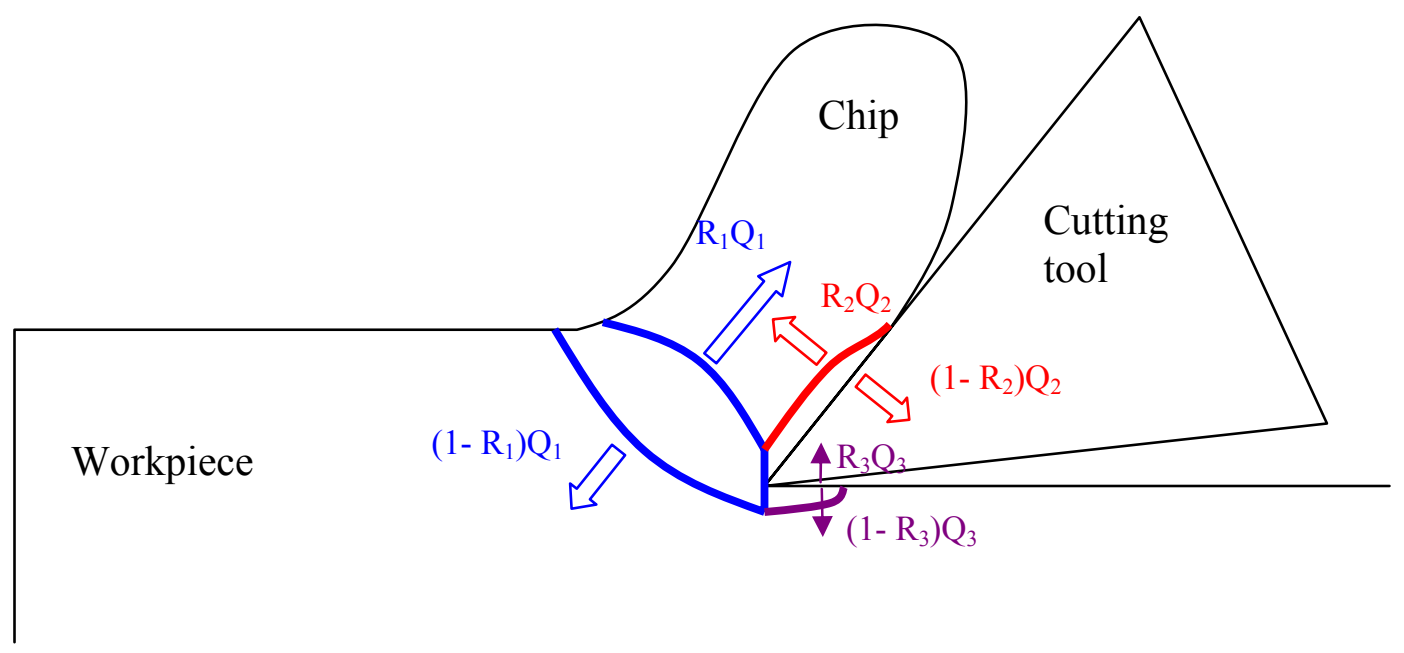

Figure 3-1: Energy partitioning diagram.

The main assumptions employed in the thermal model development are:

- The cutting edge is assumed to be sharp so that the tertiary zone can be neglected.

- All energy involved in plastic deformation (in the shear zone and at the chip-tool interface) is converted into heat.

- The primary and secondary zones are plane surfaces.

- The heat generated along the friction interface and the heat generated along the shear zone is evenly distributed.

- The chip formation takes place along a thin shear zone and moves as a rigid body along the rake face of the tool. 
- The chip leaves the shear zone at a constant temperature equal to the shear plane temperature.

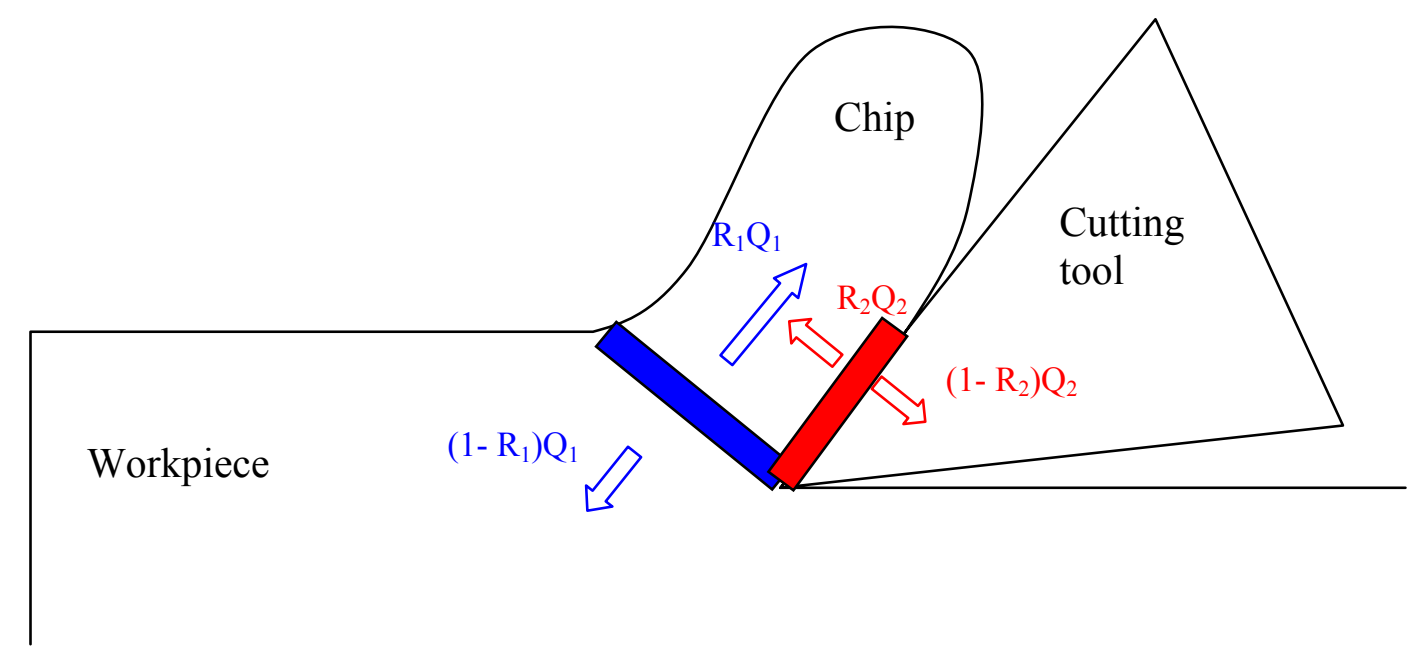

Figure 3-2: Simplified energy partitioning diagram.

The predictive model developed in the following sections predicts the temperature distribution of the tool only. Heat from the shear zone is not considered in this model. The cutting operation modeled in this thesis is classical longitudinal turning of the outer diameter of a bar. The geometry of the rotary tool consists of a torus with a rectangular cross section; the outer and inner diameters are $27 \mathrm{~mm}$ and $13 \mathrm{~mm}$, respectively. Both rake and clearance angles are equal to zero. Dry machining is assumed with a convection heat transfer coefficient of $100 \mathrm{~W} \cdot \mathrm{m}^{-2} \cdot \mathrm{K}^{-1}$ (coefficient used by Kishawy et al., 2003 for carbide tool) and the tool is initially at an ambient temperature of $20^{\circ} \mathrm{C}$. Table $3-1$ gives the density, heat capacity and thermal conductivity of the tool and the workpiece materials used in this work. 
Table 3-1: Thermal and physical properties of tool and workpiece materials.

\begin{tabular}{|c|c|c|c|}
\hline Material & $\begin{array}{c}\rho \\
\left.\text { kg.m }{ }^{-3}\right)\end{array}$ & $\begin{array}{c}\mathrm{c} \\
\left(\mathrm{J} \cdot \mathrm{kg} \cdot \mathrm{K}^{-1}\right)\end{array}$ & $\begin{array}{c}\mathrm{k} \\
\left(\mathrm{W} \cdot \mathrm{m}^{-1} \cdot \mathrm{K}^{-1}\right)\end{array}$ \\
\hline $\begin{array}{c}\text { Carbide tool with a } \\
\text { TiN coating }\end{array}$ & 10000 & 400 & 25 \\
\hline $\begin{array}{c}\text { Workpiece } \\
\text { AISI 52100 steel }\end{array}$ & 7827 & $\begin{array}{c}458(25<\mathrm{T}<204 \\
\left.{ }^{\circ} \mathrm{C}\right)\end{array}$ & 47 \\
\hline
\end{tabular}

\subsection{Model development}

\subsubsection{Governing equation}

As pointed out earlier, the tool temperature modeling approach used in this work differs from those proposed by Chen et al. (1992) and Kishawy et al. (2001). The approach employed in this investigation uses the finite element method (FEM) for the solution of the governing equation of heat transfer in the rotary tool cutting process. The governing equation is derived from heat conduction theory as discussed below.

The method consists of modeling the rotating tool with a transport term added to the heat conduction equation, exploiting the fact that the disk is rotationally symmetric. This permits the tool to be considered "fixed" and assigns the rotational motion to the heat source. This is done by adding a convective flux term $\rho_{t} c_{t} \vec{V}_{r} T$ to the conductive flux term $-k_{t} \nabla T$ in the heat conduction equation as follows:

$$
\rho_{t} c_{t} \frac{\partial T}{\partial t}+\nabla \cdot\left(-k_{t} \nabla T+\rho_{t} c_{t} \vec{V}_{r} T\right)=\dot{Q}
$$

where $\dot{Q}$ is the heat source power per unit volume. Frictional heat generated at the toolchip interface is incorporated as a boundary condition (taking the heat partitioning 
coefficient $\mathrm{R}_{2}$ into account) at the tool-chip interface. Consequently, the chip need not be modeled.

For a rotating tool spinning clockwise with its rotational axis assumed to be the $z$ axis, the rotational tool velocity is given by:

$$
\vec{V}_{r}=\omega_{r}\left(\begin{array}{c}
y \\
-x \\
O
\end{array}\right)_{\vec{i}, \vec{j}, \vec{k}}
$$

Performing the differentiations and using the conservation of mass equation (assuming a constant tool density):

$$
\begin{aligned}
& \frac{\partial \rho_{t}}{\partial t}+\nabla \cdot\left(\rho_{t} \vec{V}_{r}\right)=0 \\
& \nabla \cdot \vec{V}_{r}=0
\end{aligned}
$$

yields the following heat transfer equation:

$$
\rho_{t} c_{t} \frac{\partial T}{\partial t}-\nabla \cdot\left(k_{t} \nabla T\right)=\rho_{t} c_{t} \omega_{r}\left(-y \frac{\partial T}{\partial x}+x \frac{\partial T}{\partial y}\right)
$$

\subsubsection{Tool-chip interface}

The tool-chip interface is not assumed to be the uncut cross sectional area, which is approximately shaped like a "coma". The actual tool-chip interface geometry is established by the contact area between the tool and the chip. In this paper, this area is assumed to have the shape shown in Figure 3-3 where $m$ is the chip width and $l$ the toolchip contact length. 


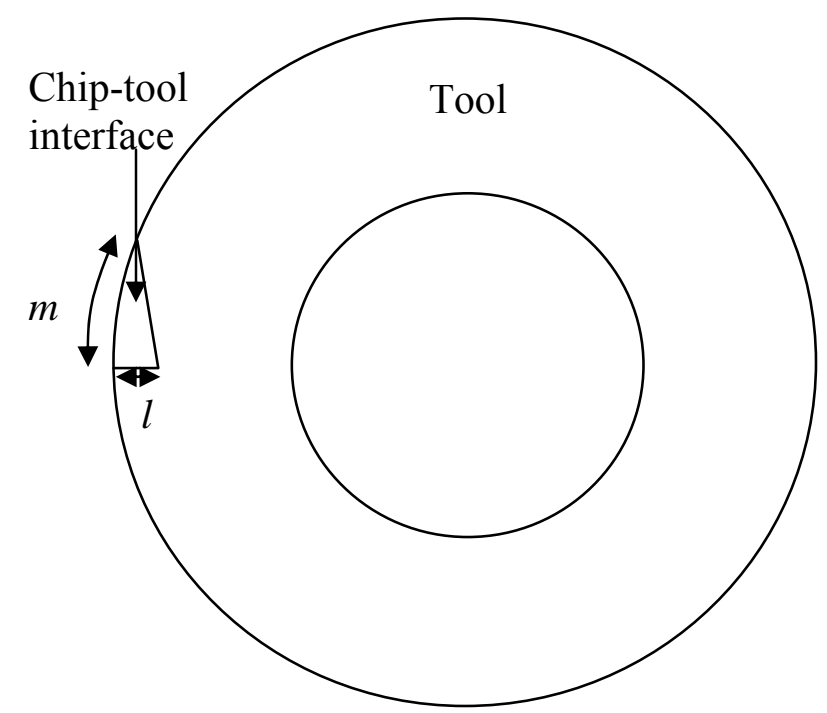

Figure 3-3: Simplified tool-chip interface.

Although the exact tool-chip interface geometry is hard to know, it can be safely assumed that $m$ is small compared to the diameter of the tool. Therefore, the tool-chip interface can be approximated as a right angled triangle whose area is given by:

$$
A_{c t}=\frac{m l}{2}
$$

\subsubsection{Heat flux at the tool-chip interface}

The power, $\mathrm{P}_{\mathrm{f}}$, dissipated due to frictional interaction at the tool-chip interface is given by:

$$
P_{f}=F V_{c r}
$$

where $F$ is the friction force at the interface and $V_{c r}$ is the relative chip velocity.

Thus, the heat flux expended in the friction zone can be computed as follows:

$$
q_{f}=\frac{P_{f}}{A_{c t}}=\frac{F V_{c r}}{A_{c t}}
$$


Using the tool-chip contact area approximation discussed above, Equation (38) can be re-written as:

$$
q_{f}=\frac{2 F V_{c r}}{m l}
$$

Note that Equation (39) holds for both rotary and fixed tool cases except that $V_{c r}$ is replaced by $V_{c}$ for the fixed tool case where the tool does not rotate.

The friction force $F$ is derived using oblique cutting theory since the force along the cutting edge is not equal to zero:

$$
F=\sqrt{\left[\left(F_{c} \cos \left(i_{s}\right)+F_{t} \sin \left(i_{s}\right)\right) \sin \left(\alpha_{n}\right)+F_{f} \cos \left(\alpha_{n}\right)\right]^{2}+\left(F_{c} \sin \left(i_{s}\right)-F_{t} \cos \left(i_{s}\right)\right)^{2}}
$$

where $F_{c}, F_{t}$, and $F_{f}$ are the cutting, thrust and feed force components respectively. And $i_{s}$ and $\alpha_{n}$ are the static inclination and normal rake angles respectively.

The peripheral tool speed $V_{r}$ and the relative chip speed are:

$$
\begin{gathered}
V_{r}=V_{w} \sin \left(i_{s}\right) \\
V_{c r}=V_{w} \sqrt{\left(\frac{b t}{b_{c} t_{c}}\right)^{2}-\sin ^{2}\left(i_{s}\right)}
\end{gathered}
$$

where $b$ and $b_{c}$ are the width of cut and the chip width, respectively. $t$ and $t_{c}$ are the undeformed and deformed chip thicknesses, respectively.

\subsubsection{Heat partitioning coefficient, $\boldsymbol{R}_{2}$}

The heat partitioning coefficient $R_{2}$ represents the heat fraction generated at the tool-chip interface and evacuated by the chip. In this work $R_{2}$ quantity is estimated via Shaw's analysis (1984) together with additional assumptions discussed below. 
Shaw derives the heat partitioning coefficient assuming a rectangular heat source of uniform strength acting as a friction slider and moving at a certain speed over a stationary semi-infinite body insulated everywhere except across the interface. However, the interface in the present work is approximated as a right angled triangle. Moreover, in rotary tool turning, the velocity of interest is no longer the absolute chip velocity but the chip velocity with respect to the tool $\left(V_{c r}\right)$ since the tool rotates about its own principal axis.

One solution to the above problem is to assume that the shape of the heat source is less important than its area. Thus, an equivalent rectangular heat source can be used as depicted in Figure 3-4:
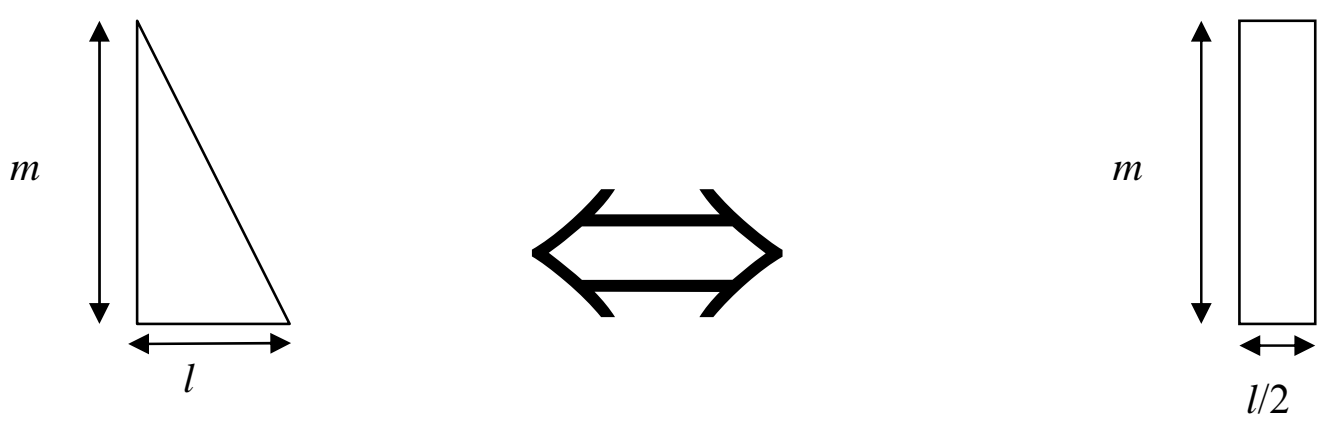

Figure 3-4: Equivalent heat sources.

Using these assumptions in Shaw's analysis, the following equation can be derived for $R_{2}$ :

$$
R_{2}=\frac{1}{1+\frac{0.754 \frac{k_{t}}{k_{c}}}{\bar{A} \sqrt{L}}}
$$


where:

- $\quad k_{t}$ and $k_{c}$ are the thermal conductivities for the tool and the chip, respectively.

- $\bar{A}$ is a geometric factor given by:

$$
\bar{A}=\frac{2}{\pi}\left(\ln \frac{4 m}{l}+\frac{1}{3} \frac{l}{2 m}+\frac{1}{2}\right)
$$

- $L$ is a velocity-diffusivity factor given by:

$$
L=\frac{V_{c r} l}{8 a_{c}}
$$

where $a_{c}$ is the thermal diffusivity of the chip.

The numerical computations required to solve Equation (35) are performed in the FEM software FEMLAB executed in the MATLAB environment.

\subsubsection{Boundary conditions}

The boundary conditions for the finite element method used to solve are as follows. Equation (39) combined with the heat partitioning coefficient $\left(1-\mathrm{R}_{2}\right)$ is imposed at the tool-chip interface. All outer surfaces of the tool are subjected to convection with a heat transfer coefficient of $100 \mathrm{~W} \cdot \mathrm{m}^{-2} \cdot \mathrm{K}^{-1}$. The inner surface (diameter) and the bottom of the tool are assumed to be completely insulated due to the geometry of the insert cartridge. 

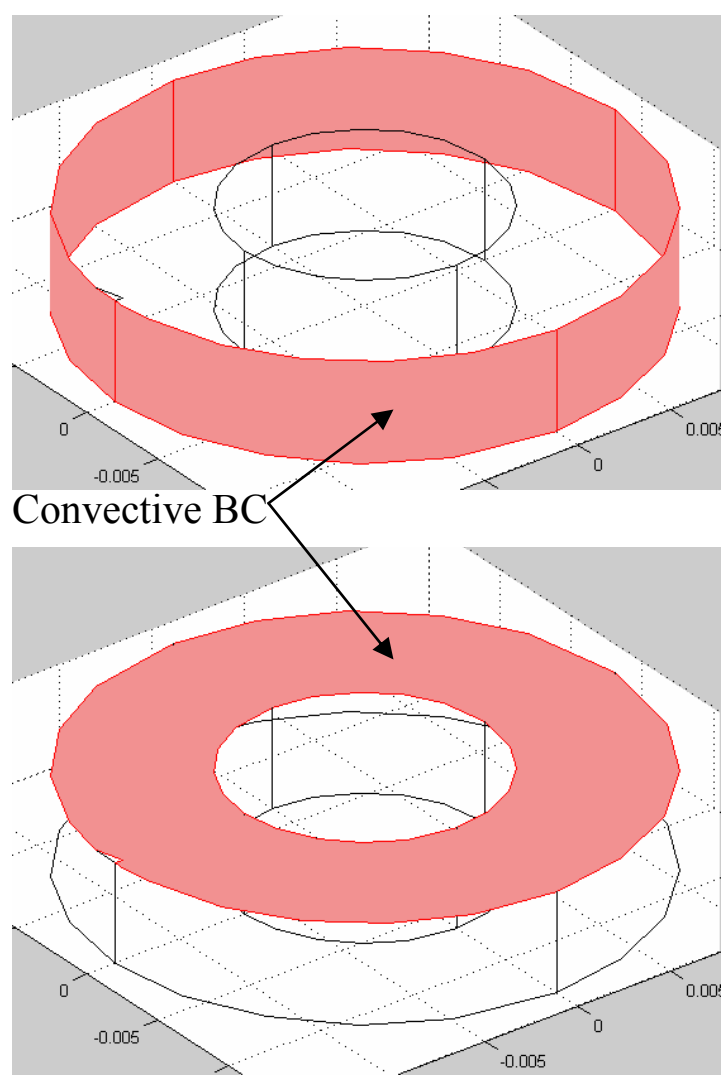

Figure 3-5: Tool surfaces subjected to convection.

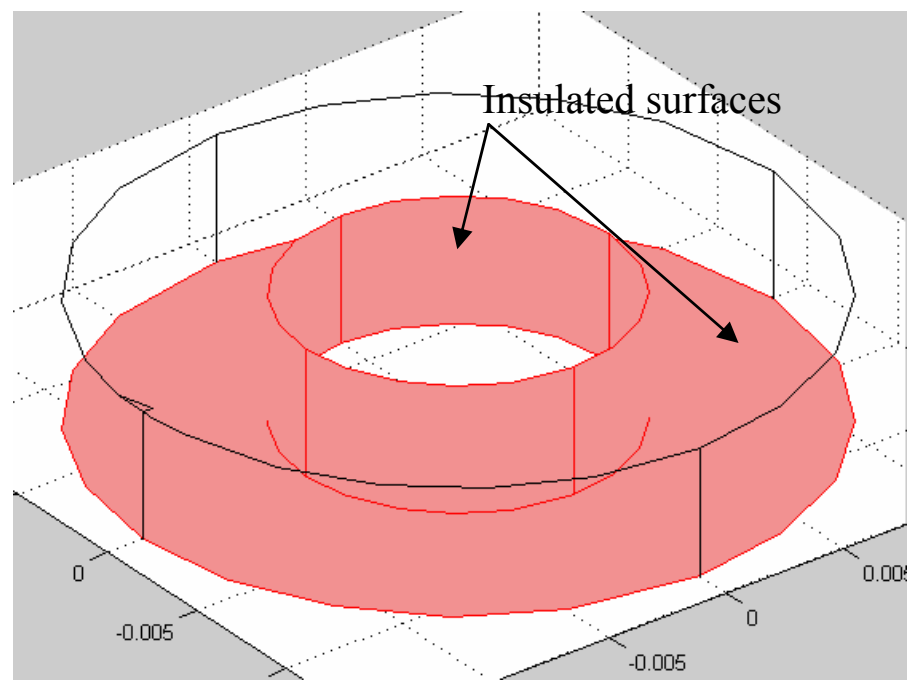

Figure 3-6: Insulated tool surfaces. 


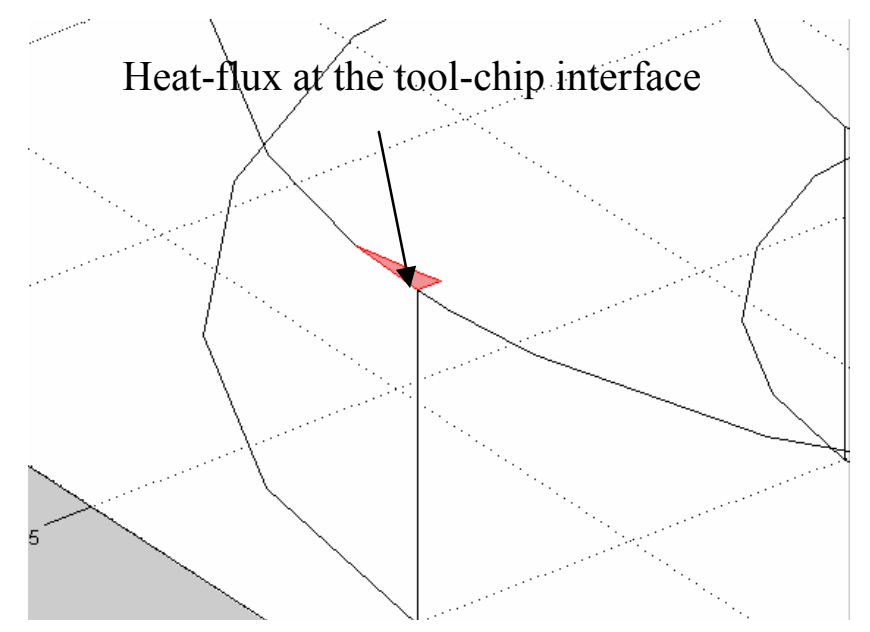

Figure 3-7: Tool-chip interface subjected to a heat-flux.

\subsubsection{Implementation of the model in FEMLAB}

FEMLAB's heat transfer physics mode is used to model the tool. The FEMLAB software uses a graphic interface. Six main modes are used to solve a problem: draw mode, boundary mode, subdomain mode, mesh mode, solver and post mode. Input parameters are given in Appendix D.

$>$ Draw mode

The geometry of the tool and the tool-chip interface are specified in this mode. The tool geometry is nothing but a torus with a rectangular cross section. Two cylinders are drawn and then differentiated to obtain this geometry. Since the tool-chip interface has certain boundary conditions imposed on it, it has to be considered as an embedded surface on the tool rake face. In this way, it constitutes an independent entity but still belongs to the tool. 


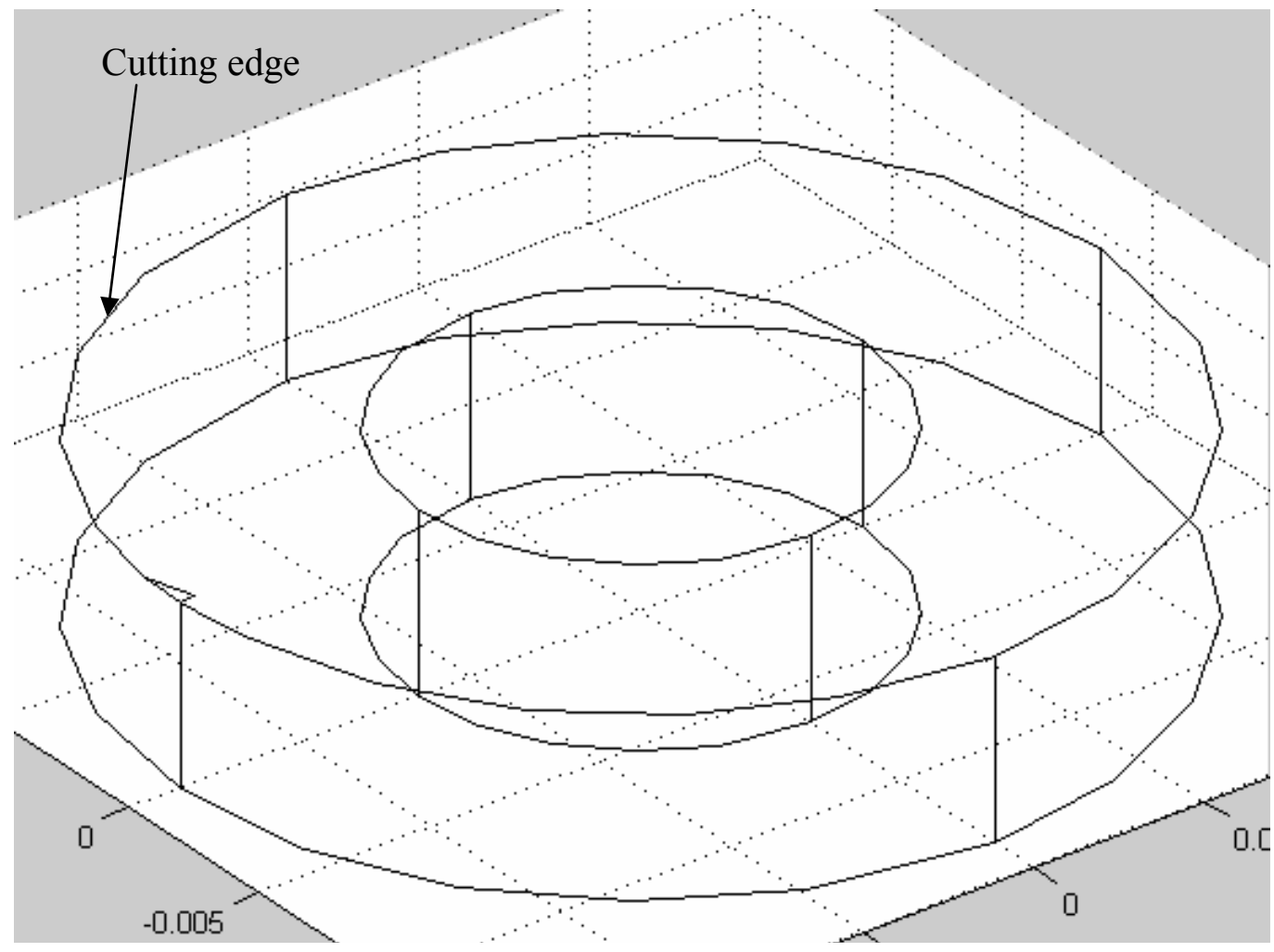

Figure 3-8: Tool in draw mode.

\section{$\underline{\text { Boundary mode }}$}

This mode permits specification of all boundary conditions. Actually, the cutting edge is circular and not a straight line as shown in Figure 3-9. This is due to the discretization of shape used by FEMLAB for display puposes. 


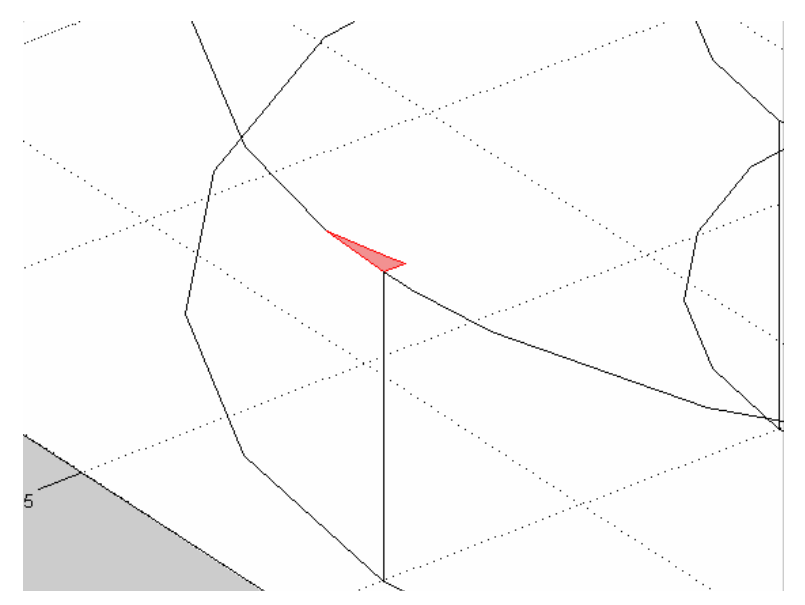

Figure 3-9: Tool-chip interface in boundary mode.

\section{$\underline{\text { Subdomain mode }}$}

In this mode, the different terms involved in the governing equation are defined.

\section{Mesh mode}

The different characteristics of the finite element mesh are set in this mode. Clearly, the finer the mesh, the more accurate the solution at the expense of longer the computation time. To get valid results, the meshing is first set to "normal" and then it is refined until the solution does not vary anymore. In this work, the "finer" meshing option has been found to be a good trade-off between the computation cost and the accuracy of the results. Table 3-2 lists the interpretation of "normal" and "fine" mesh settings. 
Table 3-2: Mesh settings.

\begin{tabular}{|c|c|c|c|c|c|c|}
\hline Mesh & $\begin{array}{c}\text { Element } \\
\text { type }\end{array}$ & $\begin{array}{c}\text { Maximum } \\
\text { edge size } \\
(\mathrm{mm})\end{array}$ & $\begin{array}{c}\text { Number } \\
\text { of } \\
\text { elements }\end{array}$ & $\begin{array}{c}\text { Number } \\
\text { of } \\
\text { nodes }\end{array}$ & $\begin{array}{c}\text { Computation } \\
\text { time } \\
(\mathrm{s})\end{array}$ & $\begin{array}{c}\text { Maximum } \\
\text { temperature } \\
\left({ }^{\circ} \mathrm{K}\right)\end{array}$ \\
\hline Normal & Triangular & 1 & 3265 & 900 & 5 & 398 \\
\hline Fine & Triangular & 0.8 & 6539 & 1687 & 7 & 407 \\
\hline Finer & Triangular & 0.55 & 12345 & 2824 & 30 & 407 \\
\hline Extra fine & Triangular & 0.35 & 47894 & 9841 & 120 & 409 \\
\hline $\begin{array}{c}\text { Extremely } \\
\text { fine }\end{array}$ & Triangular & 0.2 & 245077 & 46210 & $\begin{array}{c}\text { Out of } \\
\text { memory }\end{array}$ & $\begin{array}{c}\text { Out of } \\
\text { memory }\end{array}$ \\
\hline
\end{tabular}

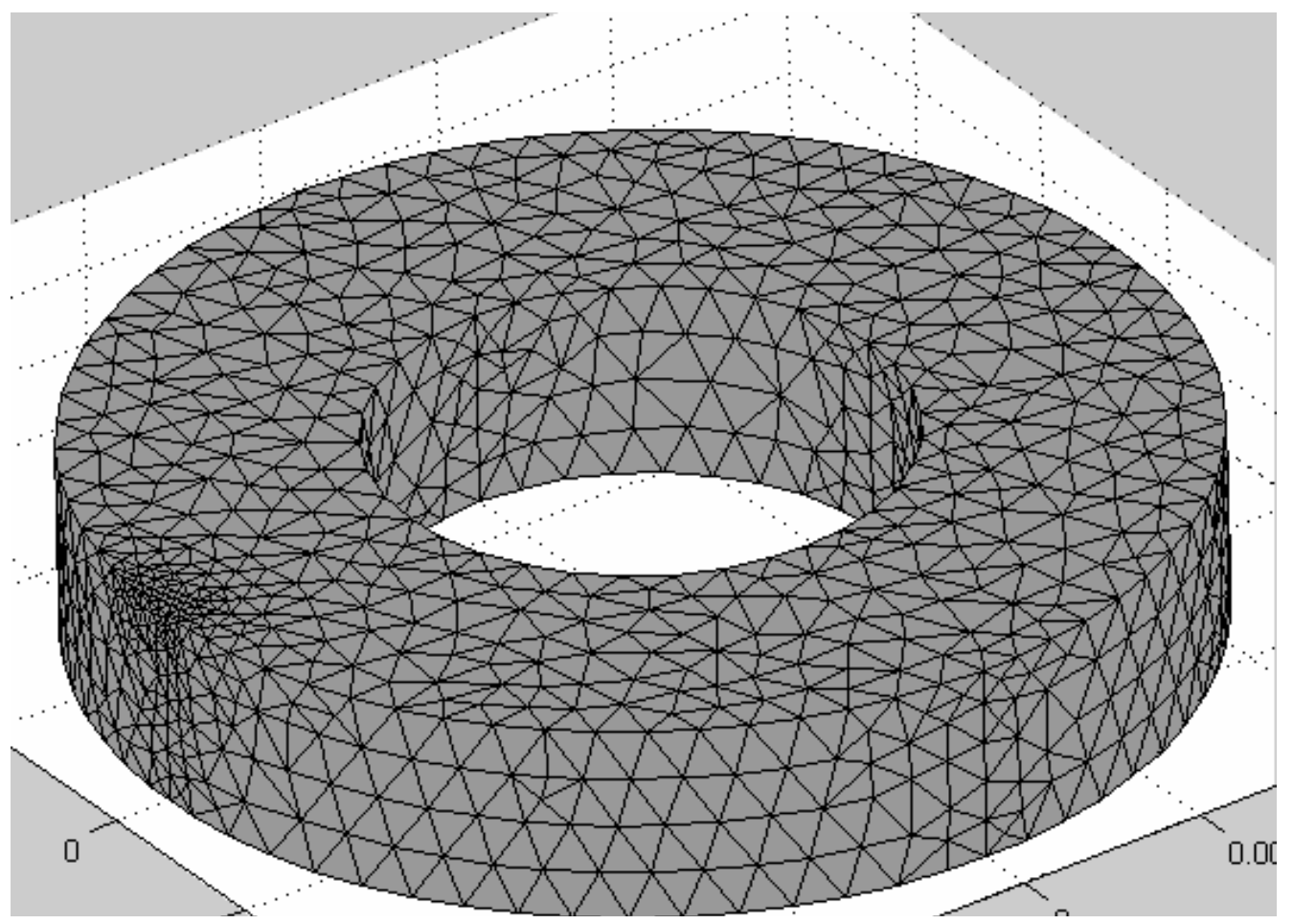

Figure 3-10: Tool in mesh mode.

\section{Problem solver}

Parameters of the solver and the solver type are set in this mode. In this investigation, the measured temperature was determined after two seconds of cutting as 
discussed in Chapter 4. Consequently, the "time-dependent" solver type was used in FEMLAB. Also, in this mode, the type of ODE solver is defined. Since the tool is considered to be stiff, the "ode15stiff" solver was used.

\section{$\underline{\text { Post mode }}$}

This mode is used to analyze the results given by the solver. Temperature, heat flux and temperature gradient can be visualized in different ways. Also, cross-section plots, plot along a line can be drawn using this mode.

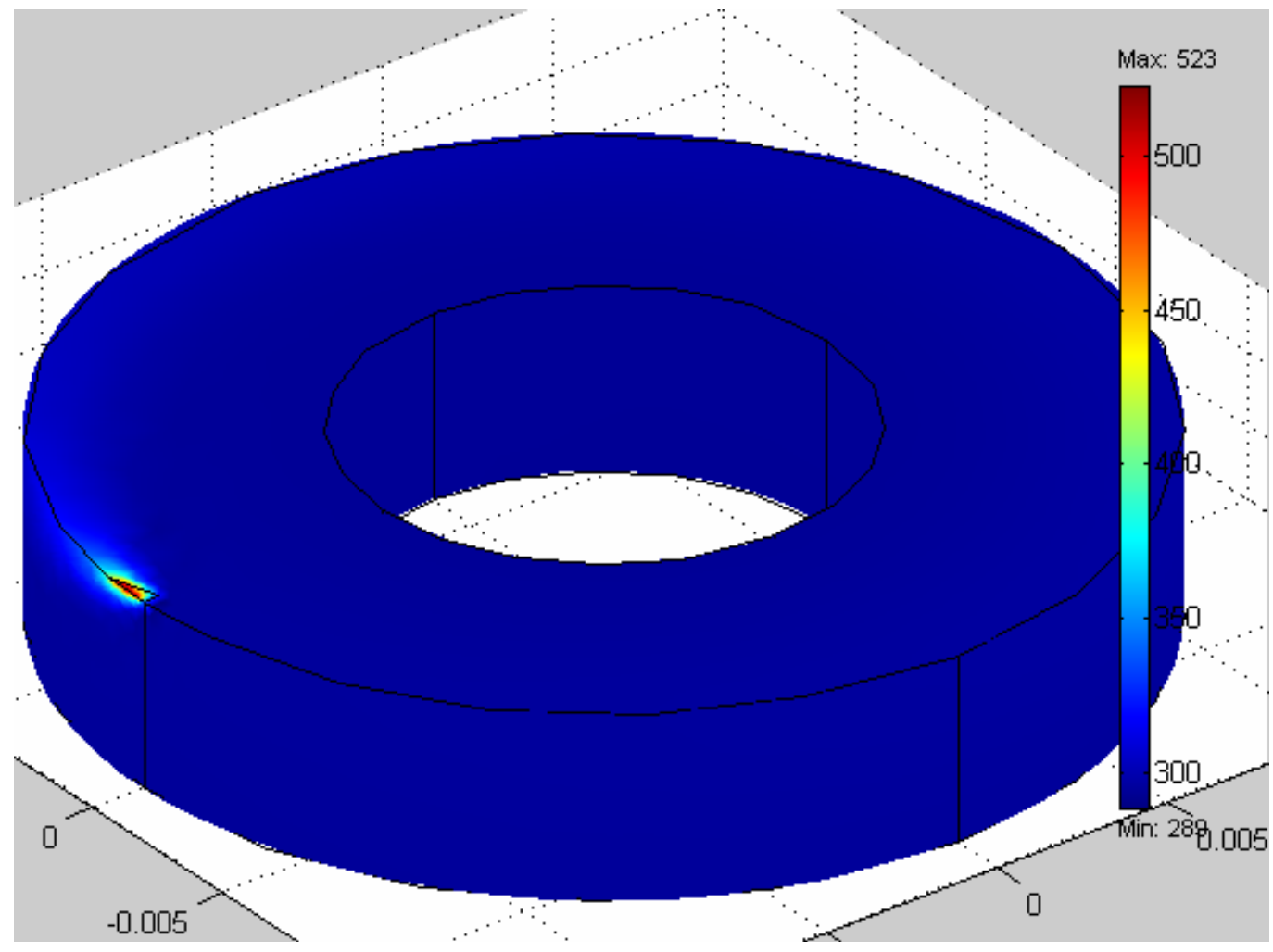

Figure 3-11: Rotary tool in post mode. 


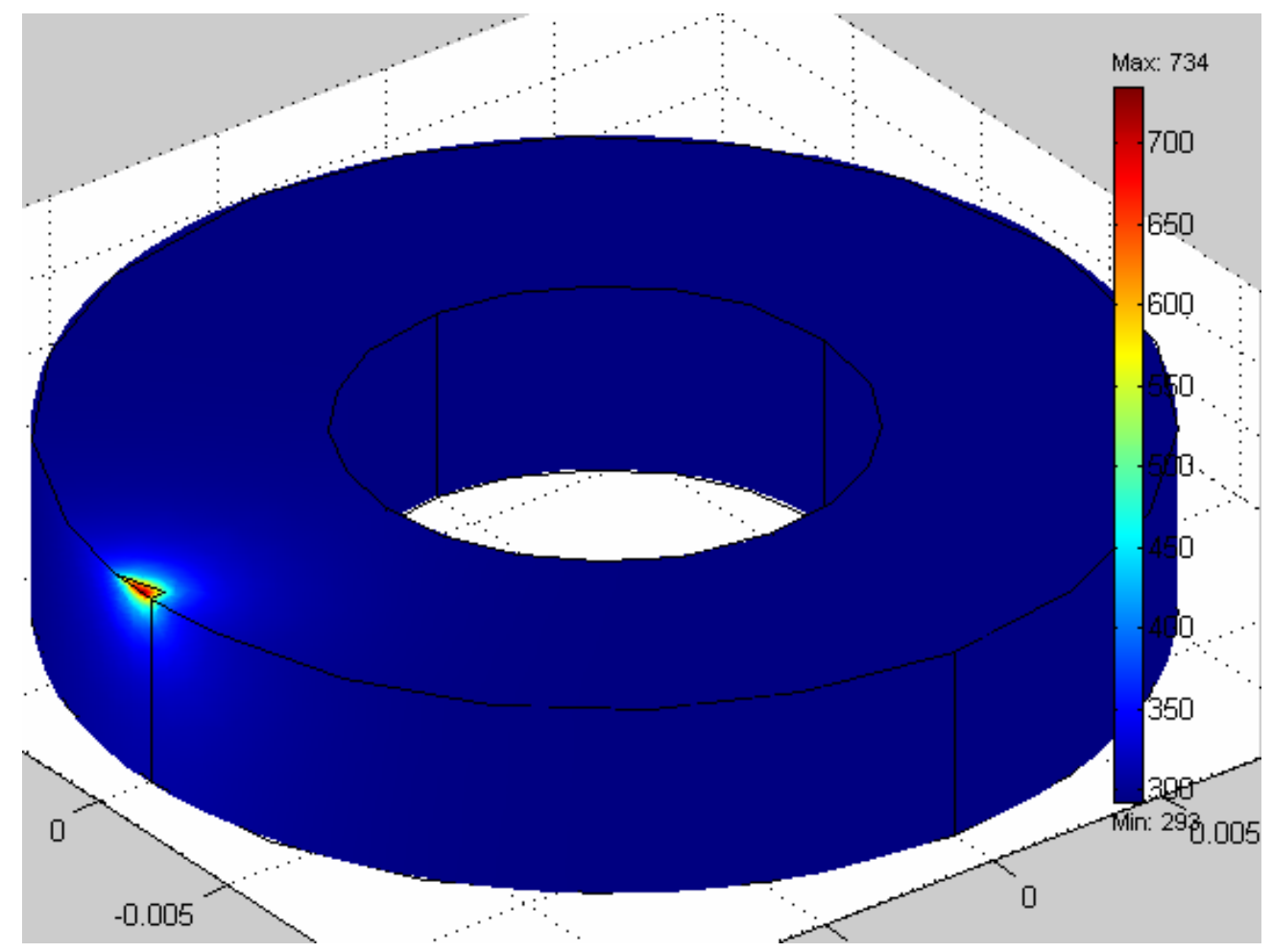

Figure 3-12: Fixed tool in post mode.

Temperature distributions provided in Figure 3-11 and Figure 3-12 are a good way to visualize energy transport in the tool. For the fixed tool, it is noticed that the tool is heated considerably around the tool-chip contact area on the rake face as well as at the tool flank-workpiece interface. In contrast, it is easily seen that heat is carried away along the cutting edge when the rotary tool is used and the flank is heated less. This characteristic may explain why researchers have found lower tool wear when a rotary tool was used. 


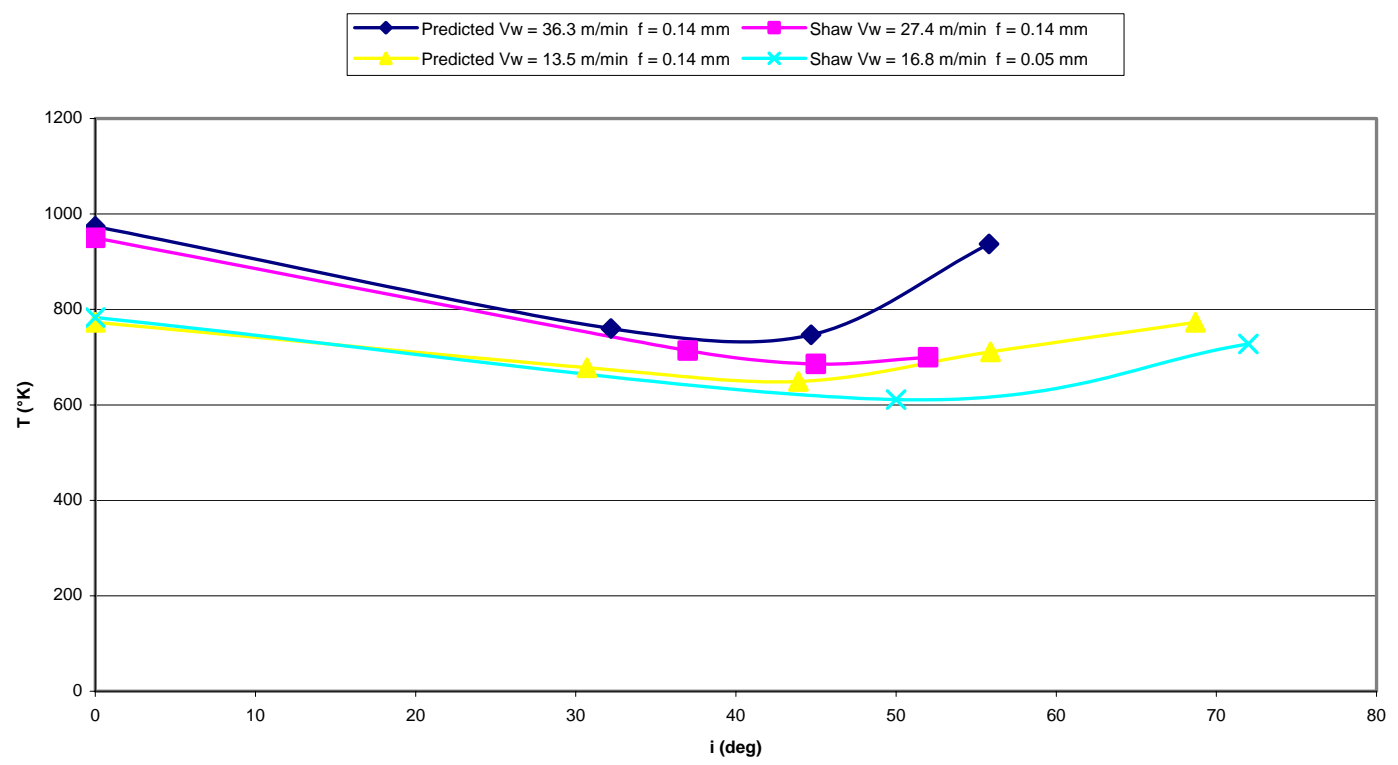

Figure 3-13: Preliminary comparison of predicted trends with published data.

In Figure 3-13, predicted temperatures are compared to measured temperatures provided in previous work by Shaw (1952). The analysis is based on the data given by Shaw (1952) when turning a steel tube with a driven orthogonal rotary tool. Thus, cutting parameters, derivation of the heat flux at the tool-chip interface and so on are calculated using numerical values of Shaw's experiments. As explained in Chapter 2, in driven rotary tool turning, an angle of inclination equal to zero corresponds to the fixed tool case (no rotation).

As pointed out earlier, Shaw used the chip-tool thermocouple technique to determine the average chip-tool interface temperatures when using stationary and rotating tools. 
Note that the predicted and measured results (Figure 3-13) are not for the same cutting conditions because Shaw (1952) did not provide all data for every case in his paper.

However, it can be seen that both predicted and experimental temperatures show the same trend consisting of a decrease in temperature with increasing inclination angle, followed by a minimum around $\mathrm{i}=40^{\circ}$ and finally an increase in the temperature. Also, rotation of the tool induces lower temperatures. In addition, it can be seen for $V_{w}=36.3$ $\mathrm{m} / \mathrm{min}$ and $\mathrm{f}=0.14 \mathrm{~mm}$, the predicted temperature is in reasonable agreement with Shaw's experimental data for $\mathrm{V}_{\mathrm{w}}=27.4 \mathrm{~m} / \mathrm{min}$ and $\mathrm{f}=0.14 \mathrm{~mm}$.

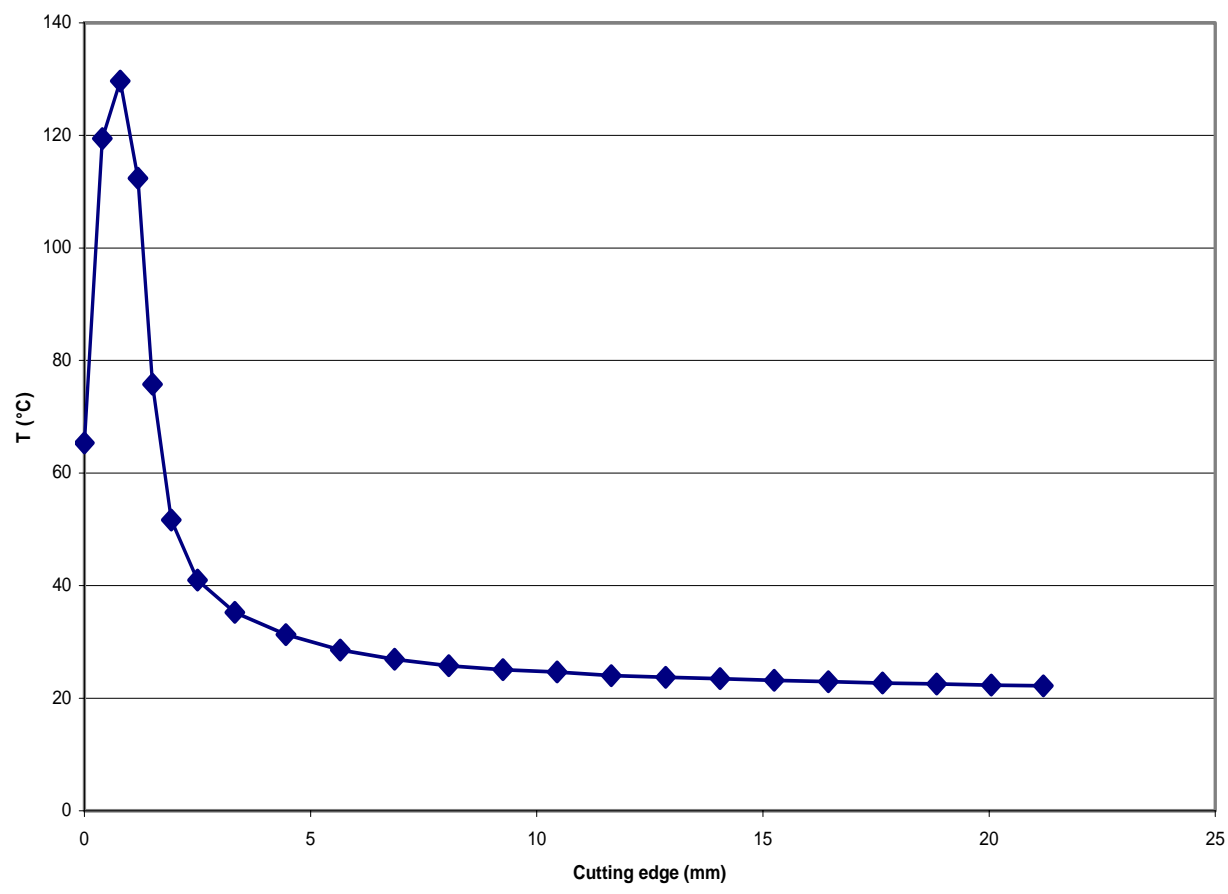

Figure 3-14: Temperature distribution along the cutting edge in rotary tool turning. 
A typical plot of the instantaneous temperature distribution along the cutting edge in rotary tool turning is shown in Figure 3-14 for an example case. The horizontal axis in this figure represents the distance along the cutting edge of the rotary insert measured from one edge of the tool-chip contact area. The peak temperature corresponds to approximately the middle of the tool-chip contact area. This type of plot is used in Chapter 5 for model verification.

\subsection{Summary}

It is noticed that the finite element model presented in this section is simpler than those presented by other researchers in terms of implementation. The model predictions show good overall agreement in trends when compared with Shaw's (1952) measured temperatures. This comparison was for a driven rotary tool process for machining a plain carbon steel with a HSS tool. The model developed in this chapter will be validated for SPRT turning of hardened steel using a infra-red thermal imaging camera in Chapters 4 and 5. 


\section{CHAPTER 4}

\section{EXPERIMENTAL WORK}

This chapter describes experimental work carried out to verify the tool temperature distribution model for the SPRT process analyzed in Chapter 3. Both selfpropelled rotary tool and fixed tool based hard turning experiments are performed. Chip geometry, cutting forces and the tool temperature distribution are measured in these experiments. The following sections describe the experimental procedure and results.

\subsection{Machining a hardened AISI 52100 steel}

\subsubsection{Experimental conditions}

Classical longitudinal turning of the outer diameter of a bar was carried out in these experiments. This kind of process involves a single point that maintains continuous contact with the workpiece during cutting. Since the goal is to see the effectiveness of the rotary tool in terms of cutting temperature, dry machining was employed. A customized tool holder with rotary tool cartridge and inserts were used in the experiments (see Figure 4-1). Another cartridge (also shown in Figure 4-1) was manufactured to accommodate a fixed insert so that both rotary and fixed processes could be compared. The geometry of the fixed tool cartridge is identical to the rotary cartridge. Circular carbide inserts of 27 mm diameter with TiN coating were used. The geometry of the cartridge and the tool holder give the inserts an effective negative rake angle of $15^{\circ}$ and an effective clearance angle of $5^{\circ}$. 
The workpiece is a hardened AISI 52100 steel round bar. This material has the following nominal chemical composition: $\mathrm{C}(0.98-1.1 \% \mathrm{wt}),. \mathrm{Cr}(1.45 \% \mathrm{wt}),. \mathrm{Fe}(97 \%$ wt.), Mn (0.35\% wt.), P ( $\max 0.025 \%$ wt.), S ( $\max 0.025 \%$ wt.), Si $(0.23 \%$ wt.). Its Young's modulus, UTS and hardness are $210 \mathrm{GPa}, 2240 \mathrm{MPa}$ and $58 \mathrm{HRC}$ (see Table 4-1), respectively. Figure 4-2 illustrates the actual rotary tool process.

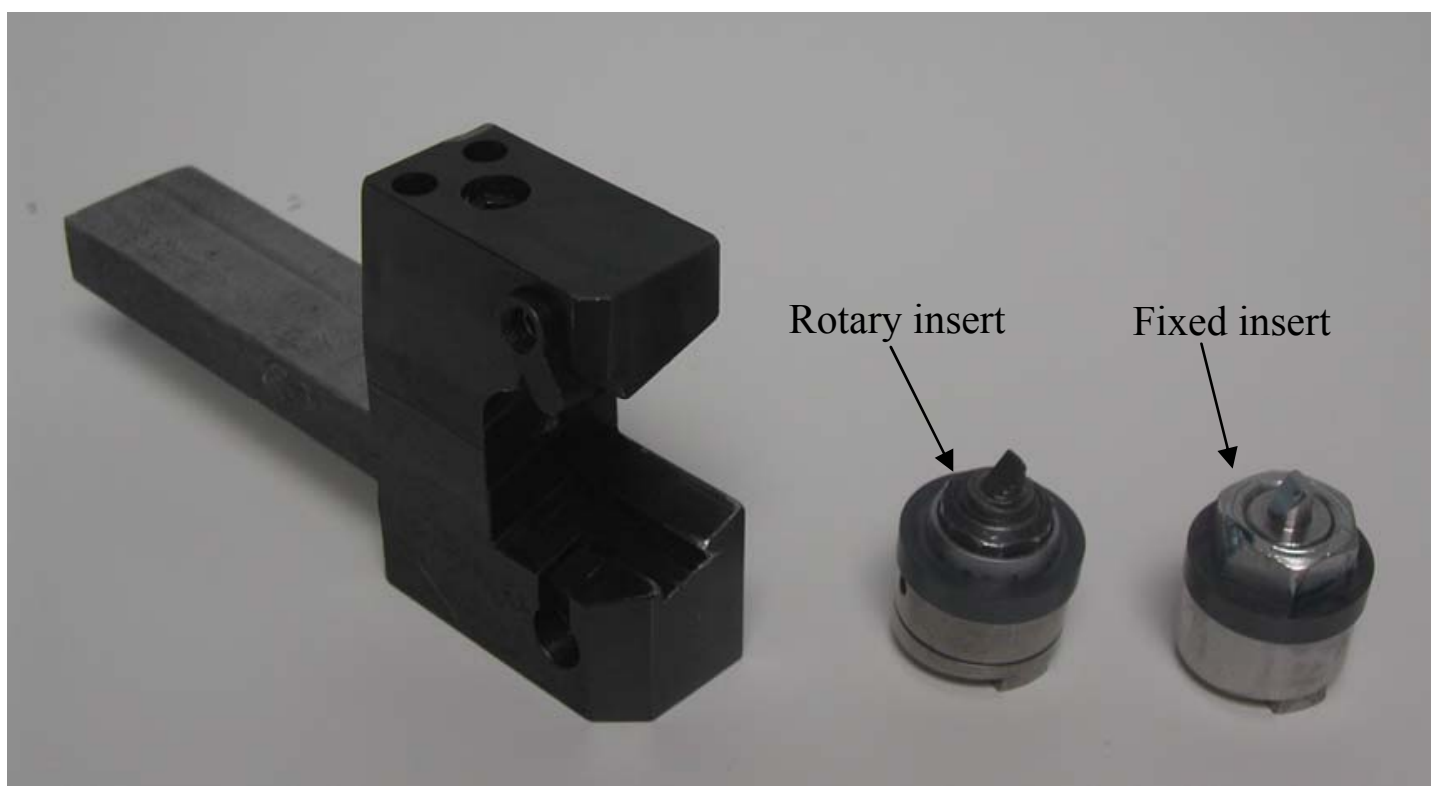

Figure 4-1: Tool holder, rotary and fixed tool cartridges.

Table 4-1: Hardness measurements.

\begin{tabular}{|c|c|c|c|c|c|}
\hline $\begin{array}{c}\text { Workpiece } \\
\text { diameter } \\
(\mathrm{mm})\end{array}$ & $\begin{array}{c}\text { Hardness } \\
\mathrm{RC} \text { (point1) }\end{array}$ & $\begin{array}{c}\text { Hardness } \\
\mathrm{RC} \text { (point 2) }\end{array}$ & $\begin{array}{c}\text { Hardness } \\
\mathrm{RC} \text { (point3) }\end{array}$ & $\begin{array}{c}\text { Hardness } \\
\mathrm{RC} \text { (point4) }\end{array}$ & $\begin{array}{c}\text { Average } \\
\text { Hardness } \\
\mathrm{RC}\end{array}$ \\
\hline 40 & 59 & 59 & 58 & 58 & 58.5 \\
\hline 36 & 59 & 58 & 58 & 58 & 58 \\
\hline
\end{tabular}




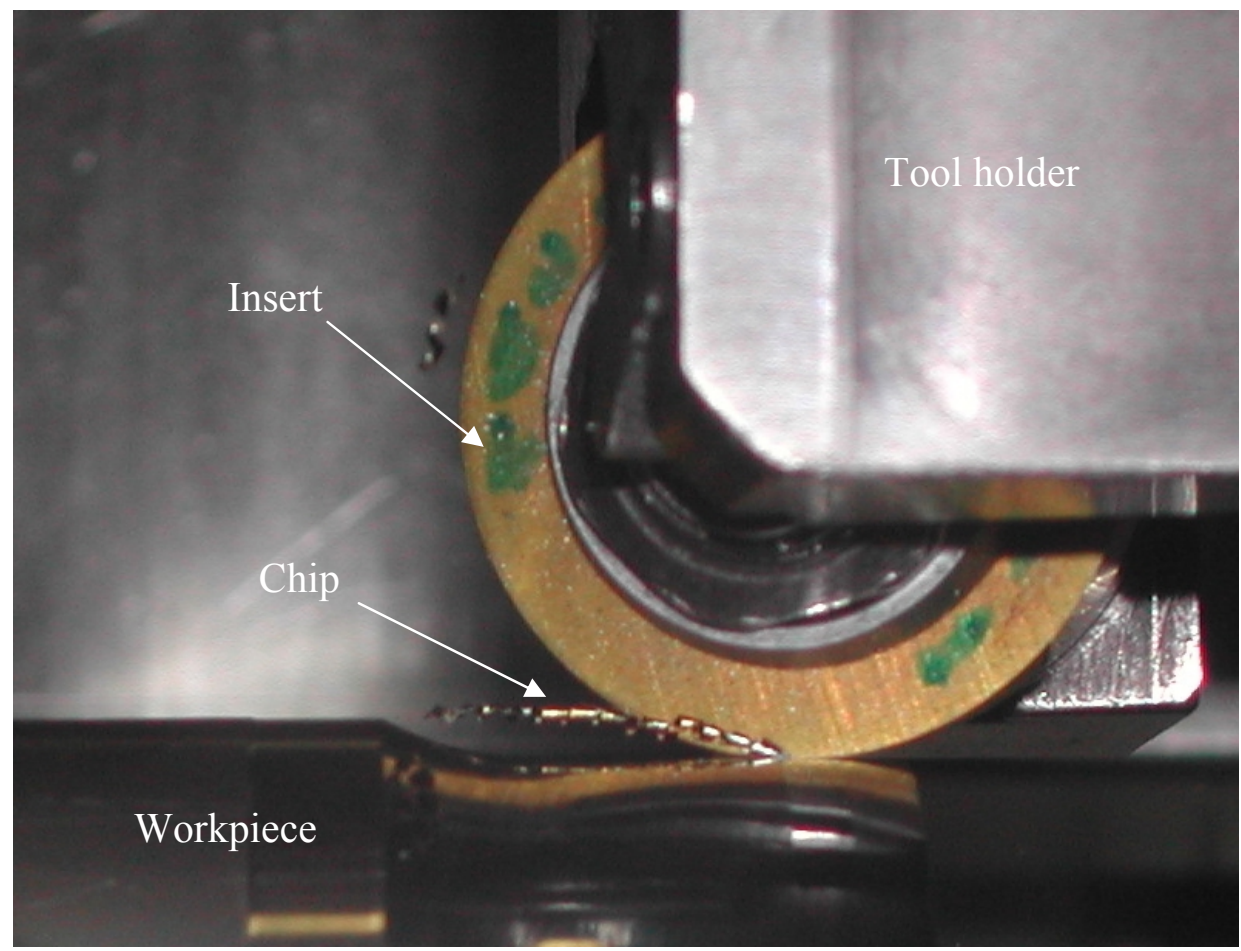

Figure 4-2: Actual self-propelled rotary tool process.

The deformed chip thickness $\left(t_{c}\right)$ and the chip width $\left(b_{c}\right)$ were measured at different locations with a caliper and a micrometer and the average values were then calculated. Determination of cutting forces is necessary to use the temperature model. The cutting forces were measured using a piezoelectric platform dynamometer (Kistler model 9257B) connected to a computer through a Kistler 5010 charge amplifier unit. A Krohn-Hite model 3384 analog filter was used to filter the measured cutting forces (Figure 4-3). The output of the Kistler dynamometer consists of three channels of force data carried through a single cable which is the input into the charge amplifier to adequately magnify the output signals. The output signals from the charge amplifier are input to a data acquisition hardware mounted in a computer. Then, forces are read and 
recorded using the DCAP software. All machining was carried out on a Hardinge T42SP $\mathrm{CNC}$ lathe located in the Precision Machining Research laboratory. 

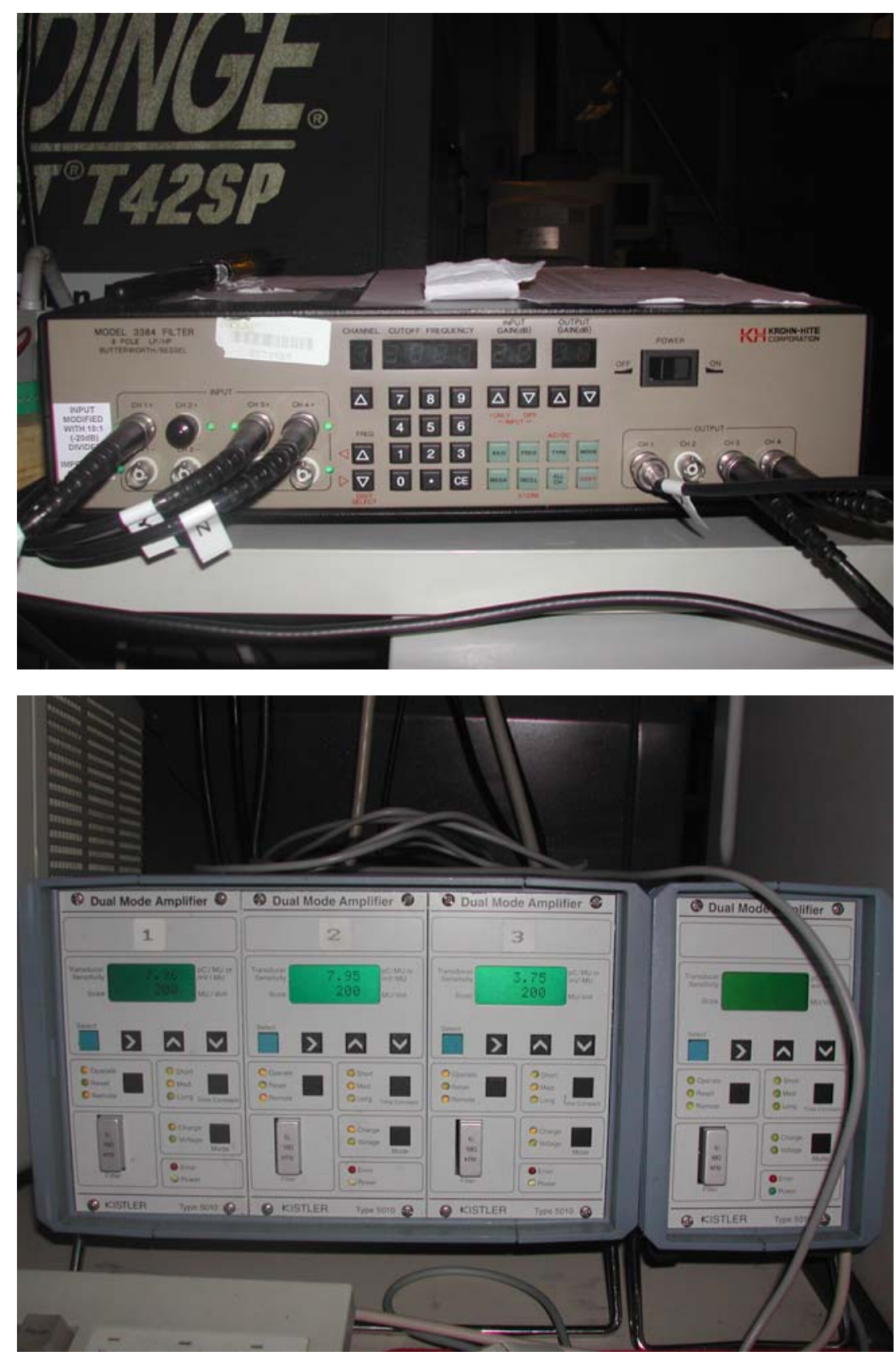

Figure 4-3: Analog filter and charge amplifier. 


\subsubsection{Cutting forces and chip geometry}

Both cutting forces and chip geometry have to be determined through experiments in order to obtain the model inputs. First, experiments were performed using a depth of cut equal to $0.2 \mathrm{~mm}$, value used by a former student in rotary tool turning of hardened steel.

\subsubsection{Results}

The trends of the different cutting forces are shown in Figure 4-4 and Figure 4-5.

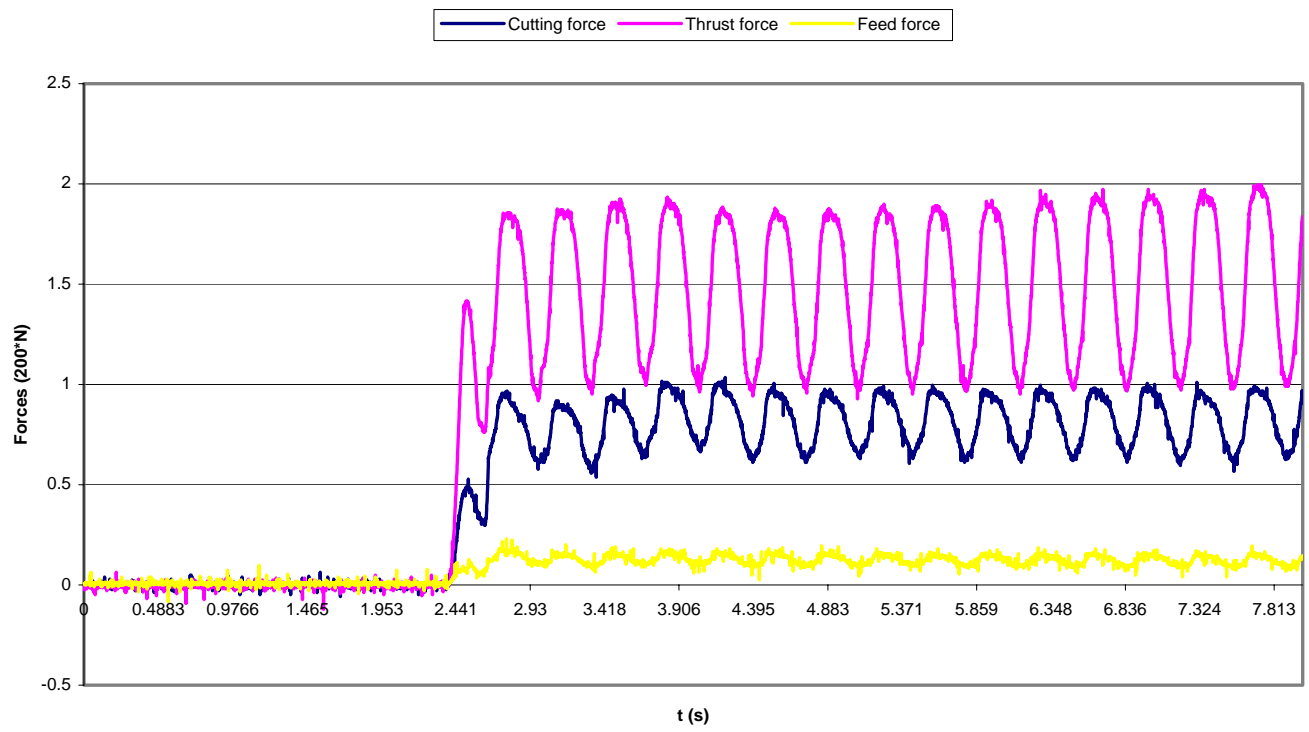

Figure 4-4: Fixed tool, $\mathrm{V}_{\mathrm{w}}=20 \mathrm{~m} / \mathrm{min}, \mathrm{f}=0.1 \mathrm{~mm} / \mathrm{rev}, \mathrm{a}_{\mathrm{p}}=0.2 \mathrm{~mm}$. 


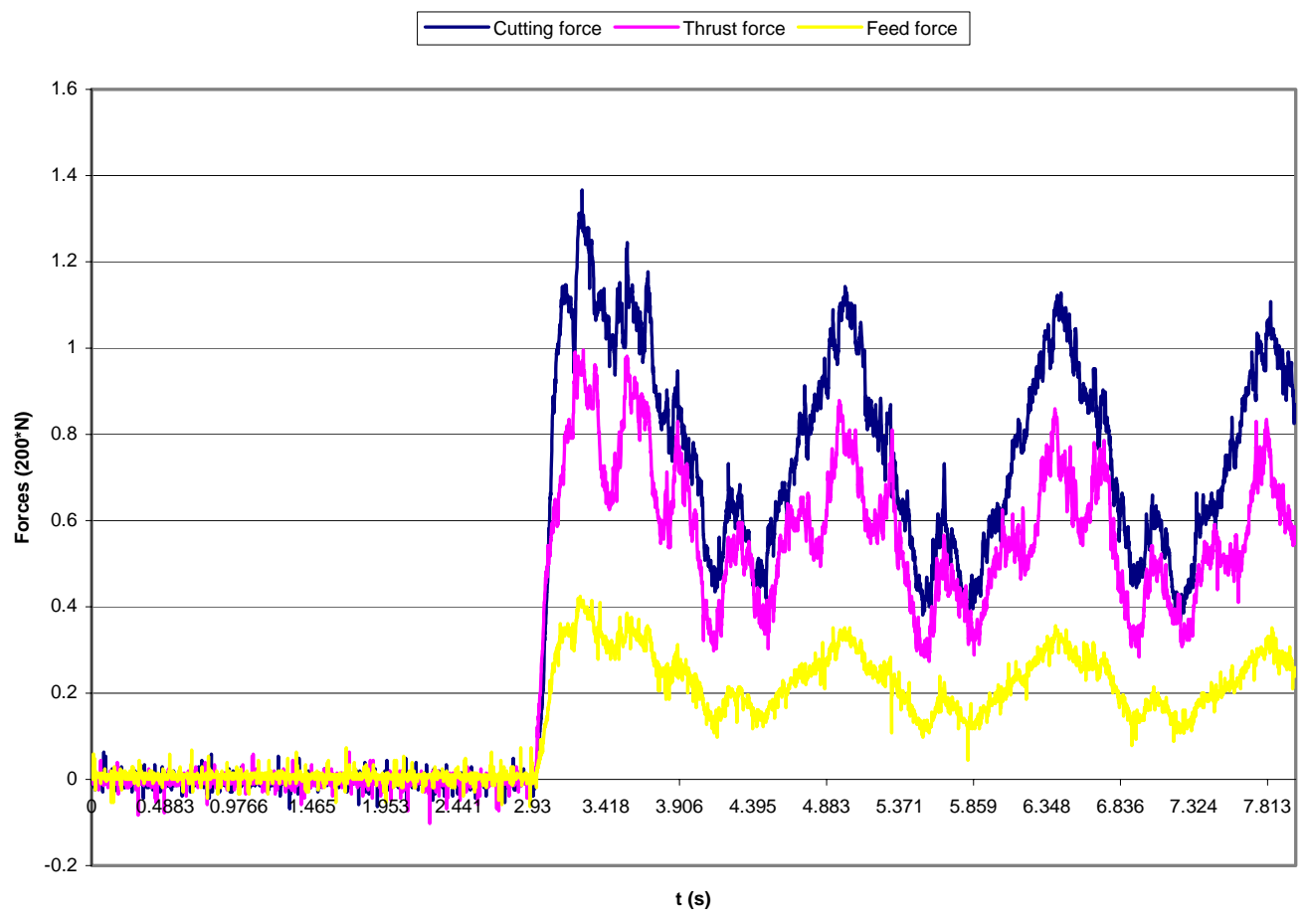

Figure 4-5: Rotary tool, $\mathrm{V}_{\mathrm{w}}=20 \mathrm{~m} / \mathrm{min}, \mathrm{f}=0.1 \mathrm{~mm} / \mathrm{rev}, \mathrm{a}_{\mathrm{p}}=0.2 \mathrm{~mm}$.

It can be seen that forces do oscillate quite a bit. This phenomenon is explained later on. Consequently, average values were used in the analysis. 
Table 4-2: Influence on the cutting speed on the forces.

\begin{tabular}{|c|c|c|c|c|c|c|c|c|c|}
\hline & \multicolumn{3}{|c|}{ Rotary tool } & \multicolumn{3}{c|}{ Fixed tool } & \multicolumn{3}{c|}{ Comparison } \\
\hline $\begin{array}{c}\mathrm{V}_{\mathrm{w}} \\
(\mathrm{m} / \mathrm{min})\end{array}$ & $\begin{array}{c}\mathrm{F}_{\mathrm{c}} \\
(\mathrm{N})\end{array}$ & $\begin{array}{c}\mathrm{F}_{\mathrm{t}} \\
(\mathrm{N})\end{array}$ & $\begin{array}{c}\mathrm{F}_{\mathrm{f}} \\
(\mathrm{N})\end{array}$ & $\begin{array}{c}\mathrm{F}_{\mathrm{c}} \\
(\mathrm{N})\end{array}$ & $\begin{array}{c}\mathrm{F}_{\mathrm{t}} \\
(\mathrm{N})\end{array}$ & $\begin{array}{c}\mathrm{F}_{\mathrm{f}} \\
(\mathrm{N})\end{array}$ & $\begin{array}{c}\Delta \mathrm{F}_{\mathrm{c}} / \mathrm{F}_{\mathrm{c}} \\
(\%)\end{array}$ & $\begin{array}{c}\Delta \mathrm{F}_{\mathrm{t}} / \mathrm{F}_{\mathrm{t}} \\
(\%)\end{array}$ & $\begin{array}{c}\Delta \mathrm{F}_{\mathrm{f}} / \mathrm{F}_{\mathrm{f}} \\
(\%)\end{array}$ \\
\hline 20 & 143 & 107 & 43 & 162 & 307 & 26 & -12 & -65 & 65 \\
\hline 40 & 150 & 159 & 50 & 193 & 397 & 37 & -22 & -60 & 34. \\
\hline 60 & 144 & 175 & 50 & 170 & 417 & 39 & -15 & -58 & 28 \\
\hline 80 & 139 & 191 & 49 & 173 & 564 & 39 & -20 & -66 & 25 \\
\hline 100 & 135 & 200 & 49 & 162 & 651 & 38 & -17 & -69 & 26 \\
\hline
\end{tabular}

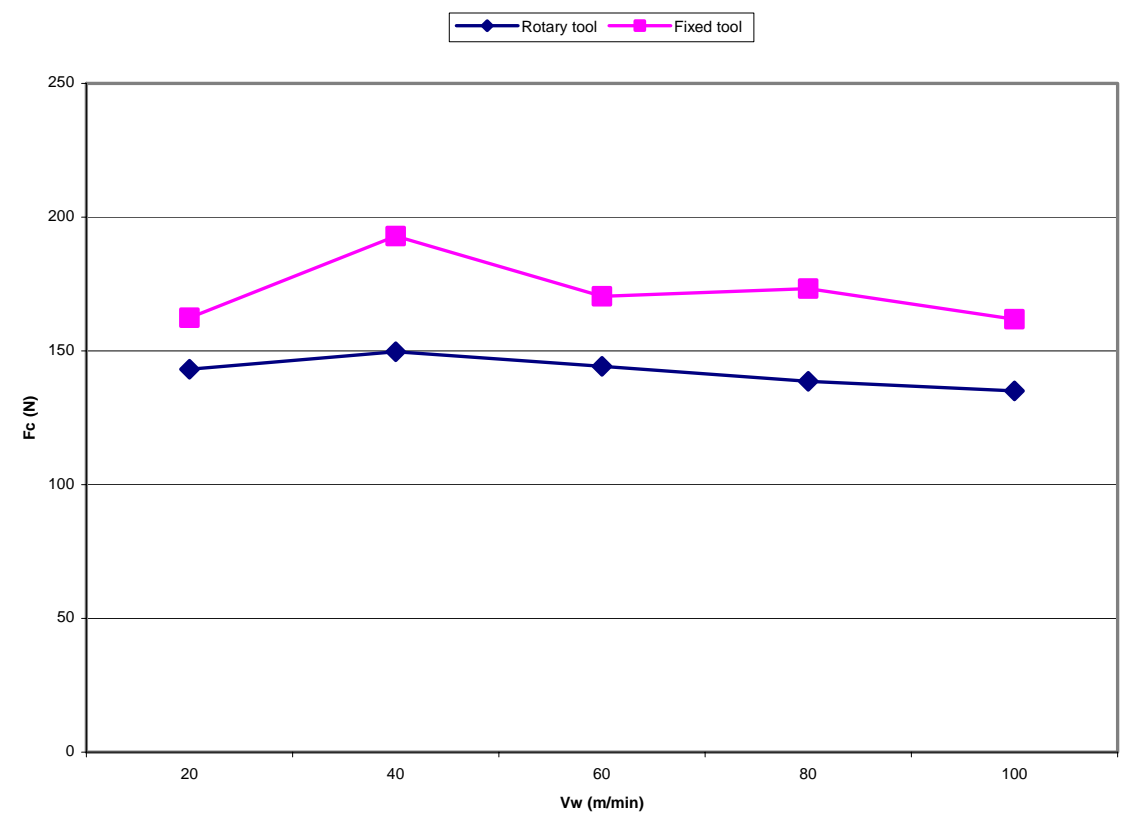

Figure 4-6: Influence of cutting speed on cutting force. 


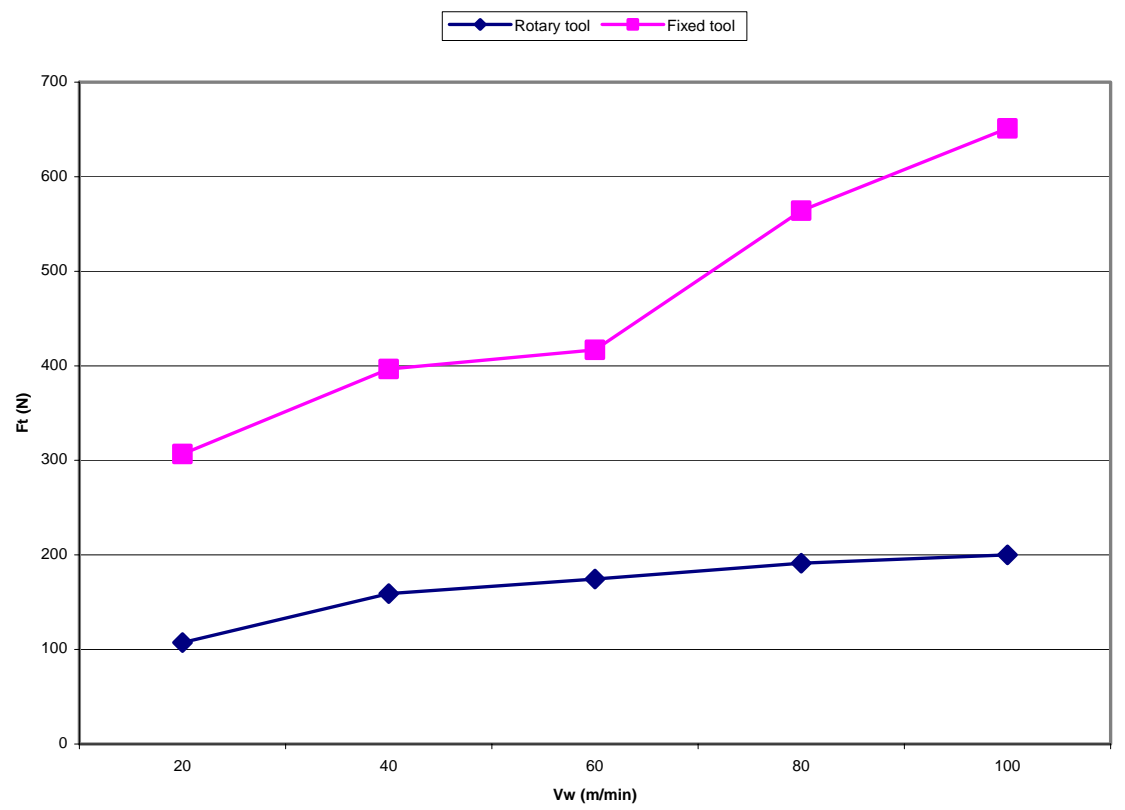

Figure 4-7: Influence of cutting speed on thrust force.

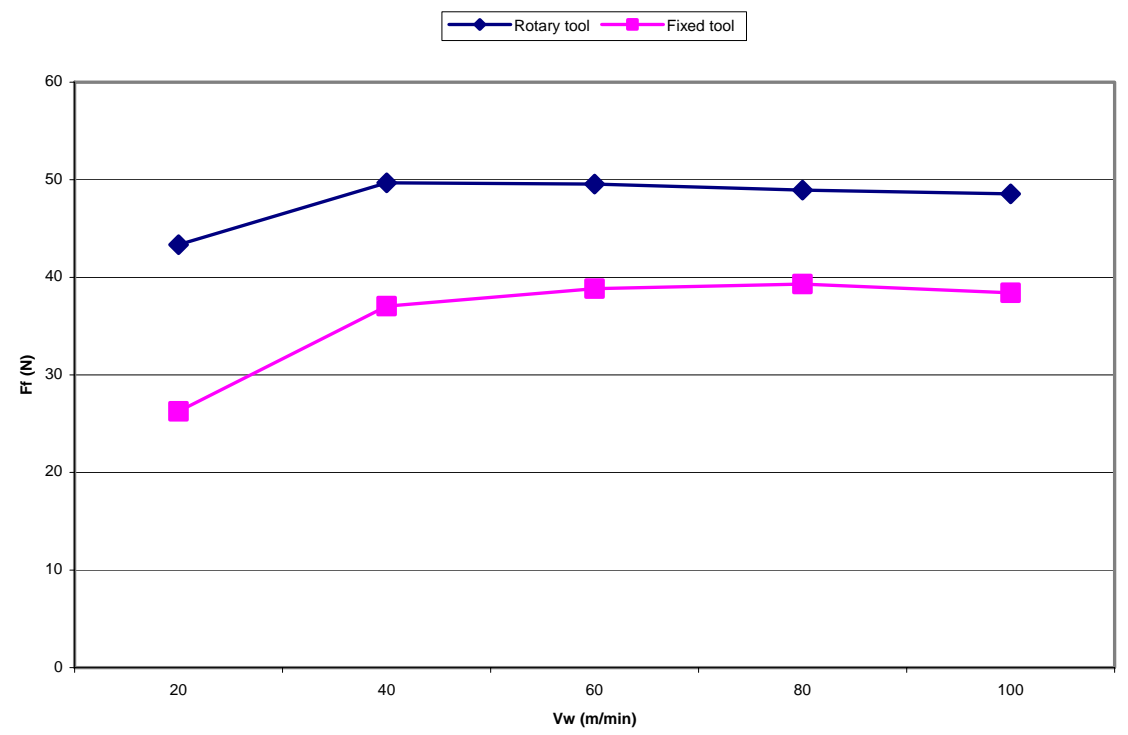

Figure 4-8: Influence of cutting speed on feed force.

In 
Table 4-2, it can be seen that the thrust force is large in magnitude while the feed force is quite small. A large thrust force is known to be typical of hard turning. Globally, the forces are higher for the fixed tool case except for the feed force, which is quite small relative to the other two components. It is important to notice that this difference can be significant, particularly for the thrust force. Contrary to what it can be seen in conventional turning, there is no noticeable size-effect in Figure 4-6, Figure 4-7 and Figure 4-8. For both the rotary and fixed tool cases, the cutting and feed forces are almost constant while the thrust force increases with cutting speed.

Table 4-3: Influence of cutting speed on chip geometry (1).

\begin{tabular}{|c|c|c|c|c|c|c|}
\hline & \multicolumn{2}{|c|}{ Rotary tool } & \multicolumn{2}{c|}{ Fixed tool } & \multicolumn{2}{c|}{ Comparison } \\
\hline $\begin{array}{c}\mathrm{V}_{\mathrm{w}} \\
(\mathrm{m} / \mathrm{min})\end{array}$ & $\begin{array}{c}\bar{t}_{c} \\
(\mathrm{~mm})\end{array}$ & $\begin{array}{c}\bar{b}_{c} \\
(\mathrm{~mm})\end{array}$ & $\begin{array}{c}\bar{t}_{c} \\
(\mathrm{~mm})\end{array}$ & $\begin{array}{c}\bar{b}_{c} \\
(\mathrm{~mm})\end{array}$ & $\begin{array}{c}\Delta \bar{t}_{c} / \bar{t}_{c} \\
(\%)\end{array}$ & $\begin{array}{c}\Delta \bar{b}_{c} / \bar{b}_{c} \\
(\%)\end{array}$ \\
\hline 20 & & & & & & \\
\hline 40 & & 1.693 & & 1.770 & & -4.31 \\
\hline 60 & 0.041 & 1.719 & 0.050 & 1.736 & -16.95 & -0.98 \\
\hline 80 & 0.040 & 1.414 & 0.045 & 1.626 & -11.32 & -13.02 \\
\hline 100 & 0.038 & 1.219 & 0.030 & 1.431 & 28.57 & -14.79 \\
\hline
\end{tabular}


Table 4-4: Influence of cutting speed on chip geometry (2).

\begin{tabular}{|c|c|c|c|c|c|c|c|c|}
\hline & \multicolumn{4}{|c|}{ Rotary tool } & \multicolumn{4}{|c|}{ Fixed tool } \\
\hline $\begin{array}{c}\mathrm{V}_{\mathrm{w}} \\
(\mathrm{m} / \mathrm{min})\end{array}$ & \multicolumn{2}{|c|}{$\begin{array}{c}\mathrm{t}_{\mathrm{c}}(\text { range }) \\
(\mathrm{mm})\end{array}$} & \multicolumn{2}{|c|}{$\begin{array}{c}\mathrm{b}_{\mathrm{c}}(\text { range }) \\
(\mathrm{mm})\end{array}$} & \multicolumn{2}{|c|}{$\begin{array}{c}\mathrm{t}_{\mathrm{c}}(\text { range }) \\
(\mathrm{mm})\end{array}$} & \multicolumn{2}{|c|}{$\begin{array}{c}\mathrm{b}_{\mathrm{c}} \text { (range) } \\
(\mathrm{mm})\end{array}$} \\
\hline 20 & & & & & & & & \\
\hline 40 & & & 1.524 & 1.778 & & & 1.651 & 1.880 \\
\hline 60 & 0.038 & 0.043 & 1.524 & 1.829 & 0.043 & 0.056 & 1.676 & 1.803 \\
\hline 80 & 0.038 & 0.043 & 1.270 & 1.524 & 0.043 & 0.048 & 1.473 & 1.880 \\
\hline 100 & 0.033 & 0.043 & 1.067 & 1.321 & 0.028 & 0.033 & 1.270 & 1.575 \\
\hline
\end{tabular}

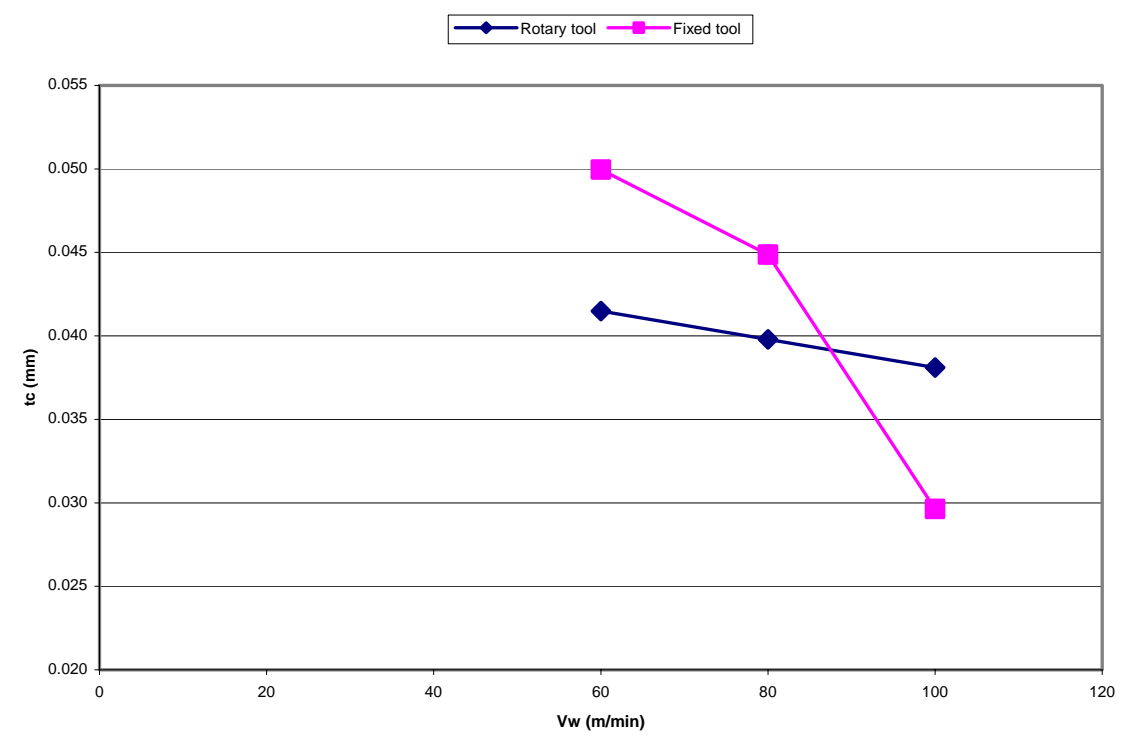

Figure 4-9: Influence of cutting speed on the average deformed chip thickness. 


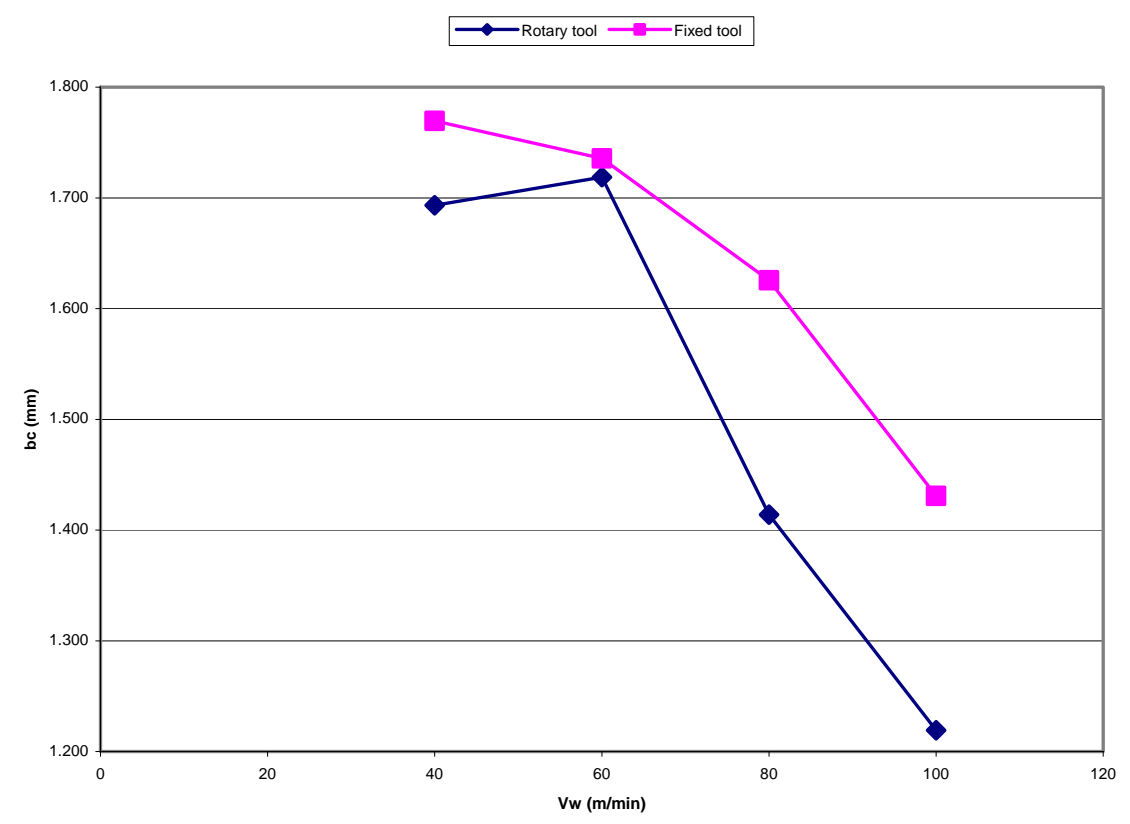

Figure 4-10: Influence of cutting speed on the average chip width.

Globally, both deformed chip thickness and chip width decrease with the cutting speed (see Figure 4-9 and Figure 4-10). The rotary tool case yields smaller values than the fixed tool case (see in Table 4-3 and Table 4-4).

\subsubsection{Discussion}

Based on qualitative observation of the results in Figure 4-6 through Figure 4-8, a cutting speed of $60 \mathrm{~m} / \mathrm{min}$ seems to be a good trade-off in terms of force minimization, productivity and surface quality. Regarding the influence of cutting speed (see Table 42), forces are smaller for the rotary tool case. Looking at the influence of cutting speed on chip geometry (see Table 4-3), the rotary tool case yields smaller chip thickness and chip width than the fixed tool case. 
Additional experiments were performed using a smaller depth of cut $(0.05 \mathrm{~mm})$. This was done with the intent of finding out why the forces oscillate significantly at 0.2 mm depth of cut.

\subsubsection{Results and discussion}

In Figure 4-11, the change in depth of cut does not affect the rotary tool. Forces still oscillate around an average value.

In Figure 4-12, something interesting happens with the fixed tool. Forces (particularly the thrust force) keep increasing with time. Forces become stable and still oscillate around an average value in Figure 4-13. In Figure 4-14, forces start to again increase a bit.

For the fixed tool, it turns out that the cartridge moves inside the tool holder. A $0.08 \mathrm{~mm}$ transversal displacement of the flank has been measured for a starting depth of cut of $0.2 \mathrm{~mm}$ (see Figure 4-15). An indicator was placed on the flank of the tool close to the contact "point". Obviously, since the measurement was not performed at the contact "point" and since the cutting edge is circular, this is not the actual displacement. Nevertheless, it gives a good idea of motion of the insert/cartridge assembly. It is obvious from Figure 4-12, Figure 4-13 and Figure 4-14 that, for a depth of cut of $0.05 \mathrm{~mm}$, the effect of this displacement is more significant. First, the cartridge keeps moving back in the tool holder and thus the depth of cut decreases. Then, the cartridge seems to stay in the same place. Two issues occur with this displacement. First, the depth of cut decreases and thus the insert does not cut anymore. In reality, there is rubbing between the insert and the workpiece and the forces are much higher. Moreover, the displacement of the 
insert seems to decrease the clearance angle leading to increased rubbing between the tool flank and the workpiece. Thus, significant tool flank wear occurs after a single pass (see Figure 4-16).

For the rotary tool case, force oscillations occur for both depths of cut used in the experiments. No displacement has been noticed for the rotary insert. It looks like the oscillations are due to the process itself (rotation of the insert; slight centerline offset of the insert etc.). No significant tool wear was observed (see Figure 4-17).

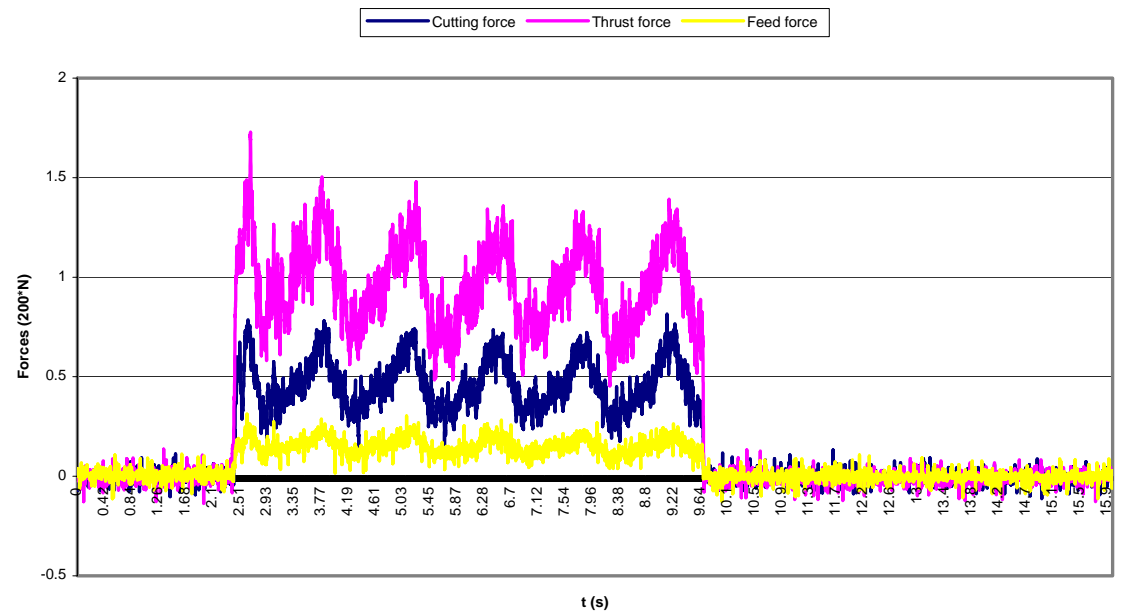

Figure 4-11: Rotary tool, $\mathrm{V}_{\mathrm{w}}=20 \mathrm{~m} / \mathrm{min}, \mathrm{f}=01 \mathrm{~mm} / \mathrm{rev}, \mathrm{a}_{\mathrm{p}}=0.05 \mathrm{~mm}$. 


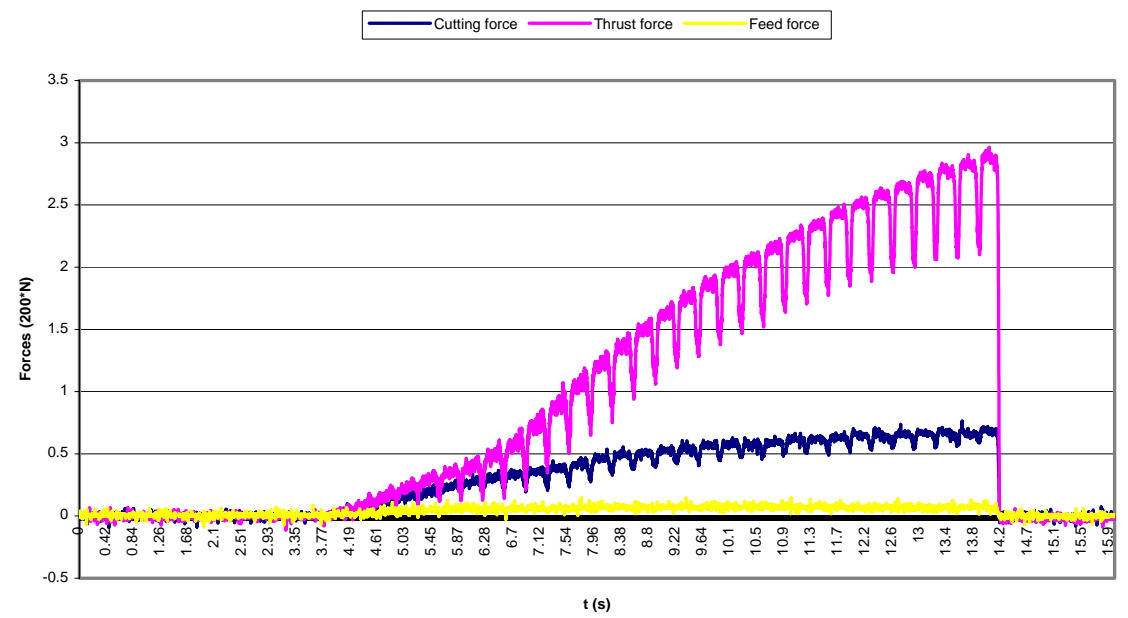

Figure 4-12: Fixed tool, $\mathrm{V}_{\mathrm{w}}=20 \mathrm{~m} / \mathrm{min}, \mathrm{f}=0.1 \mathrm{~mm} / \mathrm{rev}, \mathrm{a}_{\mathrm{p}}=0.05 \mathrm{~mm}$, first cut.

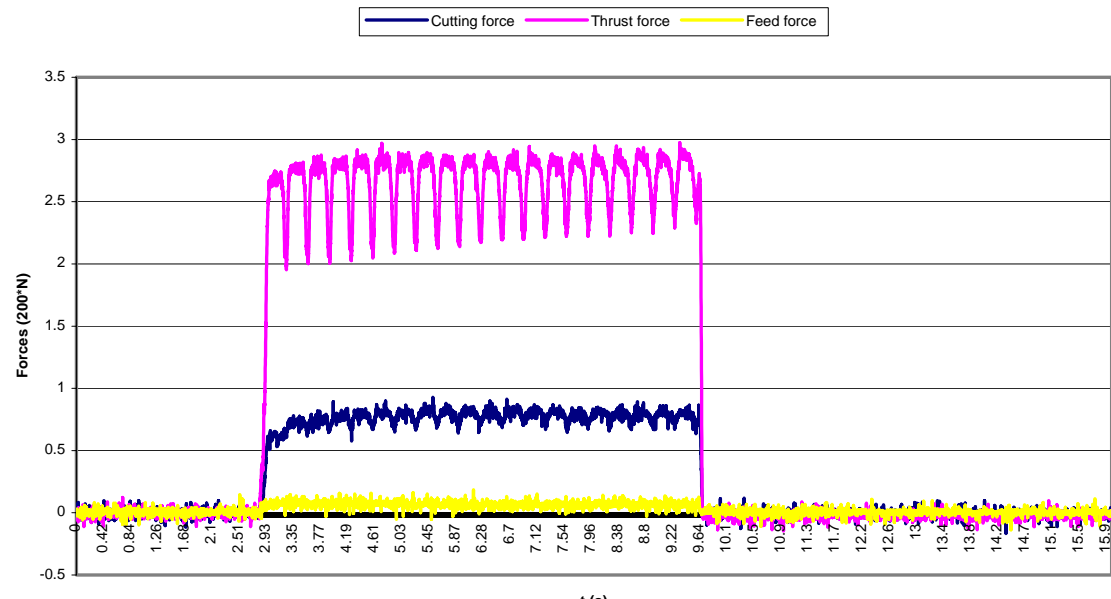

Figure 4-13: Fixed tool, $\mathrm{V}_{\mathrm{w}}=20 \mathrm{~m} / \mathrm{min}, \mathrm{f}=0.1 \mathrm{~mm} / \mathrm{rev}, \mathrm{a}_{\mathrm{p}}=0.05 \mathrm{~mm}$, second cut. 


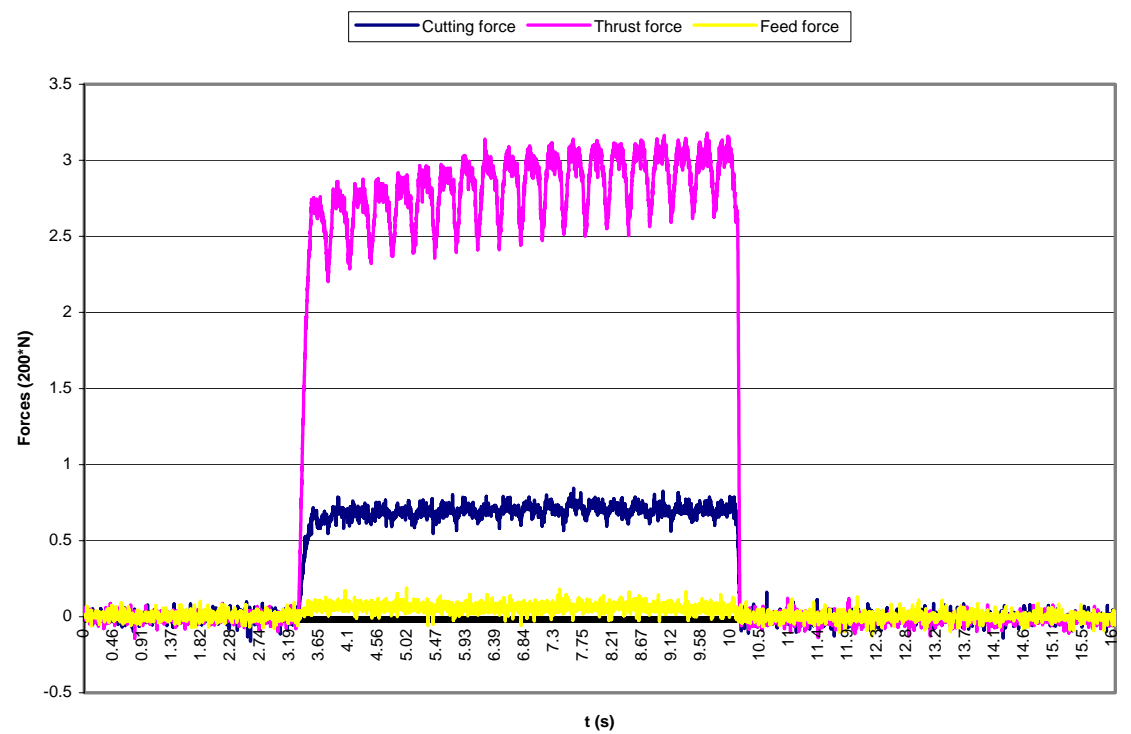

Figure 4-14: Fixed tool, $\mathrm{V}_{\mathrm{w}}=20 \mathrm{~m} / \mathrm{min}, \mathrm{f}=0.1 \mathrm{~mm} / \mathrm{rev}, \mathrm{a}_{\mathrm{p}}=0.05 \mathrm{~mm}$, third cut.

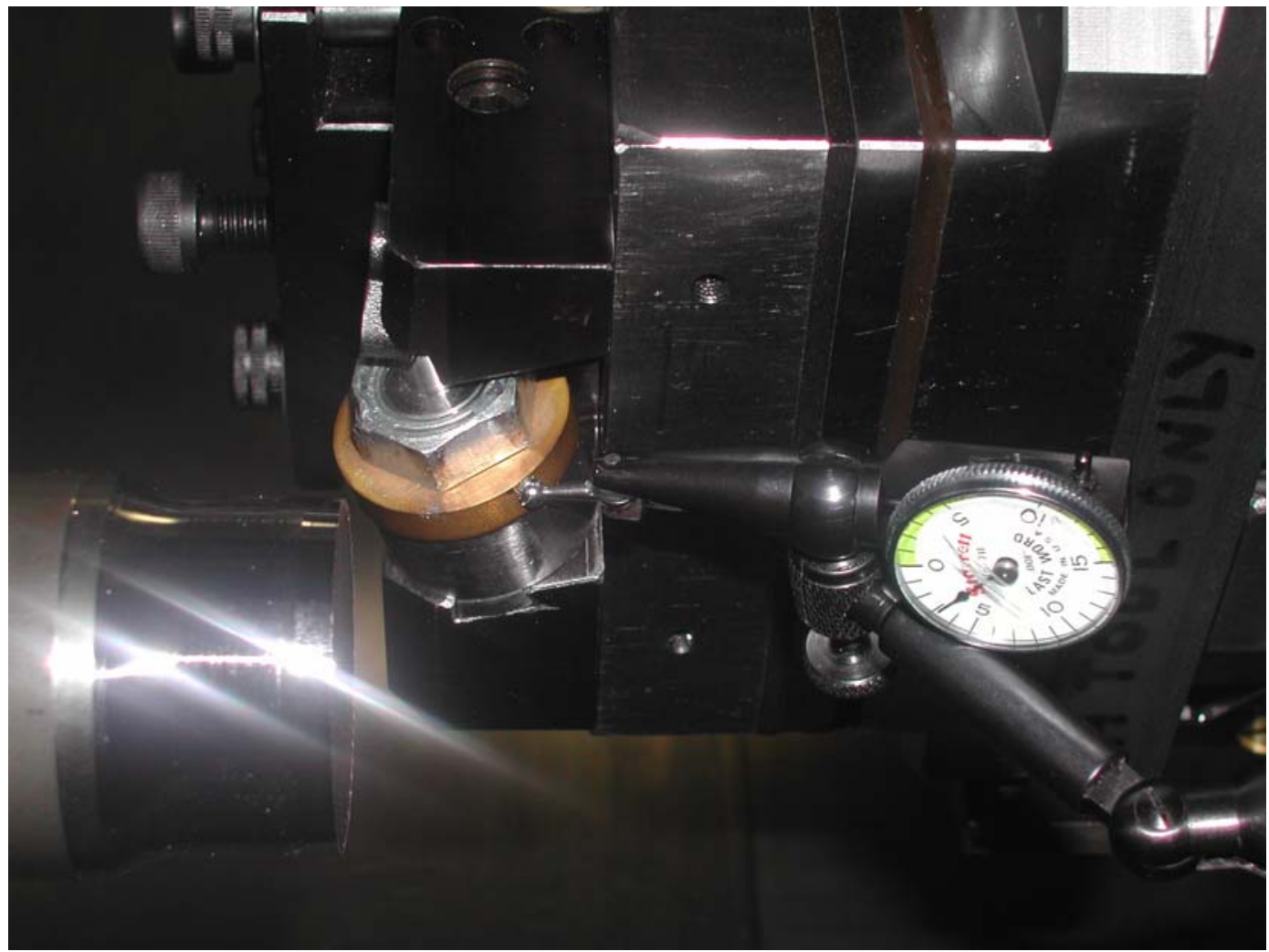

Figure 4-15: Measurement of the displacement of the fixed tool. 


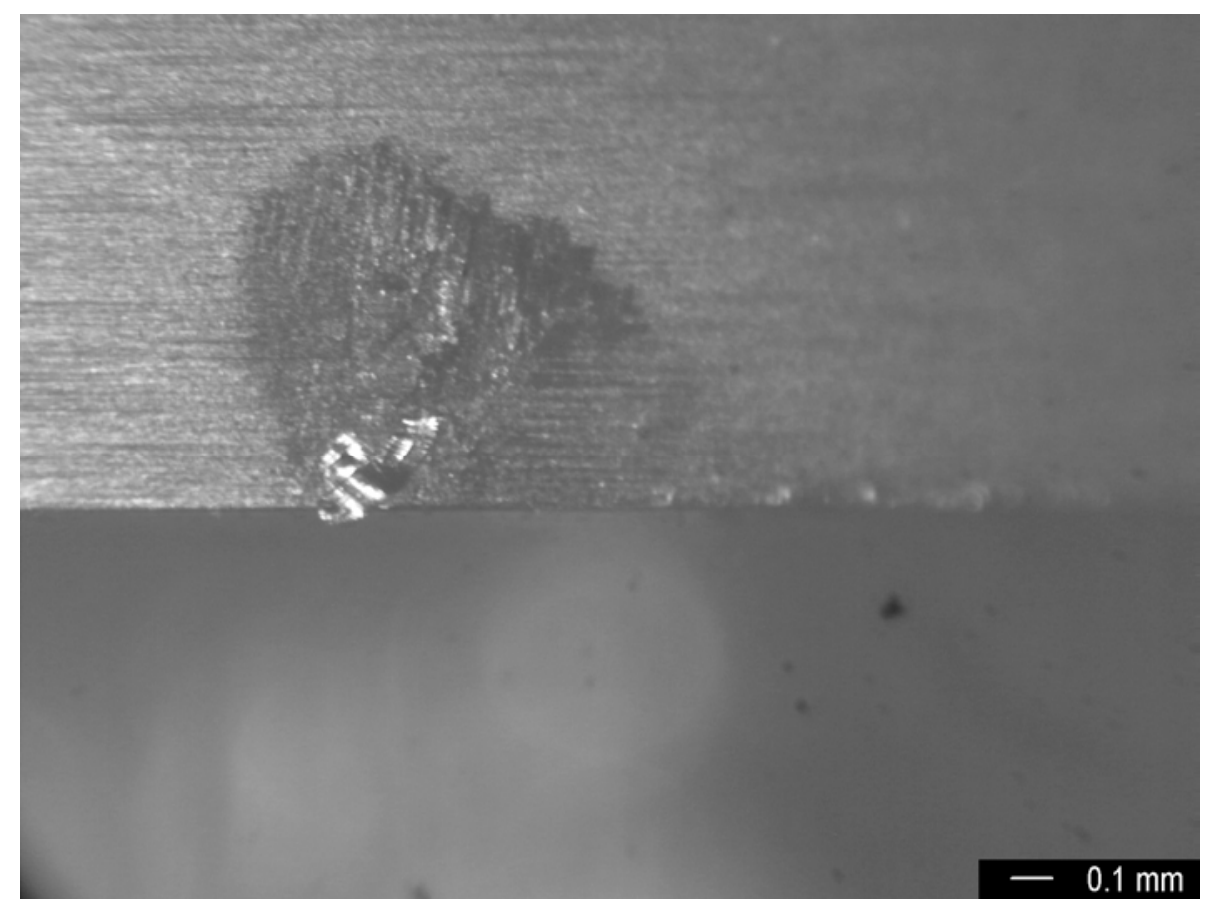

Figure 4-16: Fixed tool, flank wear, $\mathrm{V}_{\mathrm{w}}=20 \mathrm{~m} / \mathrm{min}, \mathrm{f}=0.1 \mathrm{~mm} / \mathrm{rev}, \mathrm{a}_{\mathrm{p}}=0.05 \mathrm{~mm}$.

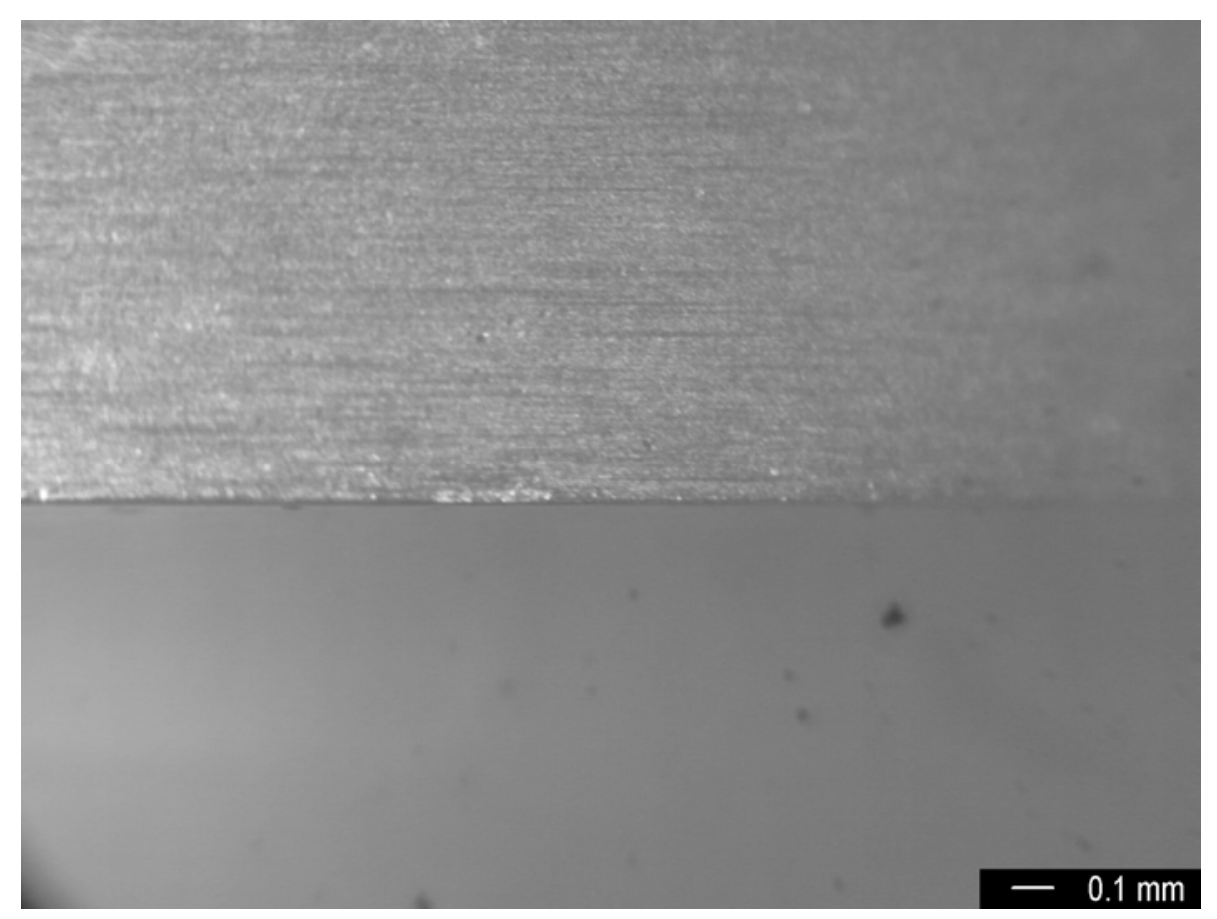

Figure 4-17: Rotary tool, flank wear, $\mathrm{V}_{\mathrm{w}}=20 \mathrm{~m} / \mathrm{min}, \mathrm{f}=0.1 \mathrm{~mm} / \mathrm{rev}, \mathrm{a}_{\mathrm{p}}=0.05 \mathrm{~mm}$. 
Table 4-5: Influence of cutting speed on the forces.

\begin{tabular}{|c|c|c|c|c|c|c|}
\hline & \multicolumn{3}{|c|}{ Rotary tool } & \multicolumn{3}{|c|}{ Fixed tool } \\
\hline $\begin{array}{c}\mathrm{V}_{\mathrm{w}} \\
(\mathrm{m} / \mathrm{min})\end{array}$ & $\begin{array}{l}F_{c} \\
(\mathrm{~N})\end{array}$ & $\begin{array}{c}F_{t} \\
(\mathrm{~N})\end{array}$ & $\begin{array}{l}F_{f} \\
(\mathrm{~N})\end{array}$ & $\begin{array}{l}F_{c} \\
(N)\end{array}$ & $\begin{array}{c}\mathrm{F}_{\mathrm{t}} \\
(\mathrm{N})\end{array}$ & \\
\hline 20 & 92 & 188 & 30 & & & \\
\hline 40 & 84 & 236 & 30 & & & \\
\hline 60 & 79 & 256 & 28 & & & \\
\hline 80 & 77 & 277 & 27 & & & \\
\hline 100 & 76 & 292 & 27 & & & \\
\hline
\end{tabular}

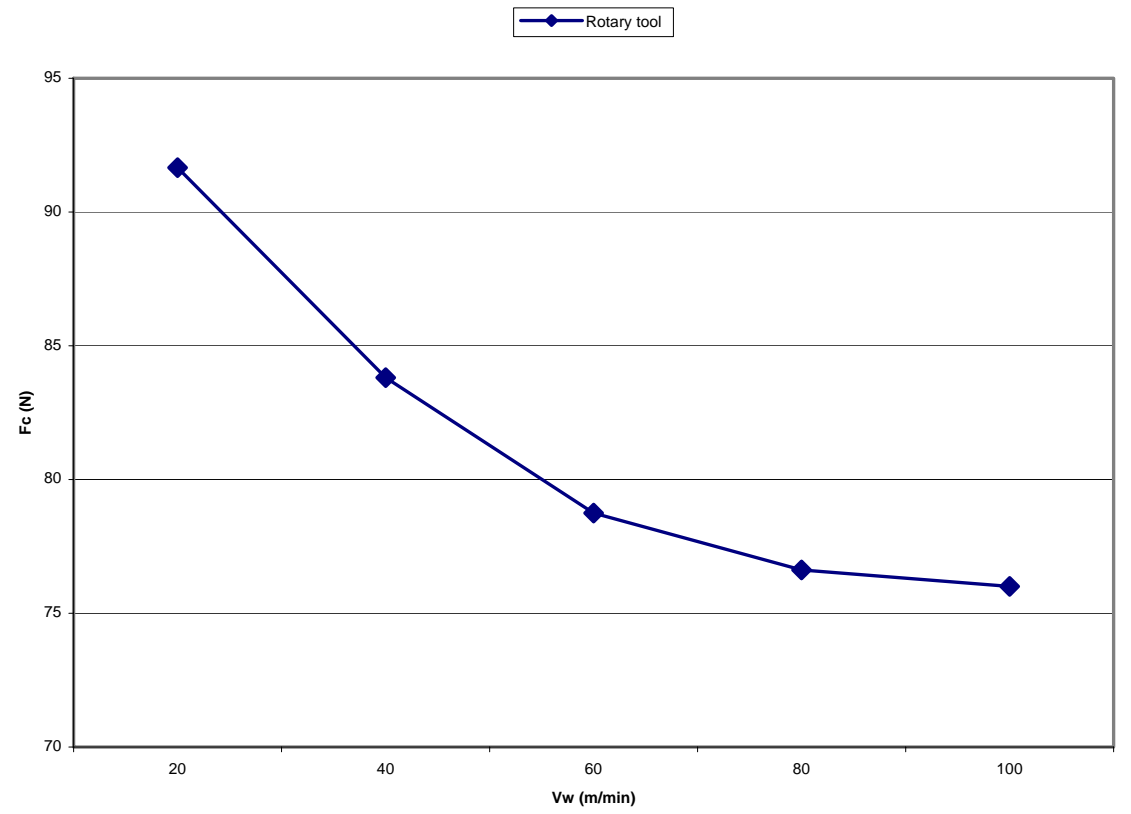

Figure 4-18: Influence of cutting speed on cutting force. 


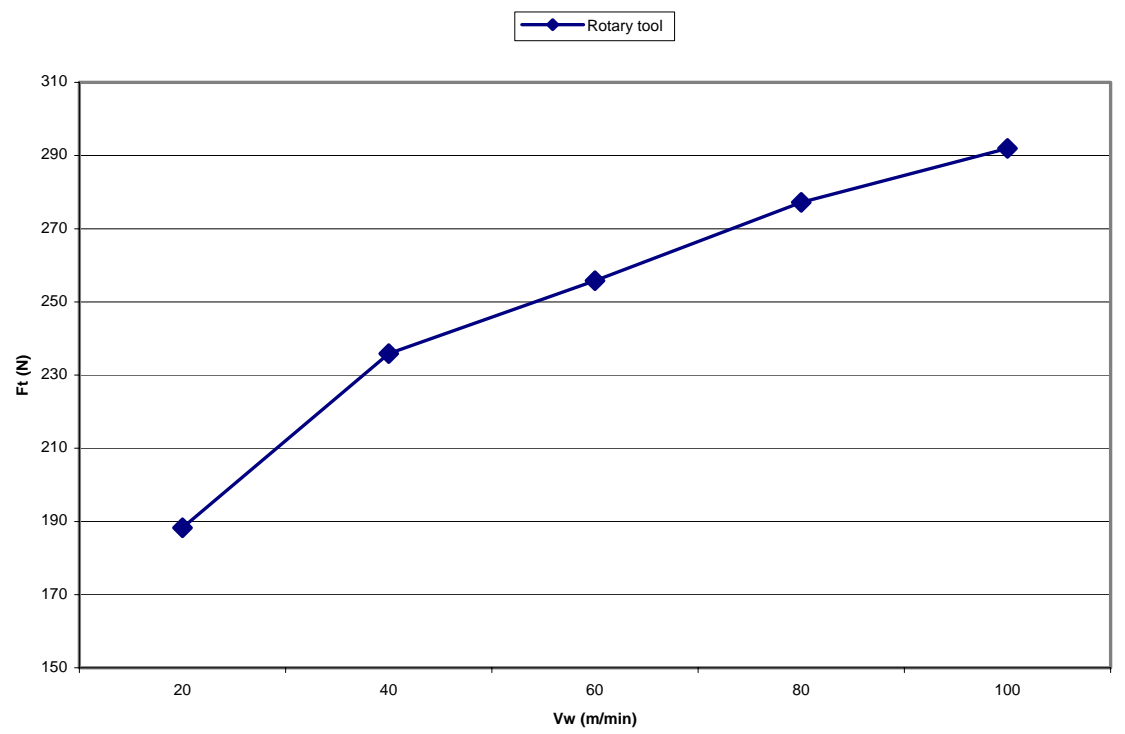

Figure 4-19: Influence of cutting speed on thrust force.

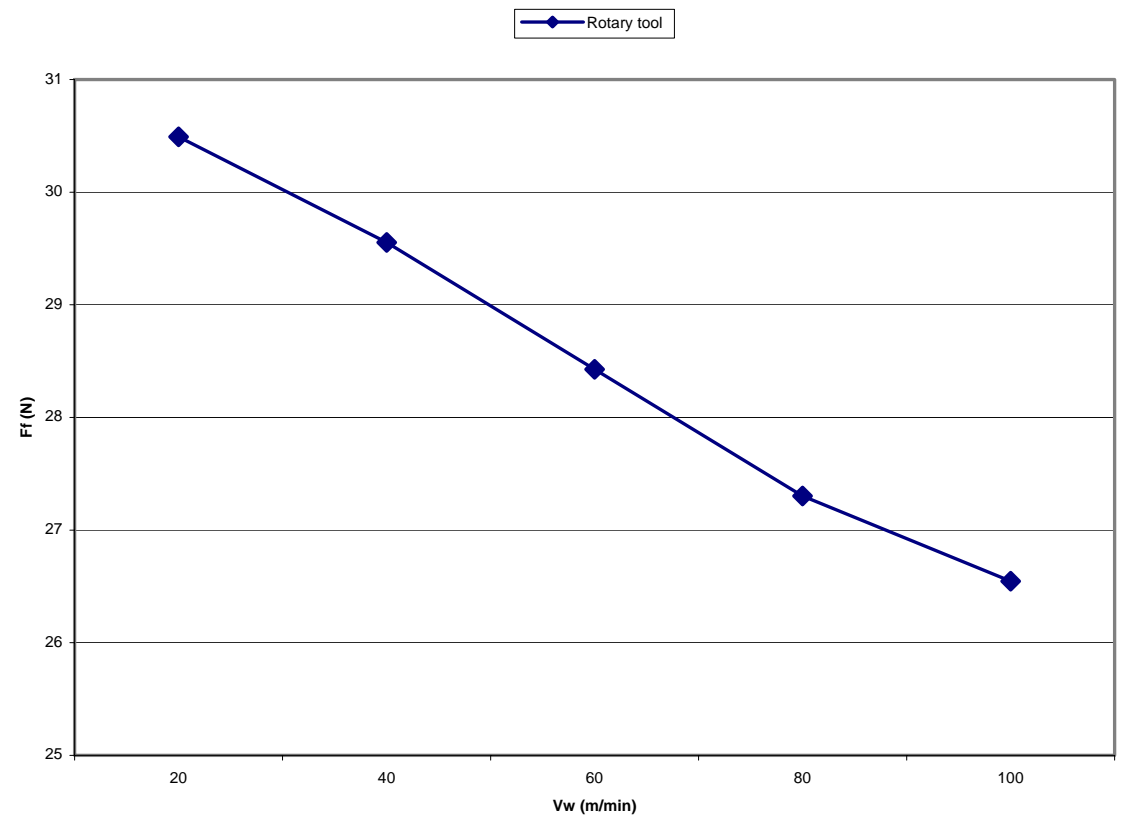

Figure 4-20: Influence of cutting speed on feed force. 
In Figure 4-18 and Figure 4-20, the cutting and the feed forces look like they have the same behavior as in conventional turning. When the speed increases, the forces decrease until they reach a constant value.

In Figure 4-19, contrary to the other components, the thrust force keeps increasing when the cutting speed increases. This behavior sometimes happens in hard turning and particularly when the tool radius is large.

It is important to notice that the variations in both the cutting and feed forces (see Table 4-5) are small compared to the thrust force. In this case, it is impossible to have a minimum cutting speed that minimizes all three force components since the thrust force keeps increasing. Thus, the choice of the cutting speed must be made by looking at the thrust force alone.

\subsection{Temperature measurements}

\subsubsection{Set-up}

In order to validate the tool temperature prediction model, rotary tool temperature measurements were made with an infra-red thermal imaging camera. Other methods such as the tool-work or the embedded thermocouple technique are not suitable because of the rotary tool. One advantage in using a camera is its ability to visually record and display in real time the temperature distribution of the tool. Additionally, to the author's knowledge, no work has been done on rotary tool temperature distribution measurements using an infra-red thermal imaging camera. Contrary to a conventional lathe, the Hardinge $\mathrm{CNC}$ lathe is an enclosed machining center. Thus, the front door of the lathe had to be kept open during the experiments to get visual access to the tool and the workpiece. 
The specific temperature measurement device used was a ThermaCAM IR camera model 280 manufactured by Inframetrics Inc (seen in Figure 4-21). This camera looks like a standard video camera and is mounted on a tripod for suitable stability. The detection of infra-red radiation (with a spectral band of 3.4 to $5 \mu \mathrm{m}$ ) is achieved by a 256 $\times 256$ array of platinum silicide focal planes, cooled by a Stirling cycle refrigerator. (Inframetrics, 1995). Selection and setting of parameters such as full image or spot mode, zoom (2:1 or 4:1), color palettes, background temperature and temperature span are possible. The target emissivity ( 0 to 1$)$ is also set by means of the camera. The sensitivity of the camera and its image update rate are $0.1^{\circ} \mathrm{C}$ and $60 \mathrm{~Hz}$, respectively. The camera output is an input into a GRAMcard (data acquisition board) mounted in a computer. The card allows the image captured by the camera to be observed in real time on the computer screen using the ThermaGRAM software.

Material emissivity is of particular concern when a thermal imaging camera is used. By definition, the emissivity of an object is the amount of radiation which it emits relative to a pure black body. A black body is a perfect emitter and a perfect absorber as well. Emissivity is rated from 0 to 1 where an emissivity of 1 corresponds to a black body. In thermal imaging applications, it is preferable to have high emissivity (and thus a low reflectivity) so that the sensor detections are not jammed because of reflection. Also, it is well-known that the tool emissivity varies as a function of temperature. To deal with this issue, the first thought was to assign a constant emissivity to the tool. Therefore, the tool was coated with a Pyro-paint 634-SiC high temperature silicon carbide paint from Aremco Products, Inc. This paint can withstand temperatures of up to $1400{ }^{\circ} \mathrm{C}$ and is grey in color. Also, the emissivity of $\mathrm{SiC}$ does not vary between $20{ }^{\circ} \mathrm{C}$ and $1200{ }^{\circ} \mathrm{C}$ and 
has an approximately constant value of 0.87 . The main problem with this technique was that the paint was quickly erased by the rubbing action of the chip on the rotating insert. Consequently, another solution (explained in the next section) had to be investigated to deal with emissivity variation.

Tool temperatures have been investigated in rotary turning of 52100 hardened steel. Flank measurements (as viewed from a side view) are usually employed in IRbased temperature measurement since the chip does not cover this surface. However, due to the lathe geometry restrictions, the temperature was measured on the rake face (as viewed from a top view) of the tool. Figure 4-21 shows the actual tool temperature measurement set-up when machining the outer diameter of the hardened steel bar. Also, to be able to get reliable temperature data, suitable cutting conditions had to be determined. For this task, the goal was to get cutting conditions which allowed the tool rake face to be cleared of the chip quickly. In other words, the chip had to be small and discontinuous in order not to produce excessive brightness and thereby allow measurement of the rake face temperature distribution. In rotary tool turning, predicted and measured temperatures have been determined for four cutting conditions listed in Table 4-6. Comparison with the circular fixed tool has been done only for two cutting conditions since other cases did not yield analyzable results in terms of temperature measurements. 
Table 4-6: Cutting conditions used for temperature measurements.

\begin{tabular}{|c|c|c|c|c|c|c|}
\hline & \multicolumn{3}{|c|}{ Rotary } & \multicolumn{3}{c|}{ Fixed } \\
\hline Cutting speed $\mathrm{V}_{\mathrm{w}}(\mathrm{m} / \mathrm{min})$ & 10 & 15 & 20 & 25 & 10 & 15 \\
\hline Feed f $(\mathrm{mm} / \mathrm{rev})$ & 0.1 & 0.1 & 0.1 & 0.1 & 0.1 & 0.1 \\
\hline Depth of cut $\mathrm{a}_{\mathrm{p}}(\mathrm{mm})$ & 0.05 & 0.05 & 0.05 & 0.05 & 0.05 & 0.05 \\
\hline Cutting fluid & \multicolumn{3}{c|}{ Dry machining } & \multicolumn{3}{c|}{ Dry machining } \\
\hline
\end{tabular}

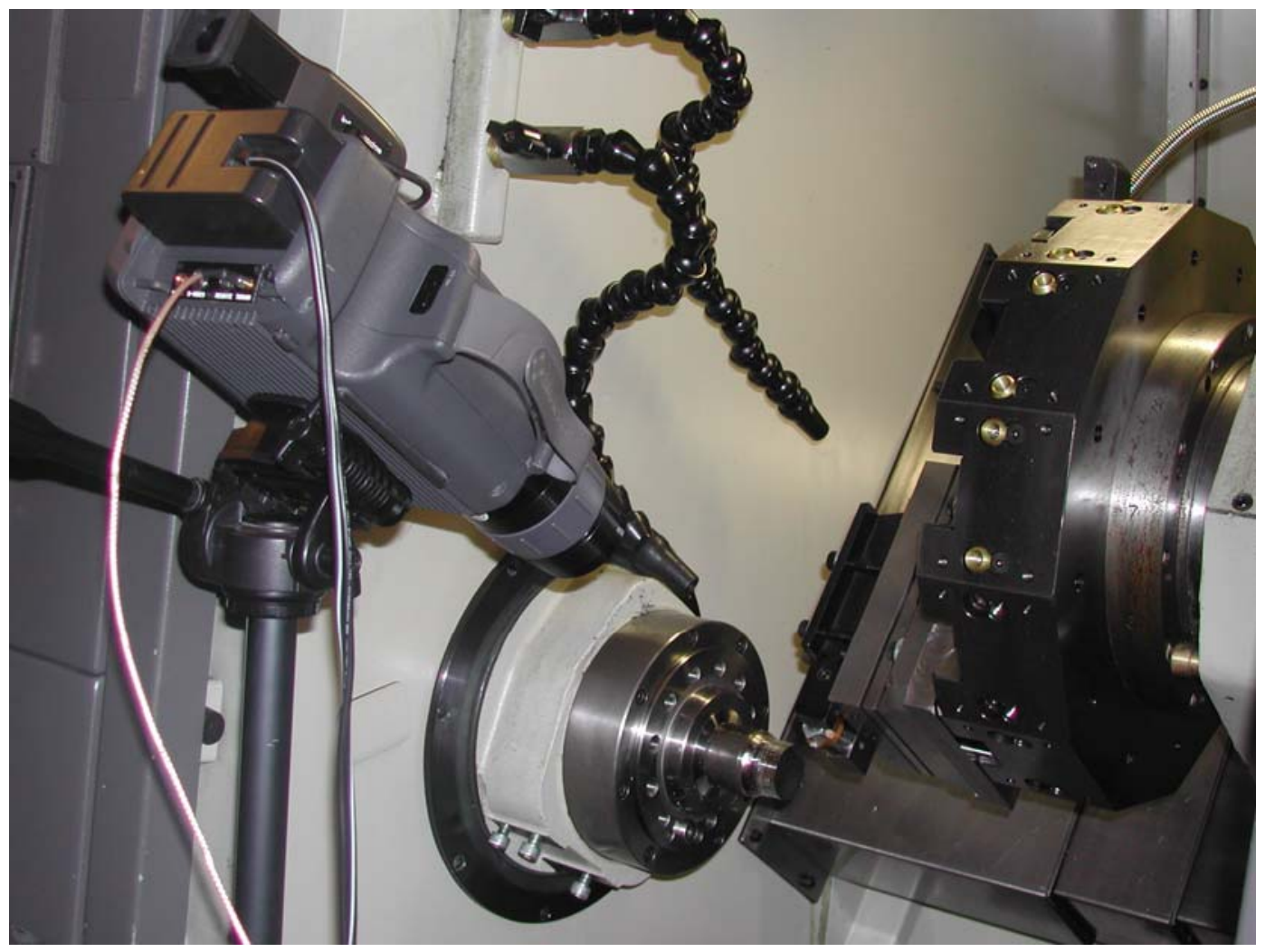

Figure 4-21: Temperature measurement set-up. 


\subsubsection{Camera calibration}

Since the SiC paint method to eliminate emissivity variation did not work, the thermal camera had to be calibrated to get the actual tool temperature. Also, since the chip covers the tool-chip interface during cutting, the chip temperature was measured instead of the tool temperature at the interface. Consequently, the workpiece had to be calibrated as well. The tool and the workpiece were calibrated in an identical manner as follows. The insert (workpiece) was placed in an induction furnace and heated. A thermocouple mounted in the furnace gave the actual temperature of the insert (workpiece) inside the furnace. Temperature measurements of the insert (workpiece) were made for multiple temperatures using the IR camera. A constant emissivity of 1 was set in the camera since this value was used for temperature measurements during cutting. Measurements were analyzed with the Thermagram software. Figure 4-22 and Figure 4-23 show the calibration curves obtained for the tool and workpiece material, respectively.

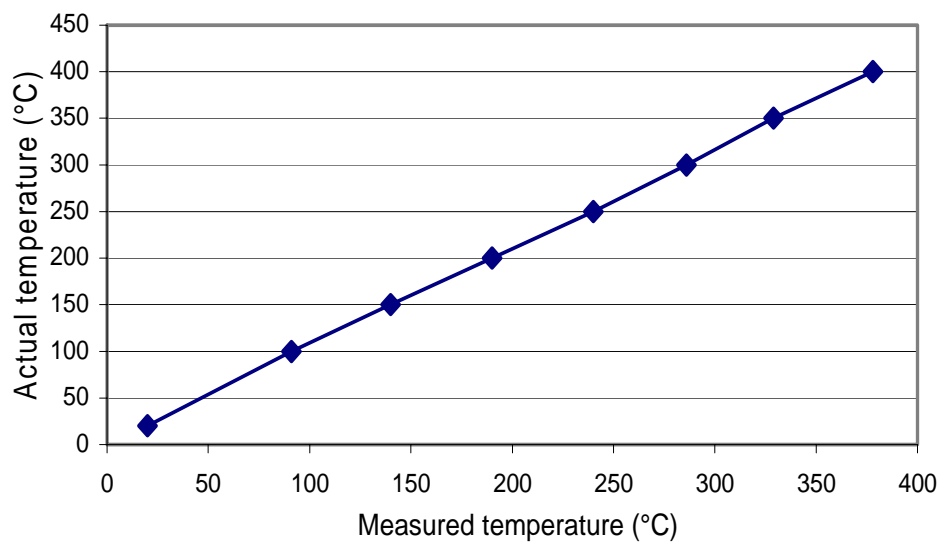

Figure 4-22: Camera calibration for the tool material. 


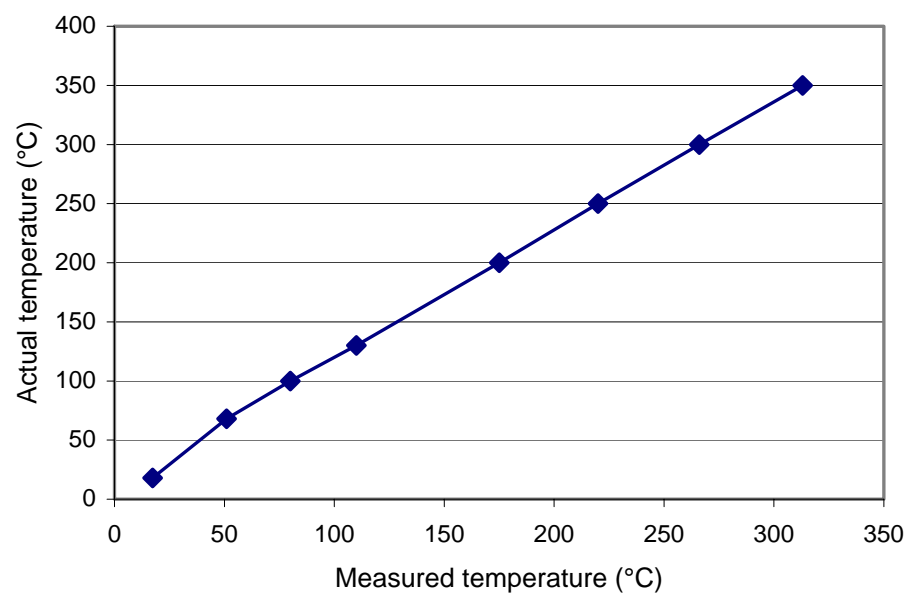

Figure 4-23: Camera calibration for the workpiece material.

For both the tool and workpiece, the actual temperature is higher than the measured value since the emissivity is always lower than 1 . Both materials yield the same tendency in terms of temperature variation. Actual temperature almost increases linearly as the measured temperature increases. The calibration curves were used for all tool temperature measurements made during cutting.

\subsubsection{Sample results}

An example of measured rotary tool temperature distribution is shown in Figure 4-24. Measured temperatures were processed with the ThermaGRAM software via the infra-red thermal imaging camera. For validation purposes, the measured temperature is plotted along the cutting edge. 


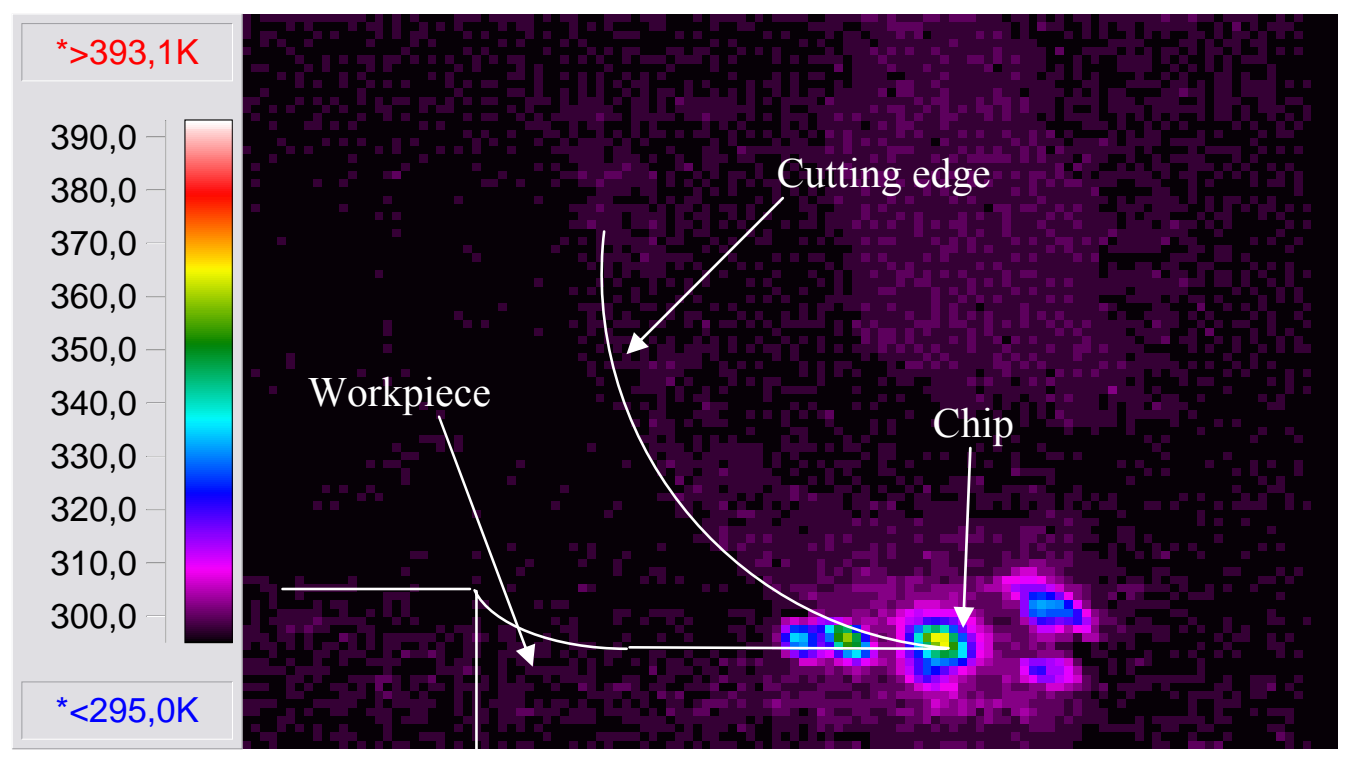

Figure 4-24: Rotary tool temperature distribution using an IR thermal imaging camera.

\subsection{Summary}

The experimental set-up and the different experimental devices discussed in this chapter are critical for this research since they govern the reliability of the results and their accuracy. In this work, cutting forces and chip geometry were obtained experimentally. The temperature measurements obtained with the thermal infra-red imaging camera are presented in the next chapter. 


\section{CHAPTER 5}

\section{RESULTS AND DISCUSSION}

In this chapter, the rotary tool temperature model presented in Chapter 3 is validated against the experimental measurements described in Chapter 4. Predicted and measured tool temperatures are compared. In addition, this chapter also presents a comparison of rotary and fixed tool temperatures.

\subsection{Tool temperature distribution in rotary tool turning}

Examples of predicted and measured tool temperature distribution are shown in Figure 5-1 and Figure 5-3, respectively. Figure 5-2 shows a zoomed view of the temperature distribution shown in Figure 5-1. Predicted temperatures are obtained from the FEMLAB solution of the temperature model and the measured temperatures are processed with the ThermaGRAM software via the infra-red thermal imaging camera as described in Chapter 4. As explained earlier, brightness due to the chip was the main problem in obtaining good temperature measurements. Cutting conditions given in Table 4-6 were used and yielded the following cutting forces and chip geometry measurements. 
Table 5-1: Average forces and average chip dimensions.

\begin{tabular}{|c|c|c|c|c|c|}
\hline $\begin{array}{c}\text { Cutting } \\
\text { speed } \\
(\mathrm{m} / \mathrm{min})\end{array}$ & $\begin{array}{c}\text { Cutting } \\
\text { force } \\
(\mathrm{N})\end{array}$ & $\begin{array}{c}\text { Thrust } \\
\text { force } \\
(\mathrm{N})\end{array}$ & $\begin{array}{c}\text { Feed } \\
\text { force } \\
(\mathrm{N})\end{array}$ & $\begin{array}{c}\text { Chip } \\
\text { width } \\
(\mathrm{mm})\end{array}$ & $\begin{array}{c}\text { Chip } \\
\text { thickness } \\
(\mathrm{mm})\end{array}$ \\
\hline 10 & 74 & 100 & 22 & 1.50 & 0.05 \\
\hline 15 & 85 & 150 & 28 & 1.45 & 0.05 \\
\hline 20 & 92 & 188 & 30 & 1.40 & 0.05 \\
\hline 25 & 90 & 200 & 30 & 1.35 & 0.05 \\
\hline
\end{tabular}

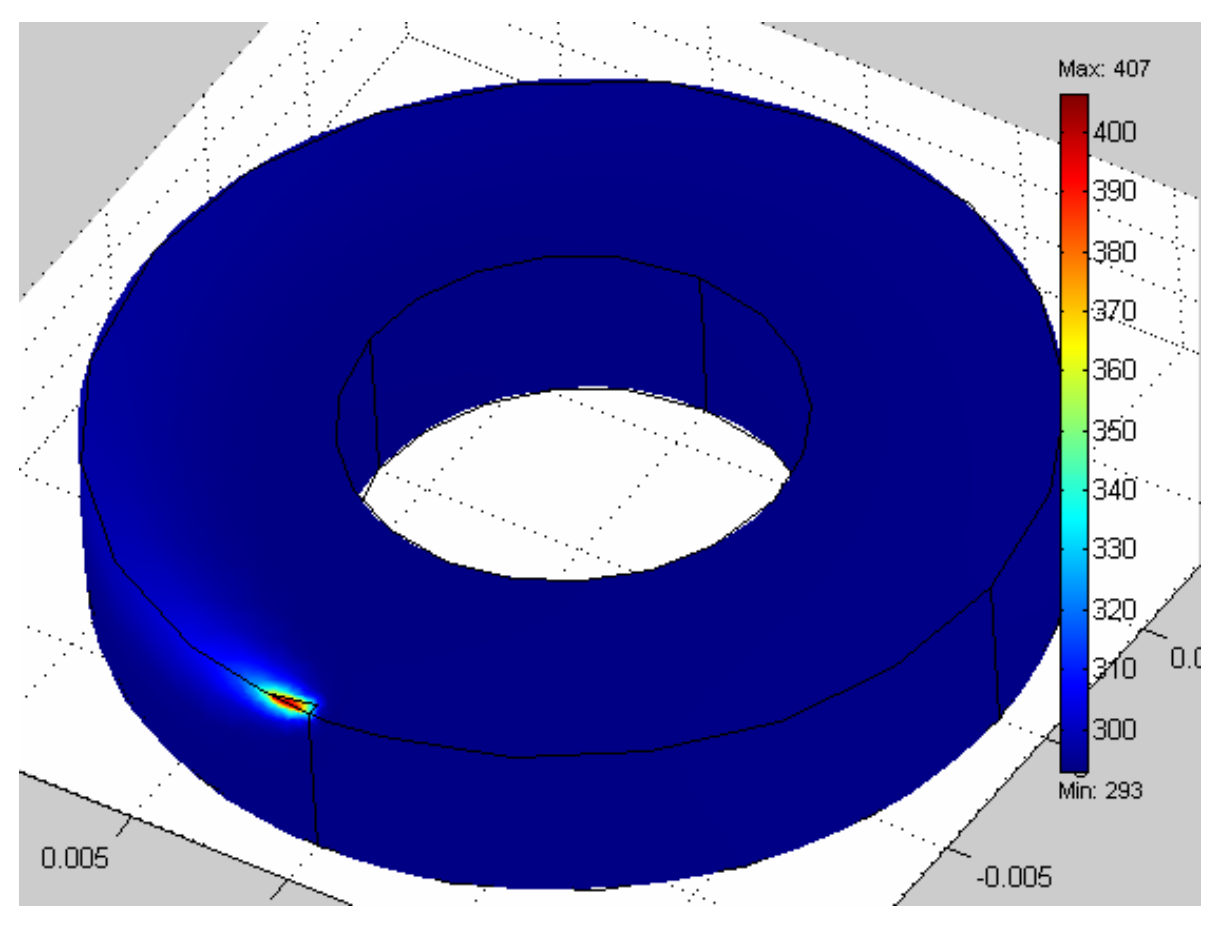

Figure 5-1: Rotary tool predicted temperature distribution (in ${ }^{\circ} \mathrm{K}$ ), $\mathrm{V}_{\mathrm{w}}=10 \mathrm{~m} / \mathrm{min}, \mathrm{f}=$ $0.1 \mathrm{~mm} / \mathrm{rev}, \mathrm{a}_{\mathrm{p}}=0.05 \mathrm{~mm}$. 


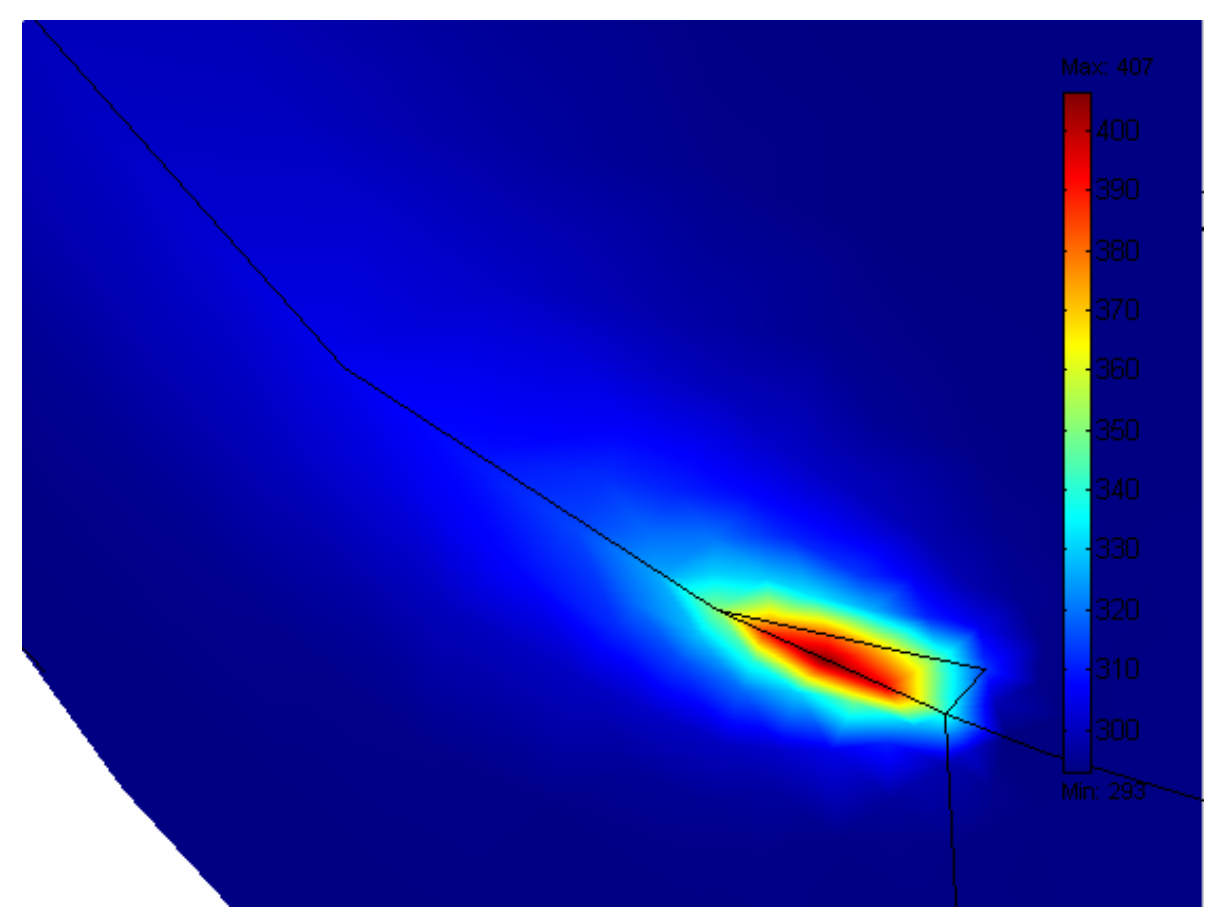

Figure 5-2: Rotary tool-chip interface predicted temperature distribution (in $\left.{ }^{\circ} \mathrm{K}\right), \mathrm{V}_{\mathrm{w}}=$ $10 \mathrm{~m} / \mathrm{min}, \mathrm{f}=0.1 \mathrm{~mm} / \mathrm{rev}, \mathrm{a}_{\mathrm{p}}=0.05 \mathrm{~mm}$.

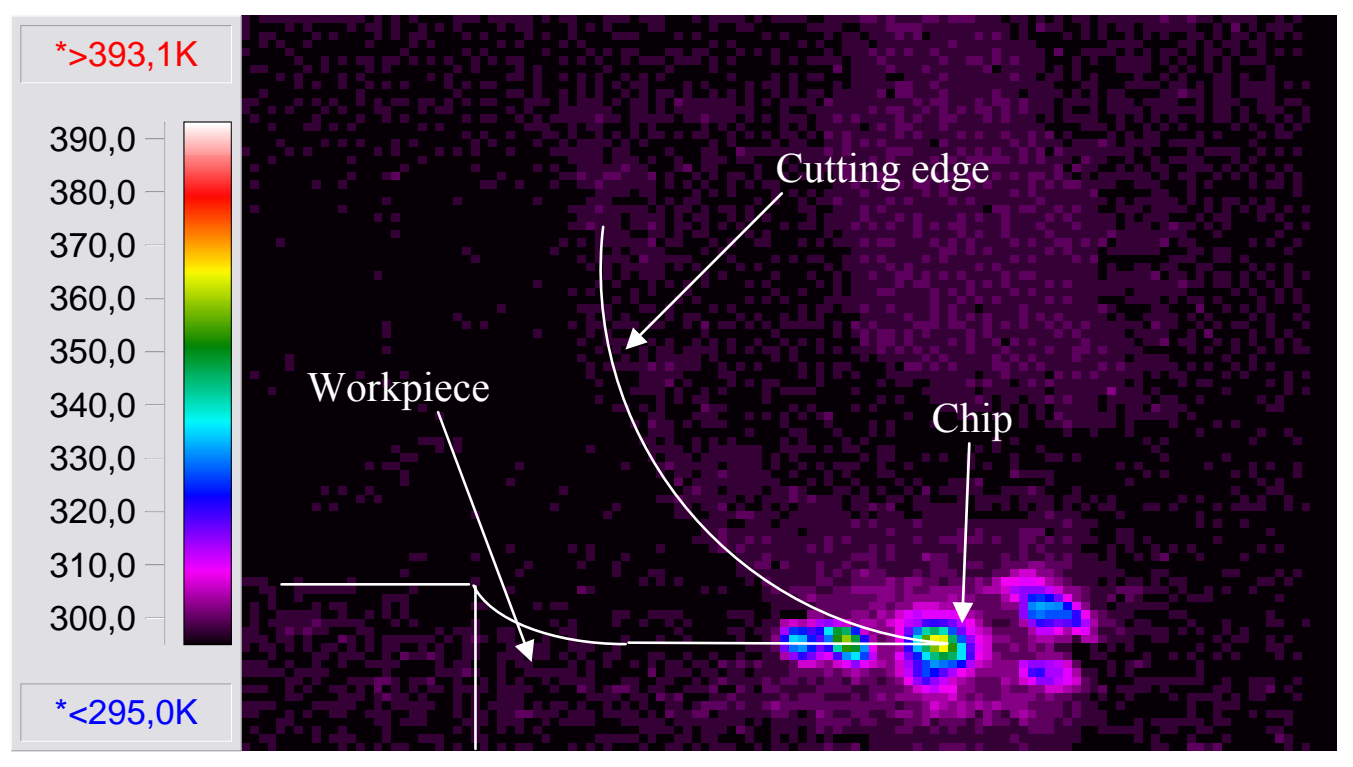

Figure 5-3: Rotary tool measured temperature distribution (in ${ }^{\circ} \mathrm{K}$ ), $\mathrm{V}_{\mathrm{w}}=10 \mathrm{~m} / \mathrm{min}, \mathrm{f}=$ $0.1 \mathrm{~mm} / \mathrm{rev}, \mathrm{a}_{\mathrm{p}}=0.05 \mathrm{~mm}$. 
In the measurement, the chip covers the tool-chip interface and consequently, the measured temperature is not the interfacial temperature but that of the chip. However, in this investigation, the chip thickness is very small (around $0.05 \mathrm{~mm}$ ). Thus, the measured chip temperature is assumed to be equal to the interface temperature. In order to validate the model, a particular portion of the tool has to be analyzed. A critical aspect of generating temperature distributions is the ability to post-process the images to obtain meaningful data. In this investigation, analysis had to be focused on a portion of the tool for predicted and measured temperatures comparison to be strictly valid. The cutting edge is chosen for this investigation since it is the easiest entity to define both in FEMLAB and ThermaGRAM.

\subsection{Tool temperature along the cutting edge in rotary tool turning}

The predicted and measured temperature profiles are plotted along the cutting edge starting from the tool-workpiece contact point to one quarter of the circular cutting edge. The predicted and measured temperatures are compared for four cutting speeds after two seconds of cutting. Plots are given in Figure 5-4, Figure 5-5, Figure 5-6 and Figure 5-7 where predicted and measured trends show good overall agreement. The model sensitivity with respect to the rotational tool frequency is given in Table 5-2. It is seen that a $10 \%$ variation in the tool frequency provides a relative error smaller than $2 \%$ in terms of the maximum tool-chip interface temperature. Table 5-3 lists the maximum measured chip temperature for five measurements, the mean value and the standard deviation which is less than 14. 
Table 5-2: Model sensitivity.

\begin{tabular}{|c|c|c|c|c|c|c|c|}
\hline $\begin{array}{c}\omega_{\mathrm{r}} \\
(\mathrm{rad} / \mathrm{s})\end{array}$ & $\begin{array}{l}\omega_{\mathrm{r}+10 \%} \\
(\mathrm{rad} / \mathrm{s})\end{array}$ & $\begin{array}{c}\omega_{\mathrm{r}-10 \%} \\
(\mathrm{rad} / \mathrm{s})\end{array}$ & $\begin{array}{l}T_{\max } \\
\left(\omega_{\mathrm{r}}\right) \\
(\mathrm{K})\end{array}$ & $\begin{array}{c}\mathrm{T}_{\max } \\
\left(\omega_{\mathrm{r}+10 \%}\right) \\
(\mathrm{K})\end{array}$ & $\begin{array}{c}\Delta \mathrm{T} / \mathrm{T} \\
\left(\omega_{\mathrm{r}+10 \%)}\right) \\
(\%)\end{array}$ & $\begin{array}{c}\mathrm{T}_{\max } \\
\left(\omega_{\mathrm{r}-10 \%}\right) \\
(\mathrm{K})\end{array}$ & $\begin{array}{c}\Delta \mathrm{T} / \mathrm{T} \\
\left(\omega_{\mathrm{r}-10 \%)}\right) \\
(\%)\end{array}$ \\
\hline 3.2 & 3.36 & 2.88 & 407 & 404 & 0.7 & 409 & 0.5 \\
\hline 4.8 & 5.28 & 4.32 & 478 & 473 & 1.0 & 483 & 1.0 \\
\hline 6.4 & 7.04 & 5.76 & 523 & 516 & 1.3 & 530 & 1.3 \\
\hline 8 & 8.8 & 7.2 & 535 & 528 & 1.3 & 544 & 1.7 \\
\hline
\end{tabular}

Table 5-3: Maximum measured chip temperature.

\begin{tabular}{|c|c|c|c|c|c|c|c|}
\hline $\begin{array}{c}\mathrm{V}_{\mathrm{w}} \\
(\mathrm{m} / \mathrm{min})\end{array}$ & $\begin{array}{c}\mathrm{T}_{1} \\
\left({ }^{\circ} \mathrm{C}\right)\end{array}$ & $\begin{array}{c}\mathrm{T}_{2} \\
\left({ }^{\circ} \mathrm{C}\right)\end{array}$ & $\begin{array}{c}\mathrm{T}_{3} \\
\left({ }^{\circ} \mathrm{C}\right)\end{array}$ & $\begin{array}{c}\mathrm{T}_{4} \\
\left({ }^{\circ} \mathrm{C}\right)\end{array}$ & $\begin{array}{c}\mathrm{T}_{5} \\
\left({ }^{\circ} \mathrm{C}\right)\end{array}$ & $\begin{array}{c}\mathrm{T}_{\text {average }} \\
\left({ }^{\circ} \mathrm{C}\right)\end{array}$ & $\begin{array}{c}\text { Standard } \\
\text { deviation } \\
\left({ }^{\circ} \mathrm{C}\right)\end{array}$ \\
\hline 10 & 131 & 145 & 127 & 136 & 134 & 135 & 7 \\
\hline 15 & 231 & 251 & 263 & 248 & 265 & 252 & 14 \\
\hline 20 & 279 & 273 & 283 & 258 & 272 & 273 & 10 \\
\hline 25 & 315 & 286 & 294 & 302 & 291 & 298 & 11 \\
\hline
\end{tabular}




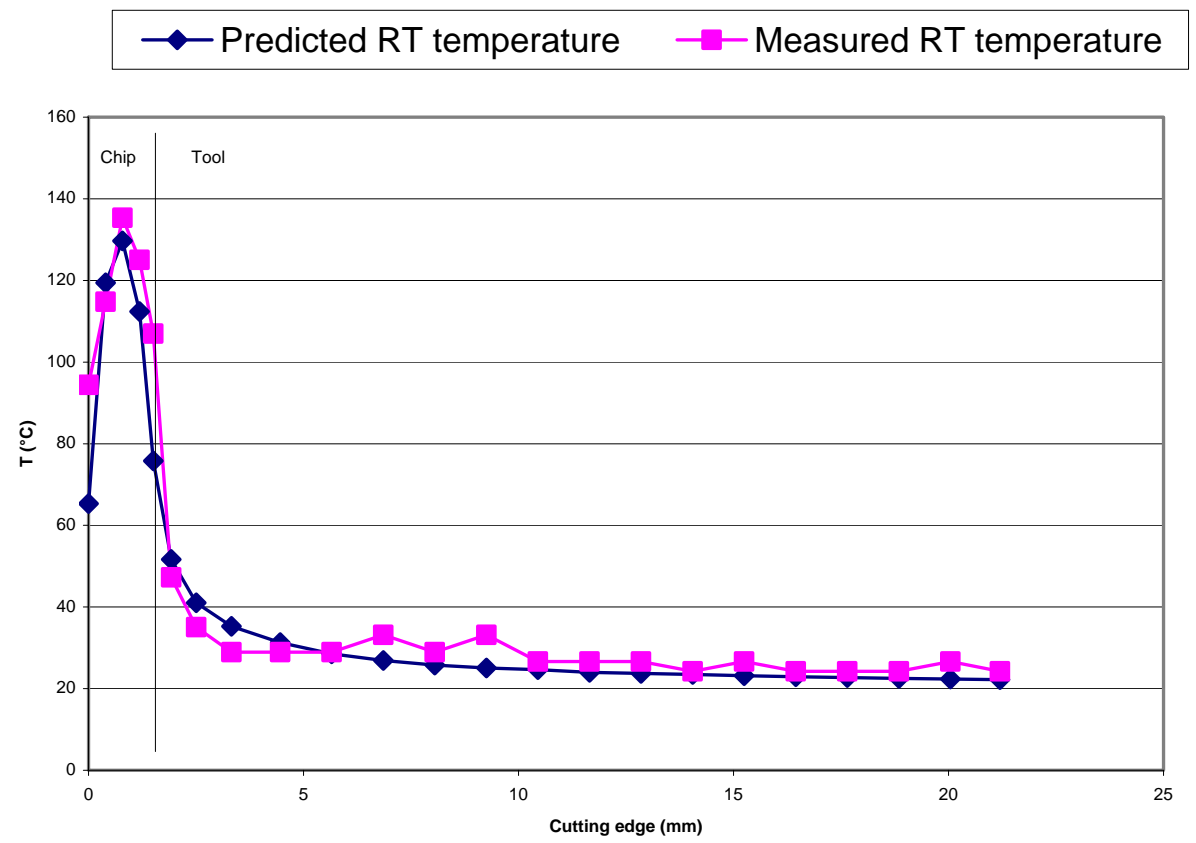

Figure 5-4: Cutting temperature along the cutting edge, $\mathrm{V}_{\mathrm{w}}=10 \mathrm{~m} / \mathrm{min}$.

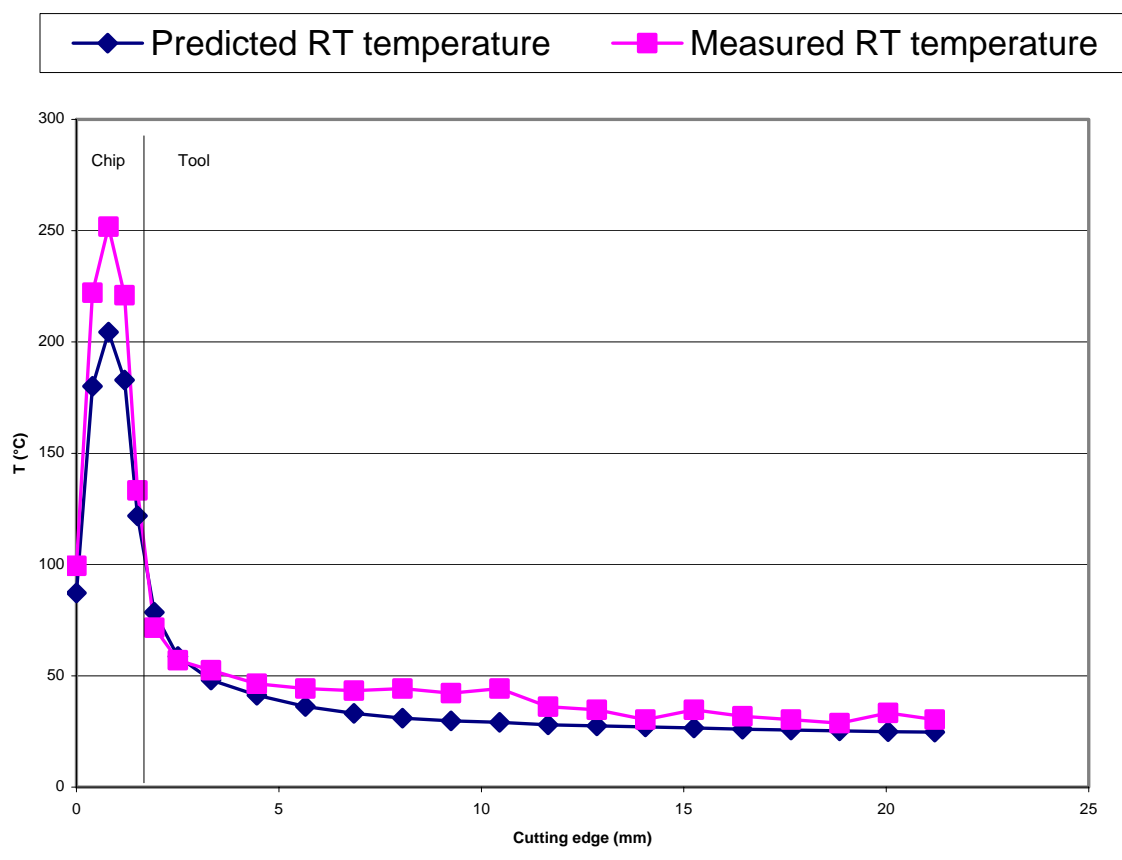

Figure 5-5: Cutting temperature along the cutting edge, $V_{w}=15 \mathrm{~m} / \mathrm{min}$. 


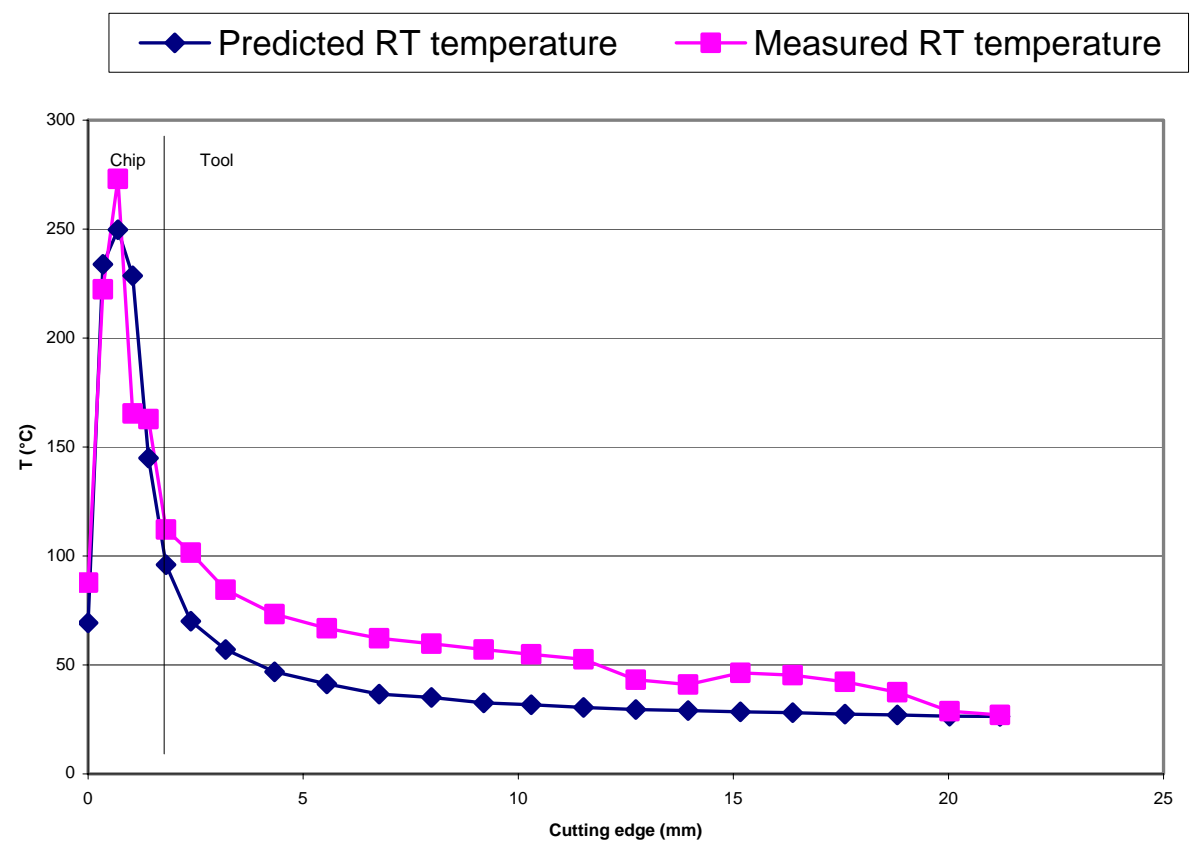

Figure 5-6: Cutting temperature along the cutting edge, $V_{w}=20 \mathrm{~m} / \mathrm{min}$.

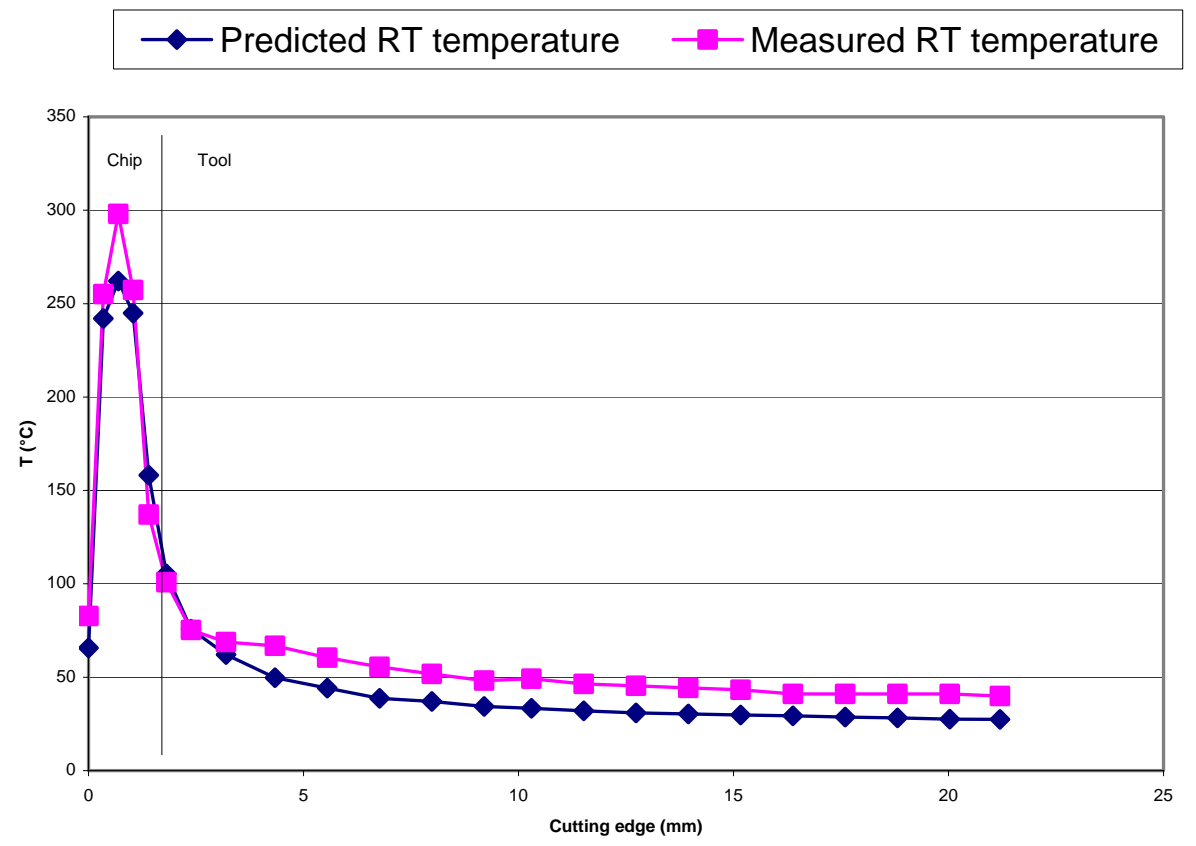

Figure 5-7: Cutting temperature along the cutting edge, $\mathrm{V}_{\mathrm{w}}=25 \mathrm{~m} / \mathrm{min}$. 
In order to obtain a valid comparison of the measured and predicted temperatures, a point on the tool cutting edge outside the region covered by the chip needs to be analyzed since the model provides the tool temperature and not the chip temperature. This point is indicated by the vertical line drawn in Figure 5-4. The region to the right of the vertical line represents the temperature distribution of the tool outside the tool-chip contact zone. It can be seen from Figure 5-8 that the temperature difference at this location ranges from 5 to $16^{\circ} \mathrm{C}$ at most.

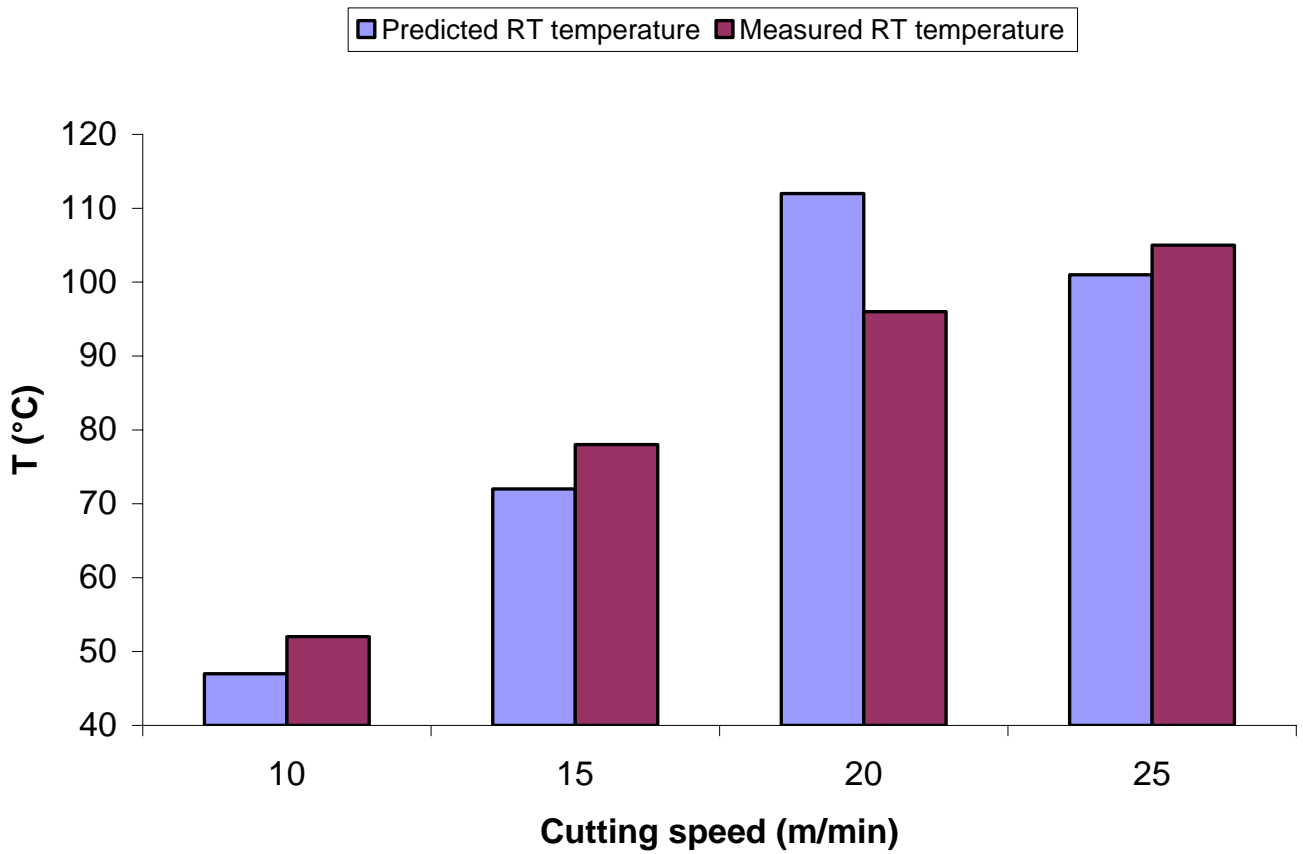

Figure 5-8: Predicted and measured temperature comparison at a given point on the tool rake face.

It is found that for all tested cutting conditions, the predicted cutting temperature shows a similar trend as the measured temperature when it is analyzed along the cutting 
edge. In addition, a good agreement between the predicted and measured temperature distribution along the cutting edge was found.

\subsection{Comparison of rotary and fixed tools}

The fixed tool temperature distribution is given in Figure 5-9. It is seen the tool rake face is heated around the tool-chip interface and temperature decreases significantly (up to $130^{\circ} \mathrm{C}$ ) when it is measured out of the interface.

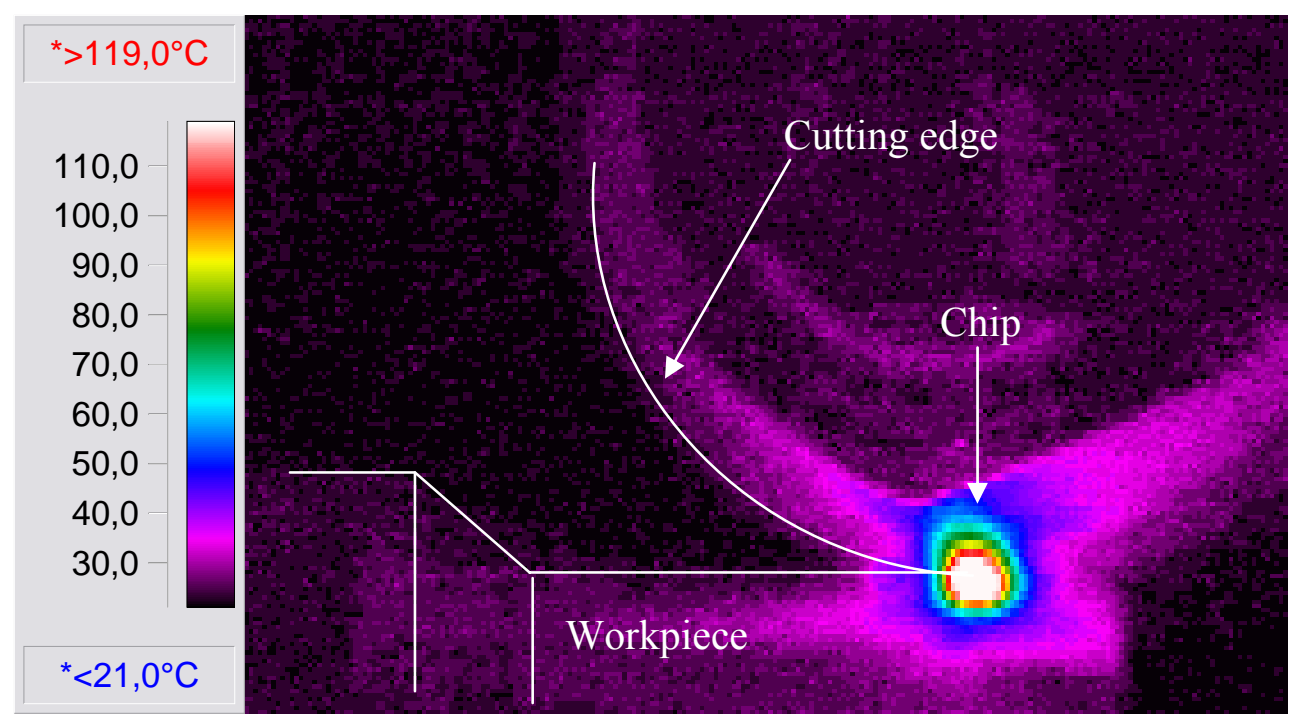

Figure 5-9: Fixed tool measured temperature distribution (in ${ }^{\circ} \mathrm{C}$ ), $\mathrm{V}_{\mathrm{w}}=10 \mathrm{~m} / \mathrm{min}, \mathrm{f}=0.1$ $\mathrm{mm} / \mathrm{rev}, \mathrm{a}_{\mathrm{p}}=0.05 \mathrm{~mm}$.

The rotary tool temperature is compared to the fixed tool case (denoted by FT) for two cutting speeds in Figure 5-10 and Figure 5-11. 


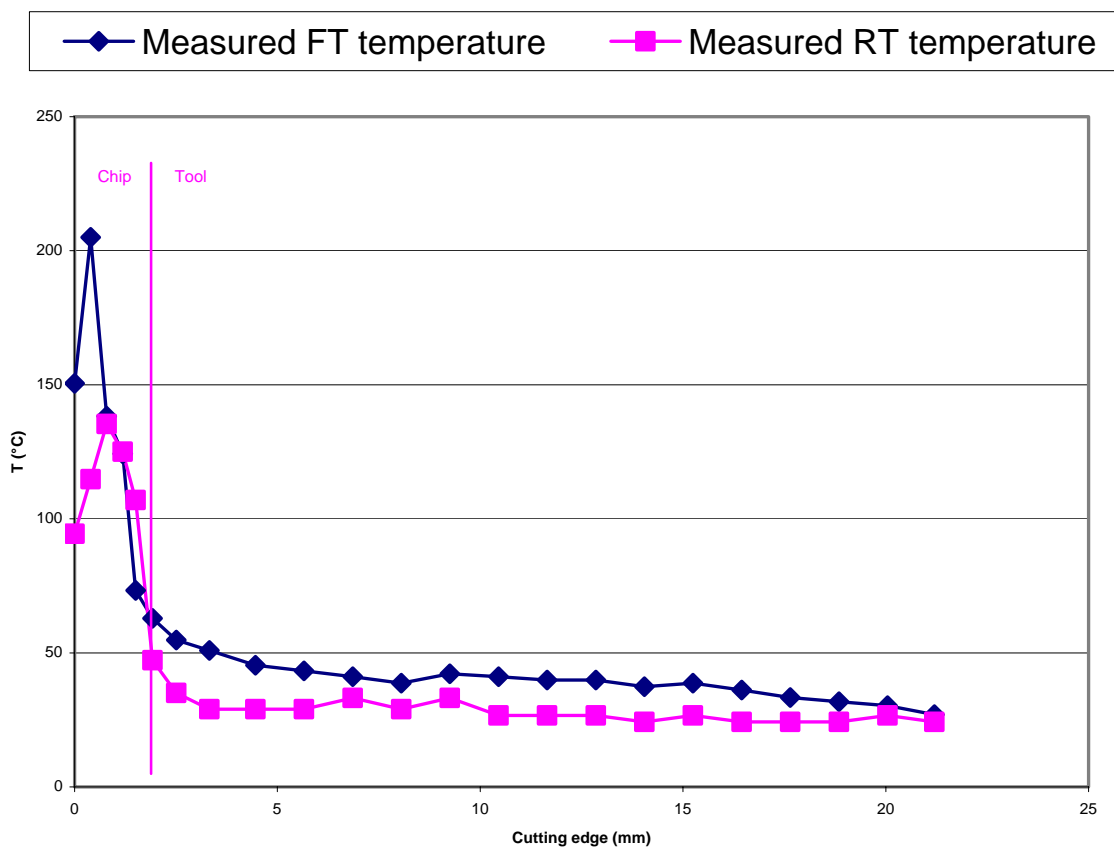

Figure 5-10: Rotary and fixed tools temperatures along the cutting edge, $V_{w}=10 \mathrm{~m} / \mathrm{min}$.

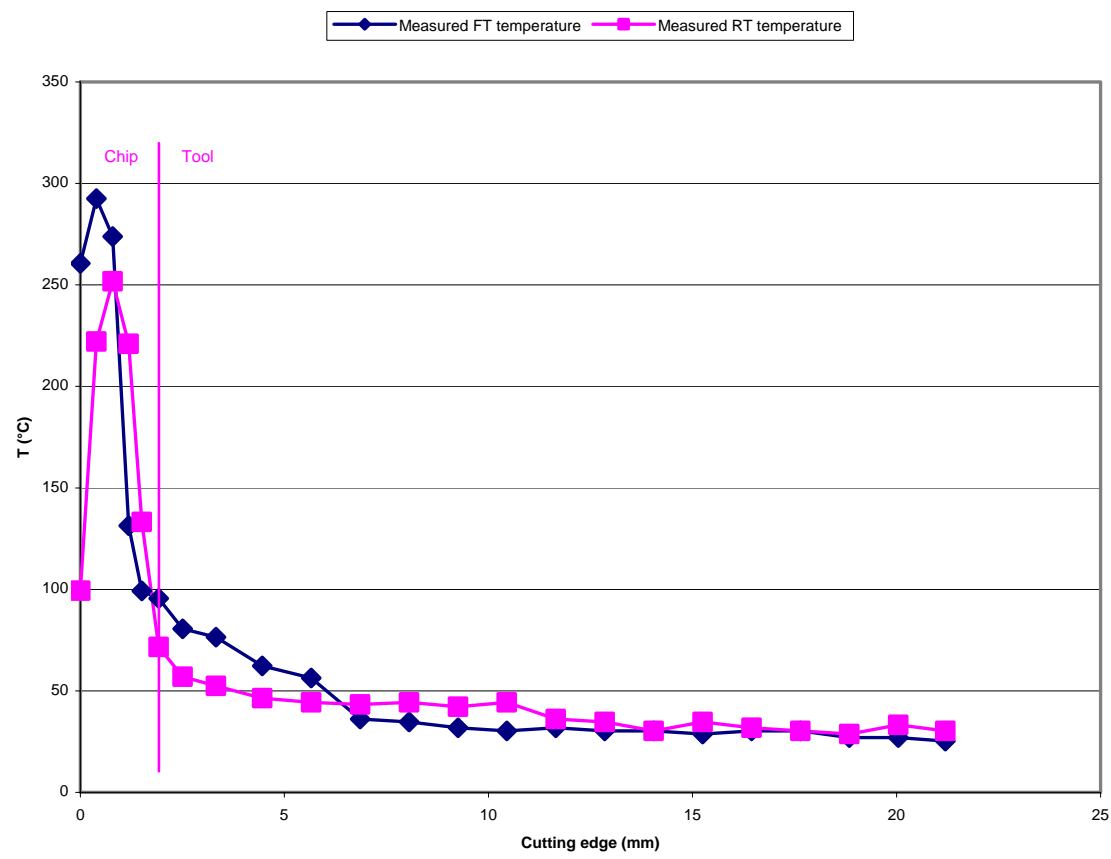

Figure 5-11: Rotary and fixed tools temperatures along the cutting edge, $V_{w}=15 \mathrm{~m} / \mathrm{min}$. 
It can be seen that the rotary tool exhibits a maximum temperature that is about 50 ${ }^{\circ} \mathrm{C}$ lower than the fixed one. It can be also seen that the peak temperature is shifted in the direction of insert rotation when the rotary tool is used. This can be explained by the kinematics of the chip on the tool rake face. The peripheral tool speed makes the chip deflect at a greater flow angle compared to the fixed tool case.

\subsection{Summary}

It is found that for all tested cutting conditions, the predicted cutting temperature shows a similar trend as the measured temperature when it is analyzed along the cutting edge. In addition, a good agreement between the predicted and measured temperature distribution along the cutting edge was found. The maximum deviation between the predicted and measured temperatures was between $5-16{ }^{\circ} \mathrm{C}$. Thus, the model can be used to give a good idea of the cutting temperature occurring during a rotary tool process.

Also, it is seen that the SPRT yields lower cutting temperatures (by $\approx 50^{\circ} \mathrm{C}$ ) compared to that obtained with a conventional non-rotating circular fixed tool under identical cutting conditions. 


\section{CHAPTER 6}

\section{CONCLUSIONS AND RECOMMENDATIONS}

\subsection{Model performance}

Results provided in this work indicate that the predictive model implemented to obtain thermal information can be used to give useful data about cutting temperature occurring in a rotary tool cutting process. Cutting forces and chip geometry data are necessary to derive the tool-chip interface heat flux and the kinematics of the process, respectively, used in the model.

The effectiveness of the model was tested in turning of 52100 hardened steel (58 HRC) with coated carbide circular inserts for several cutting conditions. Temperature measurements were conducted using an infra-red thermal imaging camera. For all tested cutting conditions, predicted and measured temperatures showed a similar trend when they were analyzed along the cutting edge. Moreover, the maximum error between the predicted and measured temperatures was between $5-16^{\circ} \mathrm{C}$.

\subsection{Temperature measurement limitations}

The experimental work and particularly the temperature measurement showed that the infra-red thermal imaging camera can be applied for rotary tool temperature measurement but its main disadvantage is its low flexibility. It was found that due to geometry and thermal restrictions (cartridge geometry and chip brighness), only a few cutting conditions could be investigated. 
Since this technique has never been studied in rotary tool turning before, improvements and additional work are required to further develop the methodology and the accuracy of the results. It is anticipated that many improvements can be made in terms of design. The tool holder and cartridge should be modified to improve their rigidity. Thus, oscillation of cutting forces would be much lower and tool wear less significant. This modification should also have a great impact on the generation of thermal imaging data. The cutting improvement due to improved rigidity of the system should provide a better flexibility to measure temperatures. The use of a vertical spindle lathe may be investigated to improve the thermal measurements. This could have an important role in terms of chip evacuation. Due to the gravity, the chip would fall down easily and thus, this would facilitate the temperature measurement of the tool rake face.

\subsection{Future work}

The temperature decrease afforded by the use of a rotary tool instead of an equivalent circular fixed tool should be promising for further work concerning tool wear and tool life. It is true that in order to compare temperature tool distribution, the same geometry must be used for both rotary and fixed tools. However, a pertinent investigation should be to compare rotary tool wear and life not to an equivalent circular non-rotating tool but to conventional non-circular tool insert since it is well-established that circular inserts are not the best choice for turning.

Temperature measurements have to be continued in turning different types of materials other than hardened steel. Some investigations have been done in machining difficult-to-machine materials as titanium alloys or metal-matrix composites (Chen et al. 
1992). The use of a thermal imaging camera may be a good method to measure cutting temperatures occurring in these processes.

The author hopes that the research done using an infra-red imaging camera serves as a foundation for future work in this area. Due to the lack of literature on thermal imaging in rotary tool turning, it is hoped that the methodology adopted for this work will be improved by other researchers. 


\section{APPENDIX A}

\section{MECHANICS OF ROTARY TOOL CUTTING PROCESSES}

\section{Driven oblique rotary tool cutting analysis}

The modified thin shear zone model and associated assumptions used in classical oblique cutting processes are applied to the rotary tool process. Also, the mechanism is still studied in the frame of the tool.

1. A continuous (with no built up edge) and straight chip is formed.

2. This chip formation is caused by shearing in a thin zone idealized by a shear plane and by friction on the rake face such that the chip is in equilibrium under the action of equal, opposite and collinear forces acting at the shear plane and rake face.

3. The shear force $\mathbf{F}_{\mathbf{s}}$ and the relative shear velocity $\mathbf{V}_{\mathbf{s}}$ are collinear as well as the friction force $\mathbf{F}$ and the relative chip velocity $\mathbf{V}_{\mathbf{c r}}$.

4. A concentrated edge force, due to ploughing or rubbing phenomena, occurs at the cutting edge which is proportional to the width of cut normal to the relative cutting velocity $\mathbf{V}$.

5. The chip transportation due to the rotation of the tool requires no additional energy.

Using these assumptions, the process is described in the following figure and is considered as a deformation process with respect to a stationary tool for obtaining an equivalent oblique cutting process. It is important to note that from the third assumption above, the angle $\eta_{\mathrm{c}}$ and $\eta_{\mathrm{c}}$ ' are equal as well as $\eta_{\mathrm{s}}$ and $\eta_{\mathrm{s}}$ '. 


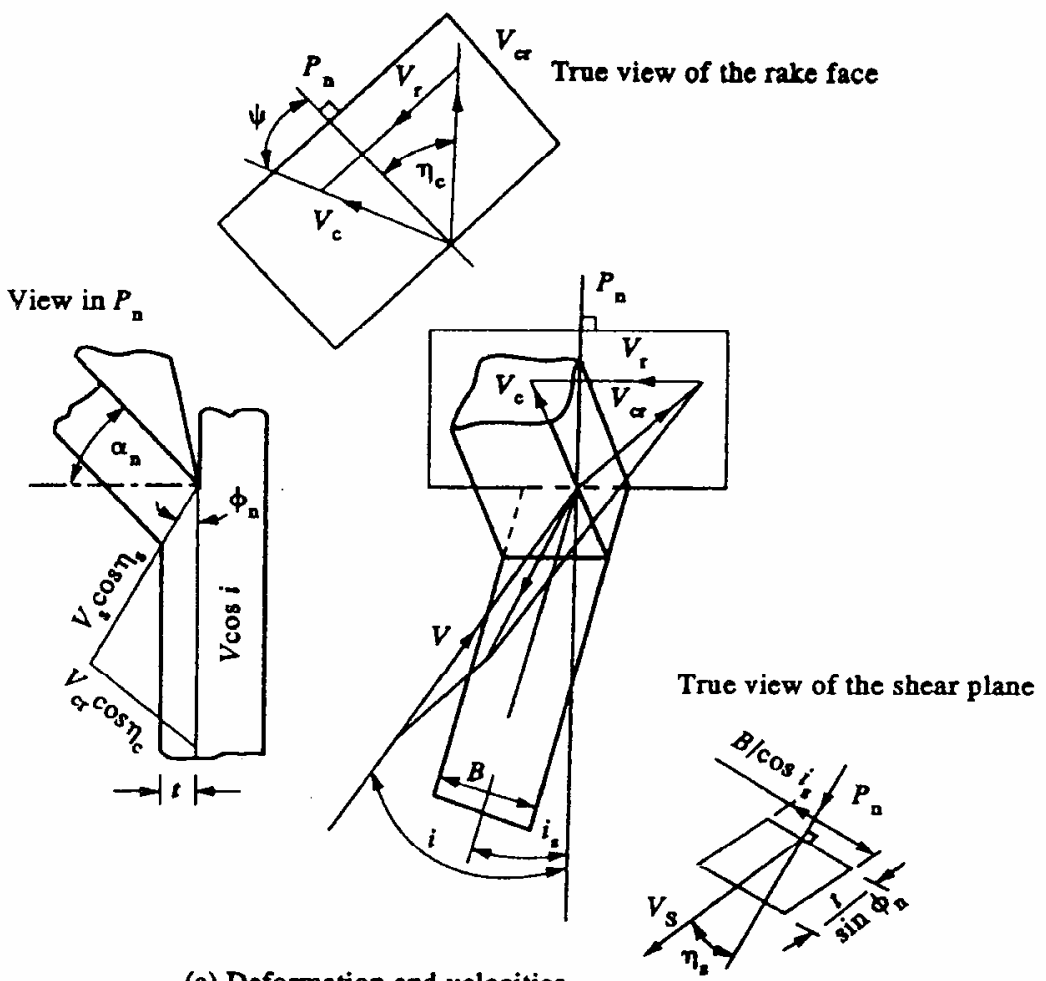

(a) Deformation and velocities

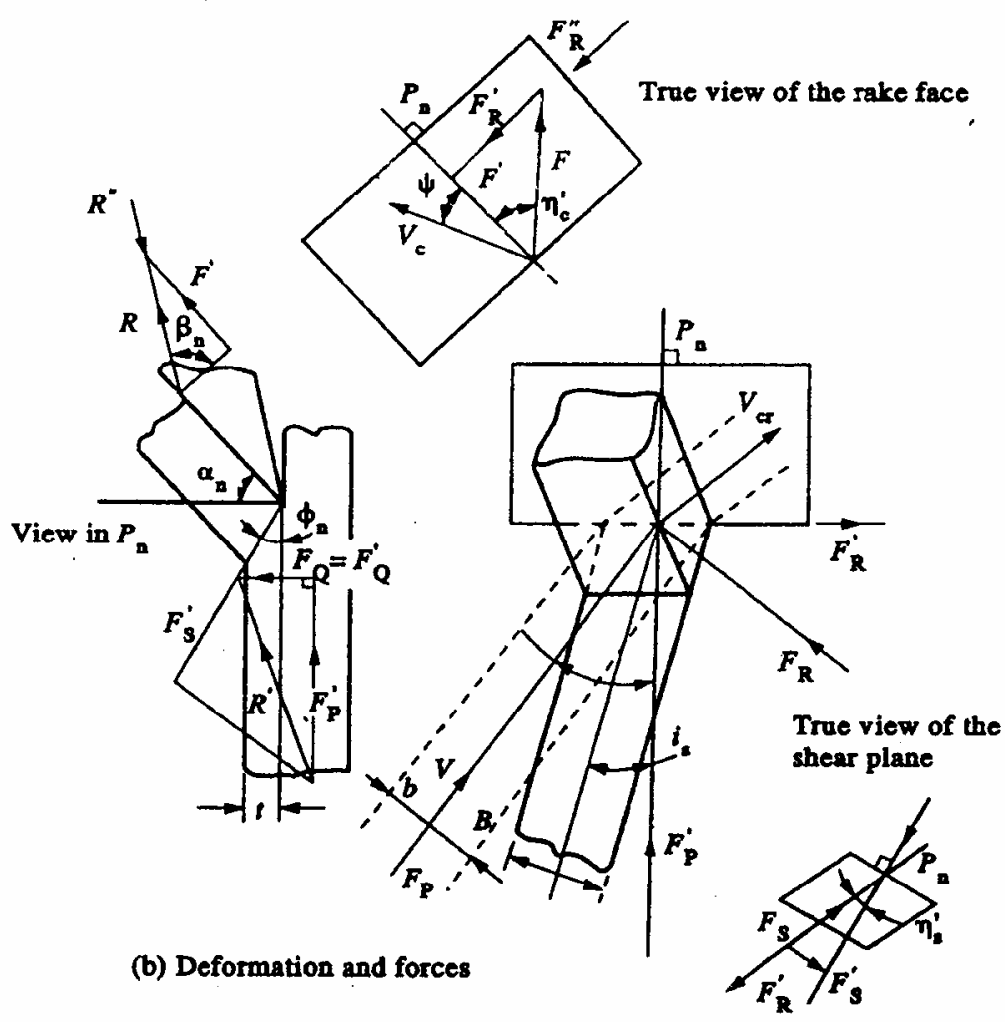

Figure A-1: Driven oblique rotary tool cutting model (Armarego et al., 1994). 
From the Figure A-1(a), mass continuity and incompressibility conditions, chip transportation and equations (3) to (7), Armarego et al. (1994) derived the following equations which have been validated by experiments:

$$
\begin{gathered}
B_{c}=B \frac{\cos \psi}{\cos i_{s}} \\
r_{t}=r_{l} \frac{\cos \psi}{\cos i_{s}} \\
r_{t}=r_{l r} \frac{\cos \eta_{c}}{\cos i} \\
\tan \eta_{c}=\frac{\sin \left(i-i_{s}\right)}{r_{t} \cos i \cos i_{s}}-\tan \psi \\
\tan \phi_{n}=\frac{r_{t} \cos \alpha_{n}}{1-r_{t} \sin \alpha_{n}}
\end{gathered}
$$

And from Equations (47), (48) and (50), two other forms can be derived for $\phi_{\mathrm{n}}$ :

$$
\begin{aligned}
& \tan \phi_{n}= \frac{r_{l} \frac{\cos \psi}{\cos i_{s}} \cos \alpha_{n}}{1-r_{l} \frac{\cos \psi}{\cos i_{s}} \sin \alpha_{n}} \\
& \tan \phi_{n}=\frac{r_{l r} \frac{\cos \eta_{c}}{\cos i_{s}} \cos \alpha_{n}}{1-r_{l r} \frac{\cos \eta_{c}}{\cos i_{s}} \sin \alpha_{n}}
\end{aligned}
$$

Also, the shear flow angle is given by:

$$
\tan \eta_{s}=\frac{\tan i \cos \left(\phi_{n}-\alpha_{n}\right)-\sin \phi_{n} \tan \eta_{c}}{\cos \alpha_{n}}
$$

On the one hand, the chip length ratio $r_{1}$ can be measured experimentally and is given by: 


$$
r_{l}=\frac{l_{c}}{l}=\frac{V_{c}}{V_{w}}
$$

On the other hand, the relative chip length ratio $r_{\text {lr }}$ cannot be measured for rotary tool processes but is given by:

$$
r_{l r}=\frac{V_{c r}}{V}
$$

From the Figure A-1(b), the equilibrium of the chip (using the second assumption mentioned above) lead to the following equations:

$$
\begin{gathered}
\tan \beta_{n}=\tan \beta \cos \eta_{c}{ }^{\prime} \\
\tan \eta_{s}{ }^{\prime}=\frac{\tan \eta_{c}{ }^{\prime} \sin \beta_{n}}{\cos \left(\phi_{n}+\beta_{n}-\alpha_{n}\right)} \\
F_{P}=\tau B t \cos i \frac{\cos \left(\beta_{n}-\alpha_{n}\right)+\tan \eta_{c}{ }^{\prime} \sin \beta_{n} \tan i}{M \sin \phi_{n} \cos i_{s}} \\
F_{Q}=\tau B t \frac{\sin \left(\beta_{n}-\alpha_{n}\right)}{M \sin \phi_{n} \cos i_{s}} \\
F_{R}=\tau B t \cos i \frac{\cos \left(\beta_{n}-\alpha_{n}\right) \tan i-\tan \eta_{c}{ }^{\prime} \sin \beta_{n}}{M \sin \phi_{n} \cos i_{s}}
\end{gathered}
$$

where

$$
M=\sqrt{\cos ^{2}\left(\phi_{n}+\beta_{n}-\alpha_{n}\right)+\tan ^{2} \eta_{c}{ }^{\prime} \sin ^{2} \beta_{n}}
$$

After the third assumption, equations (53) and (57) have to be equal, what yields to:

$$
\tan \left(\phi_{n}+\beta_{n}\right)=\frac{\tan i \cos \alpha_{n}}{\tan \eta_{c}-\sin \alpha_{n} \tan i}
$$


To summarize, it is important to note that the practical force components can be written in a functional form:

$$
F_{P}, F_{Q}, F_{R}=\text { functions }\left(\alpha_{n}, i, i_{s}, B, \tau, t, \phi_{n}, \beta\right)
$$

where $\left(V_{w}, V_{r}\right)$ can be used instead of $i$, as well as $r_{1 r}$ or $r_{1}$ for $\phi_{n}$ and $\beta_{n}$ for $\beta$.

This last form is just a useful way to show that in order to predict the practical force components due to shearing and friction, given $\mathrm{B}, \mathrm{t}, \alpha_{\mathrm{n}}, \mathrm{i}_{\mathrm{s}}$ and $\mathrm{i}$, it is necessary to know $\tau, \phi_{\mathrm{n}}, \beta_{\mathrm{n}}$.

Also, as noted in the fourth assumption, edge force coefficients per unit width of cut $\mathrm{Kl} \mathrm{P}_{\mathrm{P}}, \mathrm{Kl}_{\mathrm{Q}}$ and $\mathrm{Kl} \mathrm{R}_{\mathrm{R}}$ must be considered to allow for rubbing and ploughing and must be known to find the following forms of the total force components:

$$
\begin{aligned}
& F_{P t}=F_{P}+F_{P e}=F_{P}+K l_{P} B \frac{\cos i}{\cos i_{s}} \\
& F_{Q t}=F_{Q}+F_{Q e}=F_{Q}+K l_{Q} B \frac{\cos i}{\cos i_{s}} \\
& F_{R t}=F_{R}+F_{R e}=F_{R}+K l_{R} B \frac{\cos i}{\cos i_{s}}
\end{aligned}
$$

The total power $\mathrm{P}$ in driven oblique rotary cutting process (including the power to drive the rotary tool and the one to drive the workpiece) and the total specific cutting energy are evaluated by:

$$
\begin{gathered}
P=F_{P t} V \\
U=\frac{P}{B t V_{w}}=\frac{F_{P t} V}{b t V}=\frac{F_{P t}}{b t}
\end{gathered}
$$

Many of the above equations for the rotary tool process are similar to those for the classical oblique cutting one. It was mentioned before that if the volume material removal 
rate (with no change in $\mathrm{V}$ and $\mathrm{t}$ ) is the same for both processes, these ones can be considered equivalent. That yields to an equivalent width of cut $b=B \operatorname{cosi} / \operatorname{cosi}_{\mathrm{s}}$. In that way, rotary tool Equations (50), (53) and (58) to (62) become identical to those for classical oblique cutting.

However, a main difference exists between these processes because chip transportation occurs only with rotary tools. Thus, the absolute chip flow angle $\psi$ and the absolute chip length ratio $r_{1}$ from the equivalent process have to be compared to the relative chip flow angle $\eta_{c}$ and the relative chip length ratio $r_{l r}$ from the rotary tool one.

Finally, Armarego et al. (1994) propose a perfect equivalence between the rotary tool cutting and the classical oblique cutting processes. Consequently, the quantitative values of all common features should be the same in both processes. This model has been verified in an experimental investigation.

\section{Driven orthogonal rotary tool cutting analysis}

As pointed out earlier, the driven orthogonal rotary tool process is just a special case (where the static angle of inclination $i_{s}$ is zero) of the driven oblique rotary tool process.

Using the same modified thin shear model and substituting $i_{\mathrm{s}}=0$ in the equations derived for the driven rotary tool process, a similar analysis can be established.

The same kind of equations is derived and the comments about them are the same.

After Armarego et al. (1994), the driven orthogonal rotary tool process can be modeled as a dynamically or perfectly equivalent classical oblique cutting process where the width of cut has to be $b=$ Bcosi together with a chip transportation due to $V_{r}$ which 
requires no additional energy. Also, this model has been verified in an experimental investigation.

$$
\begin{aligned}
& V=\sqrt{V_{w}^{2}+V_{r}^{2}} \\
& \tan i=\frac{V_{r}}{V_{w}} \\
& V_{w}=V \cos i \\
& V_{r}=V \sin i \\
& V b t=V_{w} B t=V B t \cos i \\
& b=B \cos i \\
& r_{t}=r_{l} \cos \psi=r_{l r} \frac{\cos \eta_{c}}{\cos i} \\
& \tan \eta_{c}=\frac{\sin i}{r_{t} \cos i}-\tan \psi \\
& \tan \phi_{n}=\frac{r_{t} \cos \alpha_{n}}{1-r_{t} \sin \alpha_{n}} \\
& \tan \phi_{n}=\frac{r_{l} \cos \psi \cos \alpha_{n}}{1-r_{l} \cos \psi \sin \alpha_{n}} \\
& \tan \phi_{n}=\frac{r_{l r} \frac{\cos \eta_{c}}{\cos i} \cos \alpha_{n}}{1-r_{l r} \frac{\cos \eta_{c}}{\cos i} \sin \alpha_{n}} \\
& \tan \beta_{n}=\tan \beta \cos \eta_{c}{ }^{\prime} \\
& \tan \eta_{s}{ }^{\prime}=\frac{\tan \eta_{c}{ }^{\prime} \sin \beta_{n}}{\cos \left(\phi_{n}+\beta_{n}-\alpha_{n}\right)}
\end{aligned}
$$




$$
\begin{gathered}
F_{P}=\tau B t \cos i \frac{\cos \left(\beta_{n}-\alpha_{n}\right)+\tan \eta_{c}{ }^{\prime} \sin \beta_{n} \tan i}{M \sin \phi_{n}} \\
F_{Q}=\tau B t \frac{\sin \left(\beta_{n}-\alpha_{n}\right)}{M \sin \phi_{n}} \\
F_{R}=\tau B t \cos i \frac{\cos \left(\beta_{n}-\alpha_{n}\right) \tan i-\tan \eta_{c}{ }^{\prime} \sin \beta_{n}}{M \sin \phi_{n}} \\
M=\sqrt{\cos ^{2}\left(\phi_{n}+\beta_{n}-\alpha_{n}\right)+\tan { }^{2} \eta_{c}{ }^{\prime} \sin ^{2} \beta_{n}} \\
\tan \left(\phi_{n}+\beta_{n}\right)=\frac{\tan i \cos \alpha_{n}}{\tan \eta_{c}-\sin \alpha_{n} \tan i} \\
F_{P t}=F_{P}+F_{P e}=F_{P}+K l_{P} B \cos i \\
F_{Q t}=F_{Q}+F_{Q e}=F_{Q}+K l_{Q} B \cos i \\
F_{R t}=F_{R}+F_{\mathrm{Re}}=F_{R}+K l_{R} B \cos i \\
F_{R t}=
\end{gathered}
$$




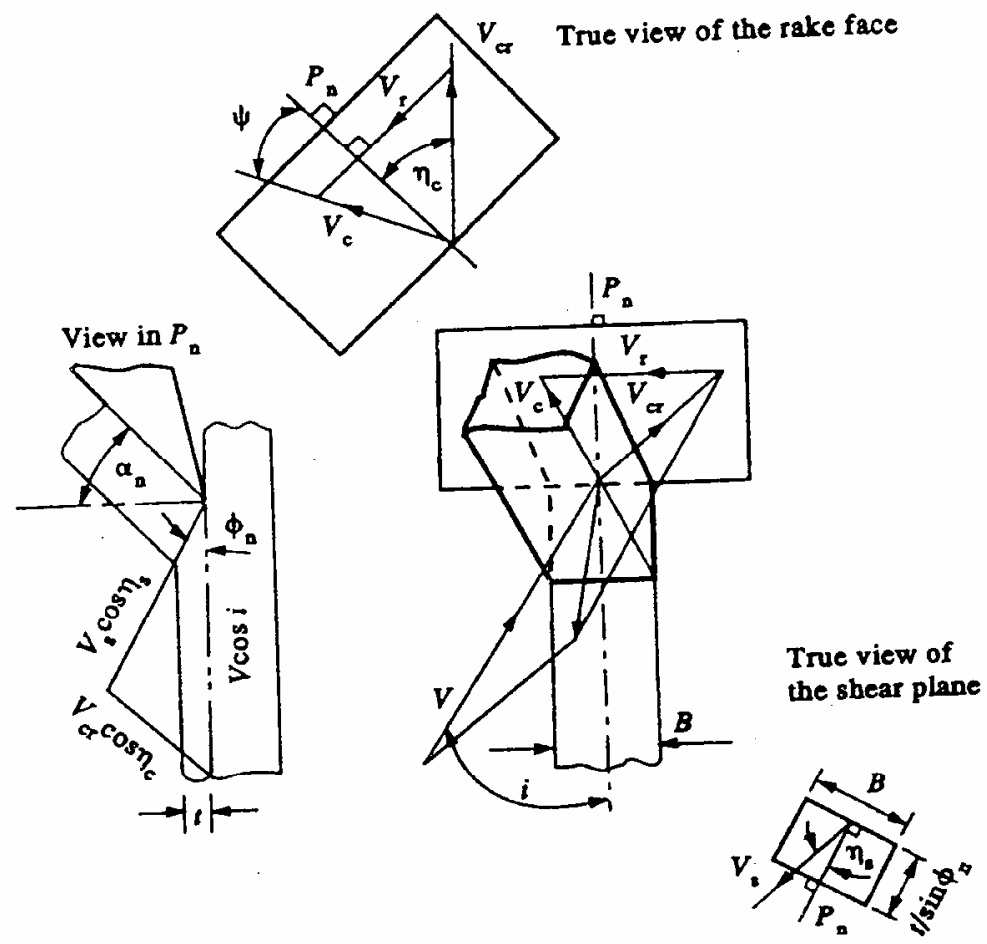

(a) Deformation and velocities

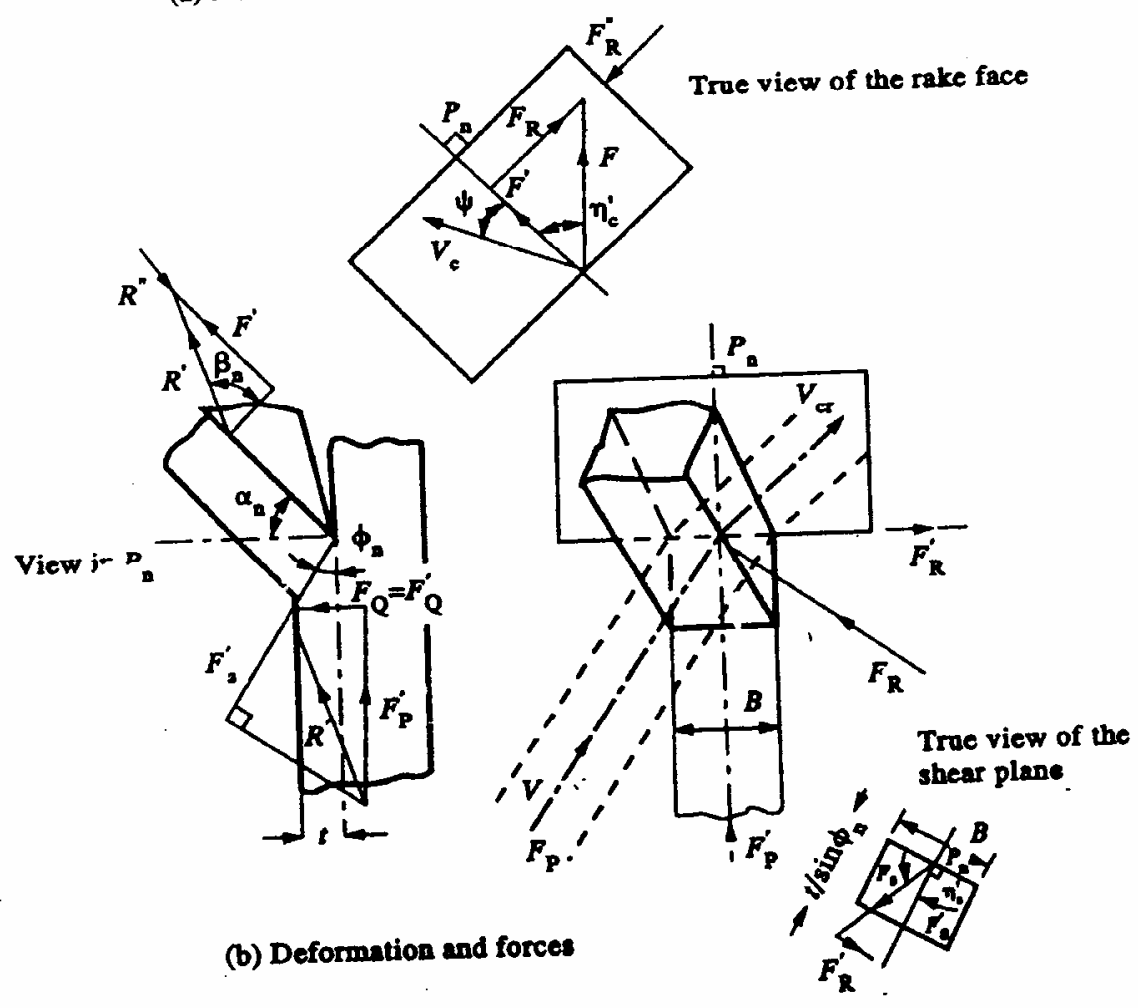

Figure A-2: Driven orthogonal rotary tool cutting model (Armarego et al., 1994). 


\section{Self-propelled oblique rotary tool cutting analysis}

As mentioned earlier, the self-propelled oblique rotary tool process can be represented as a perfectly equivalent classical orthogonal cutting process with a chip transportation which involves no additional energy.

Absolute deformation geometry, velocities and forces are represented in Figure A-3 and the equations for the self-propelled are derived from those of the driven oblique by substituting $\mathrm{i}=0$.

In this way, Armarego et al. (1994) asserted that the forces and power in selfpropelled rotary could be found using the perfectly equivalent classical orthogonal cutting analysis with an equivalent width of cut $b=B / \operatorname{cosi} i_{s}$. Equations are given below.

Like both former processes, the self-propelled one has been verified experimentally (Armarego et al., 1994).

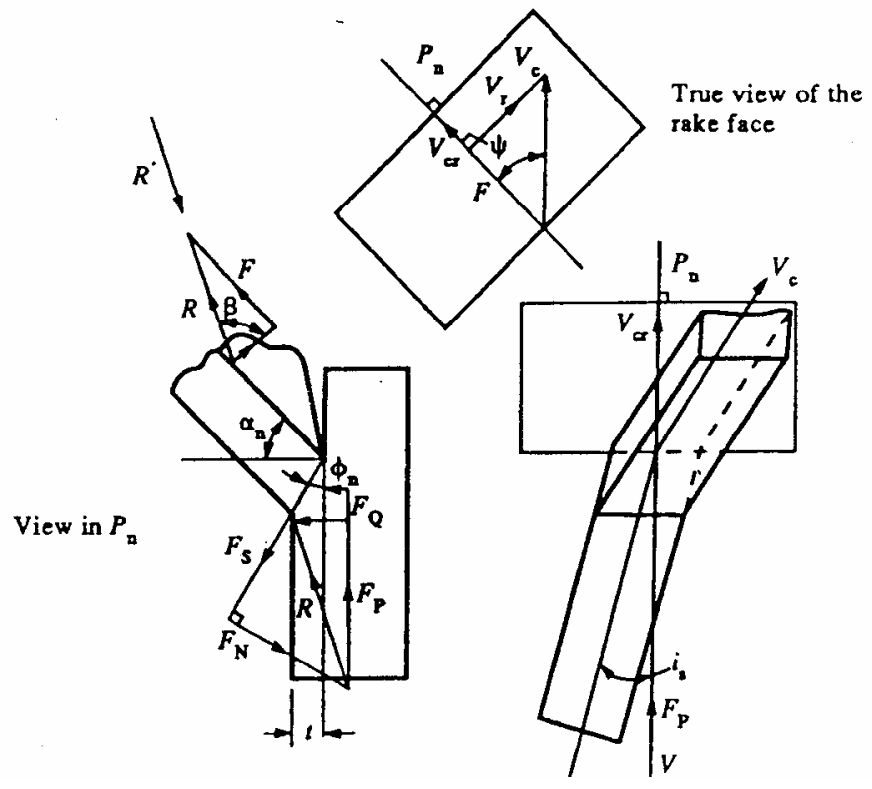

Figure A-3: Self-propelled oblique rotary tool cutting model (Armarego et al., 1994). 


$$
\begin{aligned}
& V=V_{w} \cos i_{s} \\
& V_{r}=V_{w} \sin i_{s} \\
& V b t=\frac{V B t}{\cos i_{s}}=V_{w} B t \\
& b=\frac{B}{\cos i_{s}} \\
& r_{t}=\frac{r_{l r}}{\cos i}=r_{l r}=r_{l} \frac{\cos \psi}{\cos i_{s}} \\
& \eta_{c}=0 \\
& \tan \psi=\frac{\sin \left(i-i_{s}\right)}{r_{t} \cos i \cos i_{s}} \\
& \tan \phi_{n}=\frac{r_{t} \cos \alpha_{n}}{1-r_{t} \sin \alpha_{n}} \\
& \tan \phi_{n}=\frac{r_{l} \frac{\cos \psi}{\cos i_{s}} \cos \alpha_{n}}{1-r_{l} \frac{\cos \psi}{\cos i_{s}} \sin \alpha_{n}} \\
& \tan \phi_{n}=\frac{r_{l r} \cos \alpha_{n}}{1-r_{l r} \sin \alpha_{n}} \\
& \tan \eta_{s}=0 \Rightarrow \eta_{s}=0 \\
& F_{P}=\tau B t \frac{\cos \left(\beta_{n}-\alpha_{n}\right)}{\cos \left(\phi_{n}+\beta-\alpha_{n}\right) \sin \phi_{n} \cos i_{s}} \\
& F_{Q}=\tau B t \frac{\sin \left(\beta_{n}-\alpha_{n}\right)}{\cos \left(\phi_{n}+\beta-\alpha_{n}\right) \sin \phi_{n} \cos i_{s}} \\
& F_{R}=0
\end{aligned}
$$




\section{Summary}

- The driven oblique rotary tool process is the most general case.

- The driven orthogonal rotary tool process is a particular case where the static inclination angle $i_{\mathrm{s}}$ is equal to zero.

- The self-propelled rotary tool process is a particular case where the inclination angle $\mathrm{i}$ is equal to zero.

Table A-1: Rotary tool and corresponding perfectly equivalent classical cutting processes.

\begin{tabular}{|c|c|c|c|}
\hline $\begin{array}{c}\text { Rotary tool } \\
\text { cutting processes }\end{array}$ & $\begin{array}{c}\text { Driven } \\
\text { oblique }\end{array}$ & $\begin{array}{c}\text { Driven } \\
\text { orthogonal }\end{array}$ & $\begin{array}{c}\text { Self-propelled } \\
\text { (oblique) }\end{array}$ \\
\hline $\begin{array}{c}\text { Corresponding } \\
\text { kinematically and } \\
\text { perfectly } \\
\text { equivalent } \\
\text { classical cutting } \\
\text { processes }\end{array}$ & $\begin{array}{c}\text { Oblique with a } \\
\text { chip } \\
\text { transportation } \\
\text { which requires } \\
\text { no additional }\end{array}$ & $\begin{array}{c}\text { Orthogonal if } \\
\mathrm{Vr}=0 \\
\text { with a chip } \\
\text { transportation } \\
\text { which requires } \\
\text { no additional }\end{array}$ & $\begin{array}{c}\text { Orthogonal } \\
\text { with a chip } \\
\text { transportation } \\
\text { which requires } \\
\text { no additional } \\
\text { energy }\end{array}$ \\
\hline
\end{tabular}




\section{APPENDIX B}

\section{DISCUSSION ABOUT CHEN'S MODEL}

One of the advantages of this approach is to get an analytical solution for the temperature rise. However, some assumptions must be considered carefully.

The quarter-infinite body approximation could be a good approximation but the problem is that with this assumption, Chen et al. cannot treat the movement of the tool as a rotation and actually uses a translation. It is obvious that the temperature distribution cannot be the same.

Chen et al. affirm that the heat conduction equation has the form given in Equation 69. It seems that he forgets the term due to the heat source itself. The partial differential equation that relates the temperature and energy input is (Carlsaw and Jaeger, 1959):

$$
\frac{\partial \theta}{\partial t}=K .\left(\frac{\partial^{2} \theta}{\partial x^{2}}+\frac{\partial^{2} \theta}{\partial y^{2}}+\frac{\partial^{2} \theta}{\partial z^{2}}\right)+\frac{q}{\rho c}
$$

where $\mathrm{q}$ is the heat flux at the tool-chip interface $\left(\mathrm{W} \cdot \mathrm{m}^{-2}\right)$.

In the Equation 10, Chen et al. use Q as a heat (Joules) and after, for numerical computation, he integrates it over the tool-chip interface area and time. In order to use this double integration, he cannot use this equation. Also, Chen does not use the rotational tool speed in the expression. According to Jaeger (1959), the temperature rise at time $\mathrm{t}$ at $\left(\mathrm{x}_{0}, \mathrm{y}_{0}, \mathrm{z}_{0}\right)$ due to the heat $\mathrm{q}_{\mathrm{t}} \mathrm{dt}$ ' emitted at t' is: 


$$
\Delta \theta=\frac{2 q_{t} d t^{\prime}}{8 \rho c\left(\pi K\left(t-t^{\prime}\right)\right)^{\frac{3}{2}}} \exp \left(-\frac{\left\{x_{0}-V_{t}\left(t-t^{\prime}\right)-x\right\}^{2}+\left(y_{0}-y\right)^{2}+\left(z_{0}-z\right)^{2}}{4 K\left(t-t^{\prime}\right)}\right)
$$

Integrating over the source area and time:

$$
\Delta \theta=\frac{2 q_{t} d t^{\prime}}{8 \rho c(\pi K)^{\frac{3}{2}}} \int_{0}^{t} \int_{2 S_{t}} \frac{\exp \left(-\frac{\left\{x_{0}-V_{t}\left(t-t^{\prime}\right)-x\right\}^{2}+\left(y_{0}-y\right)^{2}+\left(z_{0}-z\right)^{2}}{4 K\left(t-t^{\prime}\right)}\right)}{\left(t-t^{\prime}\right)^{\frac{3}{2}}} d S d t^{\prime}
$$




\section{APPENDIX C}

\section{DISCUSSION ABOUT KISHAWY'S MODEL}

- To derive both energy and flux continuity at the interface equations in generalized coordinates, Kishawy gives no information about its procedure and some results should be considered carefully.

- First, Kishawy et al. affirm that the Jacobian of the transformation represents the ratio of physical space to transformed space and is defined as in Equation (17). But actually, the Jacobian of the transformation from the $x, y, z$ to the $\varepsilon, \eta, \zeta$ variables is defined by (Ozisik, 1994):

$$
\begin{aligned}
& J=J\left(\frac{x, y, z}{\varepsilon, \eta, \zeta}\right)=\left|\begin{array}{ccc}
x_{\varepsilon} & x_{\eta} & x_{\zeta} \\
y_{\varepsilon} & y_{\eta} & y_{\zeta} \\
z_{\varepsilon} & z_{\eta} & z_{\zeta}
\end{array}\right| \\
& =x_{\varepsilon}\left(y_{\eta} z_{\zeta}-y_{\zeta} z_{\eta}\right)-x_{\eta}\left(y_{\varepsilon} z_{\zeta}-y_{\zeta} z_{\varepsilon}\right)+x_{\zeta}\left(y_{\varepsilon} z_{\eta}-y_{\eta} z_{\varepsilon}\right)
\end{aligned}
$$

- To get Equations 16 and 21 used by Kishawy, the above definition of the Jacobian has to be used and the starting point is the differential equation of conduction of heat in a moving medium (Carlsaw and Jaeger, 1959):

$$
\rho c\left(\frac{\partial T}{\partial t}+\frac{\partial u T}{\partial x}+\frac{\partial v T}{\partial y}+\frac{\partial w T}{\partial z}\right)=k \nabla^{2} T
$$

where $\rho$ is the density of the material, $\mathrm{k}$ and $\mathrm{c}$ are the thermal conductivity and the heat capacity of the tool respectively and the Laplacian of the temperature is given in the physical space by:

$$
\nabla^{2} T=\frac{\partial^{2} T}{\partial x^{2}}+\frac{\partial^{2} T}{\partial y^{2}}+\frac{\partial^{2} T}{\partial z^{2}}
$$


Then, terms as the gradient, the divergence and the Laplacian must be derived in generalized coordinates using the following relations:

If $\mathrm{T}$ is a scalar, the gradient of $\mathrm{T}$ is defined in the physical space by:

$$
\nabla T=\frac{\partial T}{\partial x} \vec{i}+\frac{\partial T}{\partial y} \vec{j}+\frac{\partial T}{\partial z} \vec{k}
$$

If $\vec{T}=T_{1} \vec{i}+T_{2} \vec{j}+T_{3} \vec{k}$ is a vector, the divergence of this vector in the physical space is:

$$
\begin{gathered}
\nabla \cdot \vec{T}=\frac{\partial T_{1}}{\partial x}+\frac{\partial T_{2}}{\partial y}+\frac{\partial T_{3}}{\partial z} \\
\frac{\partial T}{\partial x}=\varepsilon_{x} \frac{\partial T}{\partial \varepsilon}+\eta_{x} \frac{\partial T}{\partial \eta}+\zeta_{x} \frac{\partial T}{\partial \zeta} \\
\frac{\partial T}{\partial y}=\varepsilon_{y} \frac{\partial T}{\partial \varepsilon}+\eta_{y} \frac{\partial T}{\partial \eta}+\zeta_{y} \frac{\partial T}{\partial \zeta} \\
\frac{\partial T}{\partial z}=\varepsilon_{z} \frac{\partial T}{\partial \varepsilon}+\eta_{z} \frac{\partial T}{\partial \eta}+\zeta_{z} \frac{\partial T}{\partial \zeta} \\
\frac{\partial T}{\partial \varepsilon}=x_{\varepsilon} \frac{\partial T}{\partial x}+y_{\varepsilon} \frac{\partial T}{\partial y}+z_{\varepsilon} \frac{\partial T}{\partial z} \\
\frac{\partial T}{\partial \eta}=x_{\eta} \frac{\partial T}{\partial x}+y_{\eta} \frac{\partial T}{\partial y}+z_{\eta} \frac{\partial T}{\partial z} \\
\frac{\partial T}{\partial \zeta}=x_{\zeta} \frac{\partial T}{\partial x}+y_{\zeta} \frac{\partial T}{\partial y}+z_{\zeta} \frac{\partial T}{\partial z}
\end{gathered}
$$

Solving Equation (112) in terms of $\frac{\partial T}{\partial x}, \frac{\partial T}{\partial y}, \frac{\partial T}{\partial z}$ since $\mathrm{J}$ is not equal to zero, a new system is derived: 


$$
\begin{aligned}
& \frac{\partial T}{\partial x}=\frac{1}{J}\left(-\left(y_{\zeta} z_{\eta}-y_{\eta} z_{\zeta}\right) \frac{\partial T}{\partial \varepsilon}+\left(y_{\zeta} z_{\varepsilon}-y_{\varepsilon} z_{\zeta}\right) \frac{\partial T}{\partial \eta}+\left(y_{\varepsilon} z_{\eta}-y_{\eta} z_{\varepsilon}\right) \frac{\partial T}{\partial \zeta}\right) \\
& \frac{\partial T}{\partial y}=\frac{1}{J}\left(\left(x_{\zeta} z_{\eta}-x_{\eta} z_{\zeta}\right) \frac{\partial T}{\partial \varepsilon}-\left(x_{\zeta} z_{\varepsilon}-x_{\varepsilon} z_{\zeta}\right) \frac{\partial T}{\partial \eta}-\left(x_{\varepsilon} z_{\eta}-x_{\eta} z_{\varepsilon}\right) \frac{\partial T}{\partial \zeta}\right) \\
& \frac{\partial T}{\partial z}=\frac{1}{J}\left(-\left(x_{\zeta} y_{\eta}-x_{\eta} y_{\zeta}\right) \frac{\partial T}{\partial \varepsilon}+\left(x_{\zeta} y_{\varepsilon}-x_{\varepsilon} y_{\zeta}\right) \frac{\partial T}{\partial \eta}+\left(x_{\varepsilon} y_{\eta}-x_{\eta} y_{\varepsilon}\right) \frac{\partial T}{\partial \zeta}\right)
\end{aligned}
$$

By identification of Equations (111) and (113), the metrics of the transformation are found to be:

$$
\begin{aligned}
& \varepsilon_{x}=-\frac{1}{J}\left(y_{\zeta} z_{\eta}-y_{\eta} z_{\zeta}\right) ; \varepsilon_{y}=\frac{1}{J}\left(x_{\zeta} z_{\eta}-x_{\eta} z_{\zeta}\right), \varepsilon_{z}=-\frac{1}{J}\left(x_{\zeta} y_{\eta}-x_{\eta} y_{\zeta}\right) \\
& \eta_{x}=\frac{1}{J}\left(y_{\zeta} z_{\varepsilon}-y_{\varepsilon} z_{\zeta}\right) ; \eta_{y}=-\frac{1}{J}\left(x_{\zeta} z_{\varepsilon}-x_{\varepsilon} z_{\zeta}\right) ; \eta_{z}=\frac{1}{J}\left(x_{\zeta} y_{\varepsilon}-x_{\varepsilon} y_{\zeta}\right) \\
& \zeta_{x}=\frac{1}{J}\left(y_{\varepsilon} z_{\eta}-y_{\eta} z_{\varepsilon}\right) ; \zeta_{y}=-\frac{1}{J}\left(x_{\varepsilon} z_{\eta}-x_{\eta} z_{\varepsilon}\right) ; \zeta_{z}=\frac{1}{J}\left(x_{\varepsilon} y_{\eta}-x_{\eta} y_{\varepsilon}\right)
\end{aligned}
$$


Thus, the conservative form of the gradient in the transformed space is:

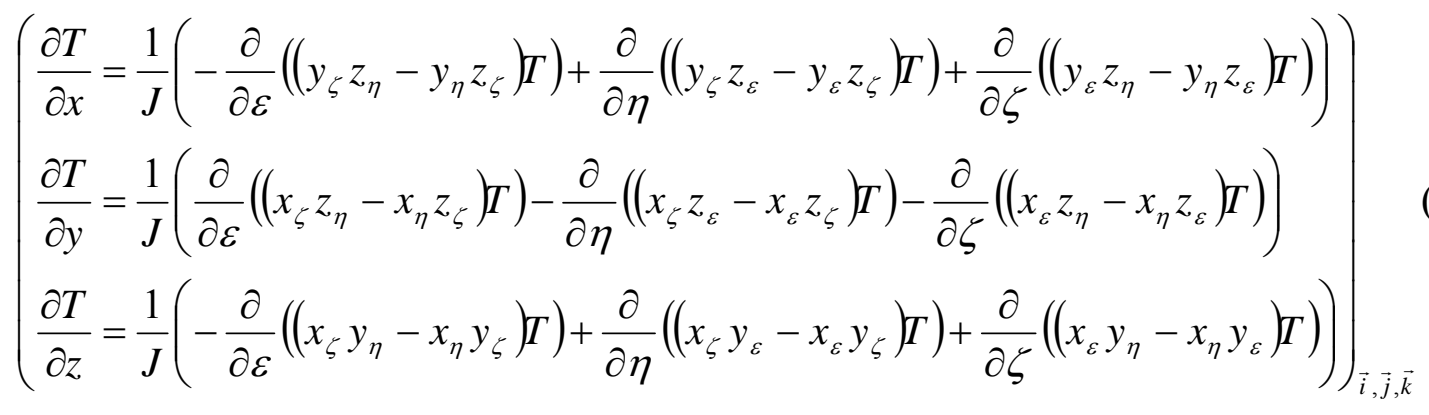

and the non-conservative form is:

$$
\left(\begin{array}{l}
\frac{\partial T}{\partial x}=\frac{1}{J}\left(-\left(y_{\zeta} z_{\eta}-y_{\eta} z_{\zeta}\right) \frac{\partial T}{\partial \varepsilon}+\left(y_{\zeta} z_{\varepsilon}-y_{\varepsilon} z_{\zeta}\right) \frac{\partial T}{\partial \eta}+\left(y_{\varepsilon} z_{\eta}-y_{\eta} z_{\varepsilon}\right) \frac{\partial T}{\partial \zeta}\right) \\
\frac{\partial T}{\partial y}=\frac{1}{J}\left(\left(x_{\zeta} z_{\eta}-x_{\eta} z_{\zeta}\right) \frac{\partial T}{\partial \varepsilon}-\left(x_{\zeta} z_{\varepsilon}-x_{\varepsilon} z_{\zeta}\right) \frac{\partial T}{\partial \eta}-\left(x_{\varepsilon} z_{\eta}-x_{\eta} z_{\varepsilon}\right) \frac{\partial T}{\partial \zeta}\right) \\
\frac{\partial T}{\partial z}=\frac{1}{J}\left(-\left(x_{\zeta} y_{\eta}-x_{\eta} y_{\zeta}\right) \frac{\partial T}{\partial \varepsilon}+\left(x_{\zeta} y_{\varepsilon}-x_{\varepsilon} y_{\zeta}\right) \frac{\partial T}{\partial \eta}+\left(x_{\varepsilon} y_{\eta}-x_{\eta} y_{\varepsilon}\right) \frac{\partial T}{\partial \zeta}\right)
\end{array}\right)_{\vec{i}, \vec{j}, \vec{k}}
$$

The conservative form of the divergence in the transformed space is:

$$
\nabla \cdot \vec{T}=\frac{1}{J}\left\{\begin{array}{l}
\frac{\partial}{\partial \varepsilon}\left[-\left(y_{\zeta} z_{\eta}-y_{\eta} z_{\zeta}\right) T_{1}+\left(x_{\zeta} z_{\eta}-x_{\eta} z_{\zeta}\right) T_{2}-\left(x_{\zeta} y_{\eta}-x_{\eta} y_{\zeta}\right) T_{3}\right] \\
+\frac{\partial}{\partial \eta}\left[\left(y_{\zeta} z_{\varepsilon}-y_{\eta} z_{\varepsilon}\right) T_{1}-\left(x_{\zeta} z_{\varepsilon}-x_{\varepsilon} z_{\zeta}\right) T_{2}+\left(x_{\zeta} y_{\varepsilon}-x_{\varepsilon} y_{\zeta}\right) T_{3}\right] \\
+\frac{\partial}{\partial \zeta}\left[\left(y_{\varepsilon} z_{\eta}-y_{\eta} z_{\varepsilon}\right) T_{1}-\left(x_{\varepsilon} z_{\eta}-x_{\eta} z_{\varepsilon}\right) T_{2}+\left(x_{\varepsilon} y_{\eta}-x_{\eta} y_{\varepsilon}\right) T_{3}\right]
\end{array}\right\}
$$


and the non-conservative form is:

$$
\nabla . \vec{T}=\frac{1}{J}\left\{\begin{array}{l}
{\left[-\left(y_{\zeta} z_{\eta}-y_{\eta} z_{\zeta}\right) \frac{\partial T_{1}}{\partial \varepsilon}+\left(x_{\zeta} z_{\eta}-x_{\eta} z_{\zeta}\right) \frac{\partial T_{2}}{\partial \varepsilon}-\left(x_{\zeta} y_{\eta}-x_{\eta} y_{\zeta}\right) \frac{\partial T_{3}}{\partial \varepsilon}\right]} \\
+\left[\left(y_{\zeta} z_{\varepsilon}-y_{\eta} z_{\varepsilon}\right) \frac{\partial T_{1}}{\partial \eta}-\left(x_{\zeta} z_{\varepsilon}-x_{\varepsilon} z_{\zeta}\right) \frac{\partial T_{2}}{\partial \eta}+\left(x_{\zeta} y_{\varepsilon}-x_{\varepsilon} y_{\zeta}\right) \frac{\partial T_{3}}{\partial \eta}\right] \\
+\left[\left(y_{\varepsilon} z_{\eta}-y_{\eta} z_{\varepsilon}\right) \frac{\partial T_{1}}{\partial \zeta}-\left(x_{\varepsilon} z_{\eta}-x_{\eta} z_{\varepsilon}\right) \frac{\partial T_{2}}{\partial \zeta}+\left(x_{\varepsilon} y_{\eta}-x_{\eta} y_{\varepsilon}\right) \frac{\partial T_{3}}{\partial \zeta}\right]
\end{array}\right\}
$$

The Laplacian in the transformed space is:

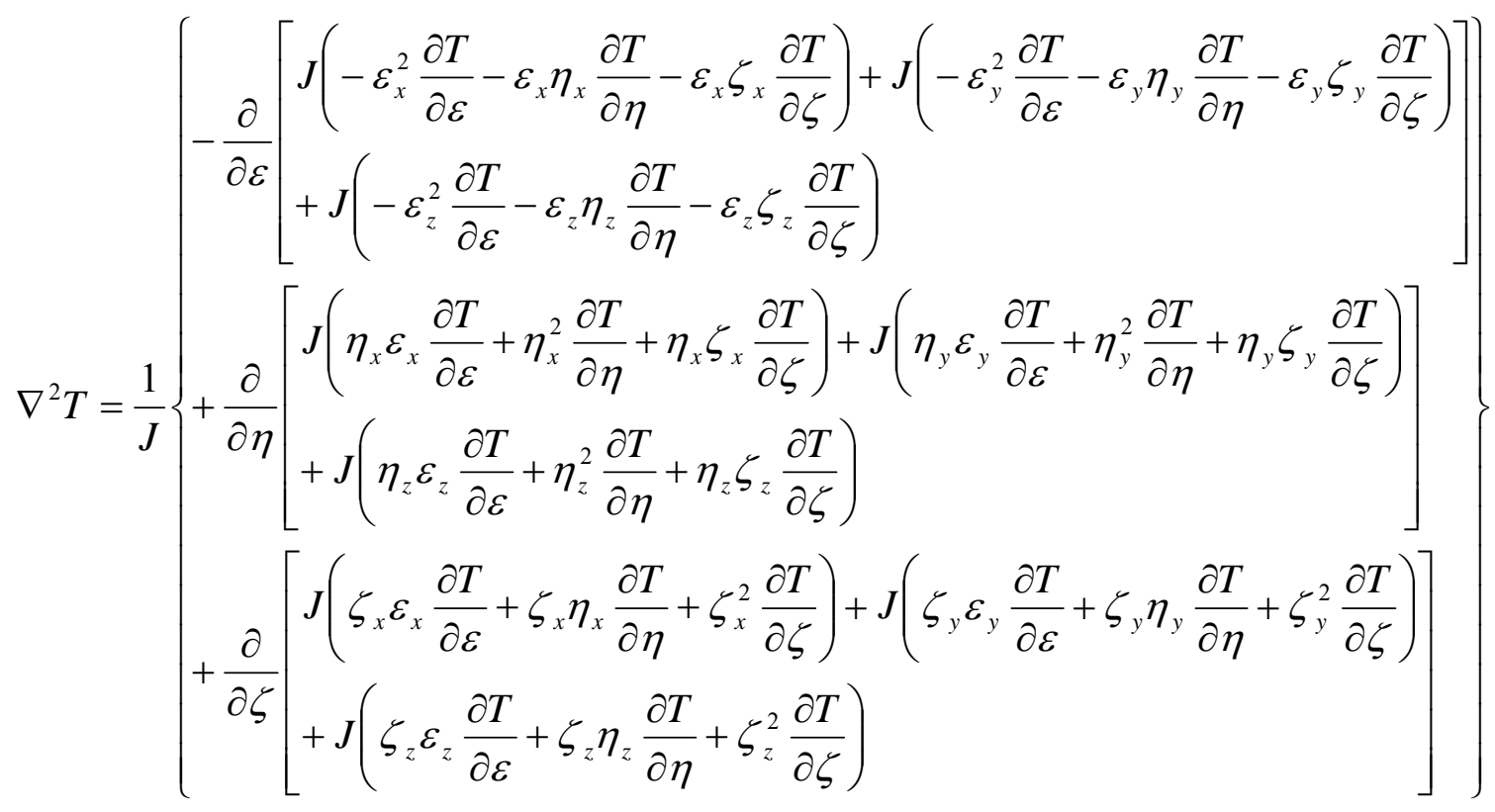

If the generalized coordinates are orthogonal (it is the case in Kishawy's model), important simplifications yield to:

$$
\nabla^{2} T=\frac{1}{J}\left\{\frac{\partial}{\partial \varepsilon}\left(J g_{11} \frac{\partial T}{\partial \varepsilon}\right)+\frac{\partial}{\partial \eta}\left(J g_{22} \frac{\partial T}{\partial \eta}\right)+\frac{\partial}{\partial \zeta}\left(J g_{33} \frac{\partial T}{\partial \zeta}\right)\right\}
$$

And finally, the equation of conduction of heat in a moving medium using generalized coordinates is given by: 


$$
\begin{aligned}
& \rho c \frac{\partial T}{\partial t}+\frac{1}{J}\left\{\frac{\partial}{\partial \varepsilon}(J U T)+\frac{\partial}{\partial \eta}(J V T)+\frac{\partial}{\partial \zeta}(J W T)\right\} \\
& =\frac{k}{J}\left\{\frac{\partial}{\partial \varepsilon}\left(J g_{11} \frac{\partial T}{\partial \varepsilon}\right)+\frac{\partial}{\partial \eta}\left(J g_{22} \frac{\partial T}{\partial \eta}\right)+\frac{\partial}{\partial \zeta}\left(J g_{33} \frac{\partial T}{\partial \zeta}\right)\right\} \\
& \frac{\partial \rho J C T}{\partial t}+\left\{\frac{\partial}{\partial \varepsilon}(J U T)+\frac{\partial}{\partial \eta}(J V T)+\frac{\partial}{\partial \zeta}(J W T)\right\} \\
& =k\left\{\frac{\partial}{\partial \varepsilon}\left(J g_{11} \frac{\partial T}{\partial \varepsilon}\right)+\frac{\partial}{\partial \eta}\left(J g_{22} \frac{\partial T}{\partial \eta}\right)+\frac{\partial}{\partial \zeta}\left(J g_{33} \frac{\partial T}{\partial \zeta}\right)\right\}
\end{aligned}
$$

- Also, for the derivation of the equation of continuity, Equation (22), Kishawy et al. give no information about it. The principal explanations follow.

First, the tool-chip interface is in the $(\varepsilon, \zeta)$ plane. The following vector belongs to this plane:

$$
\vec{r}(\zeta, \varepsilon)=x(\zeta, \varepsilon) \vec{i}+y(\zeta, \varepsilon) \vec{j}+z(\zeta, \varepsilon) \vec{k}
$$

Thus, the unit normal vector is defined by:

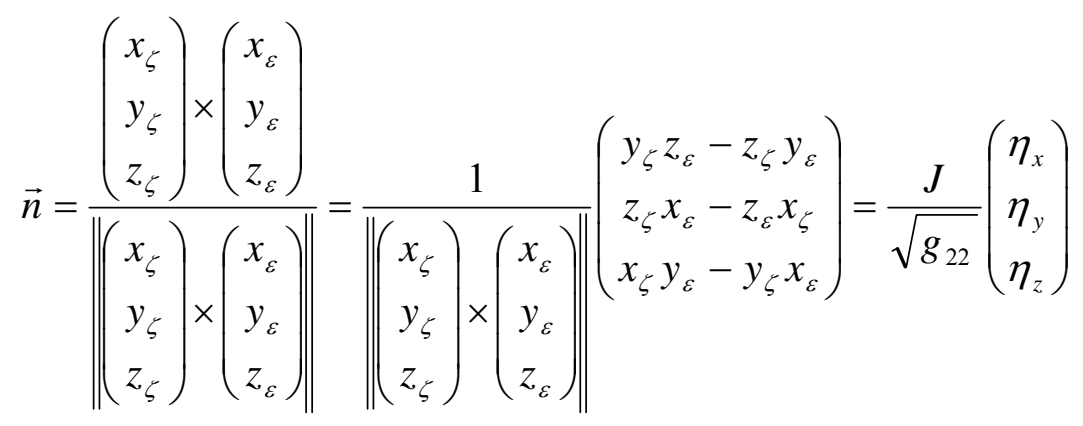


and the normal derivative of the temperature is given by:

$$
\frac{\partial T}{\partial \vec{n}}=\nabla T \cdot \vec{n}=\frac{J}{\sqrt{g_{22}}}\left(\begin{array}{l}
\varepsilon_{x} \eta_{x} \frac{\partial T}{\partial \varepsilon}+\eta_{x}^{2} \frac{\partial T}{\partial \eta}+\eta_{x} \zeta_{x} \frac{\partial T}{\partial \zeta} \\
+\eta_{y} \varepsilon_{y} \frac{\partial T}{\partial \varepsilon}+\eta_{y}^{2} \frac{\partial T}{\partial \eta}+\eta_{y} \zeta_{y} \frac{\partial T}{\partial \zeta}+\eta_{z} \varepsilon_{z} \frac{\partial T}{\partial \varepsilon}+\eta_{z}^{2} \frac{\partial T}{\partial \eta}+\eta_{z} \zeta_{z} \frac{\partial T}{\partial \zeta}
\end{array}\right)
$$

If $\varepsilon, \eta, \zeta$ are orthogonal coordinates, the left-hand side of the continuity equation is (for the chip or the tool):

$$
\frac{\partial T}{\partial \vec{n}}=J \sqrt{g_{22}} \frac{\partial T}{\partial \eta}
$$

If the above equation is integrated over the surface of the control volume with $\Delta \varepsilon$ $=\Delta \zeta=1$, no changes occurs because of the values of $\Delta \varepsilon, \Delta \zeta$.

For the right-hand side, if the heat flux at the interface is uniform and defined as:

$$
\vec{S}_{c t}=S_{c t} \vec{n}
$$

and if $\Delta \varepsilon=\Delta \eta=\Delta \zeta=1$, using the Ostrogradsky's theorem which transforms a surface integral to a volume integral and the mean approximation for the integrations:

$$
\begin{aligned}
& \iint \vec{S}_{c t} \cdot d \vec{S}=\iiint \nabla \cdot \vec{S}_{c t} d V=S_{c t} \iiint\left[\frac{\partial}{\partial \varepsilon}\left(\frac{J}{\sqrt{g_{22}}} \eta_{x}\right)+\frac{\partial}{\partial \eta}\left(\frac{J}{\sqrt{g_{22}}} \eta_{y}\right)+\frac{\partial}{\partial \zeta}\left(\frac{J}{\sqrt{g_{22}}} \eta_{z}\right)\right] d V \\
& =S_{c t}\left(\iint \frac{J}{\sqrt{g_{22}}} \eta_{x} d \eta d \zeta+\iint \frac{J}{\sqrt{g_{22}}} \eta_{y} d \varepsilon d \zeta+\iint \frac{J}{\sqrt{g_{22}}} \eta_{z} d \varepsilon d \eta\right) \\
& =S_{c t} \frac{J}{\sqrt{g_{22}}}\left(\eta_{x}+\eta_{y}+\eta_{z}\right)
\end{aligned}
$$

And finally, the continuity of flux at the tool-chip interface is given by:

$$
\begin{aligned}
& k_{t} J \sqrt{g_{22}} \frac{\partial T_{t}}{\partial \eta}+k_{c} J \sqrt{g_{22}} \frac{\partial T_{c}}{\partial \eta}=S_{c t} \frac{J}{\sqrt{g_{22}}}\left(\eta_{x}+\eta_{y}+\eta_{z}\right) \\
& k_{t} J g_{22} \frac{\partial T_{t}}{\partial \eta}+k_{c} J g_{22} \frac{\partial T_{c}}{\partial \eta}=S_{c t} J\left(\eta_{x}+\eta_{y}+\eta_{z}\right)
\end{aligned}
$$


- Normally, the power law function used by Kishawy in Equation 87 depends on the value of the Peclet number (Patankar, 1980).

Equation (25) can be written as the following form too:

$$
\begin{aligned}
& \frac{(\rho J)_{t}}{\Delta t}\left(h_{i j k}-h_{i j k} \circ\right)_{t}+\left(\Omega_{e}-F_{e} h_{i j k}\right)_{t}+\left(\Omega_{w}-F_{w} h_{i j k}\right)_{t} \\
& +\left(\Omega_{n}-F_{n} h_{i j k}\right)_{t}+\left(\Omega_{s}-F_{s} h_{i j k}\right)_{t}+\left(\Omega_{t}-F_{t} h_{i j k}\right)_{t}+\left(\Omega_{b}-F_{b} h_{i j k}\right)_{t}=0
\end{aligned}
$$

where

$$
\begin{aligned}
& \Omega_{e}-F_{e} h_{i j k}=a_{E}\left(h_{i j k}-h_{i+1 j k}\right) \\
& \Omega_{w}-F_{w} h_{i j k}=a_{W}\left(h_{i-1 j k}-h_{i j k}\right) \\
& \Omega_{n}-F_{n} h_{i j k}=a_{N}\left(h_{i j k}-h_{i j+1 k}\right) \\
& \Omega_{s}-F_{s} h_{i j k}=a_{S}\left(h_{i j-1 k}-h_{i j k}\right)
\end{aligned}
$$

and

$$
\begin{aligned}
& P_{e}<-10 \Rightarrow \frac{a_{E}}{D_{E}}=-P_{e} \\
& -10 \leq P_{e}<0 \Rightarrow \frac{a_{E}}{D_{E}}=\left(1+0.1 P_{e}\right)^{5}-P_{e} \\
& 0 \leq P_{e} \leq 10 \Rightarrow \frac{a_{E}}{D_{E}}=\left(1-0.1 P_{e}\right)^{5} \\
& P_{e}>10 \Rightarrow \frac{a_{E}}{D_{E}}=0
\end{aligned}
$$

Regarding Equation (27), Kishawy et al. infer that $0 \leq \mathrm{P}_{\mathrm{e}} \leq 10$ and it seems to have a typo in this equation; 0.5 has to be changed in 0.1 . So, numerical values are necessary to verify Kishawy's assumption.

- In the equation (29), it seems to have another problem. This equation is derived from equation (22), so the $\mathrm{J}$ in the right-hand side has to be changed in 1 . 


\section{APPENDIX D}

\section{INPUT PARAMETERS}

Table D-1: Geometric and kinematics parameters in rotary tool turning.

\begin{tabular}{|c|c|c|c|c|c|c|c|}
\hline $\begin{array}{c}\mathrm{V}_{\mathrm{w}} \\
(\mathrm{m} / \mathrm{min})\end{array}$ & $\begin{array}{c}\mathrm{V}_{\mathrm{r}} \\
(\mathrm{m} / \mathrm{min})\end{array}$ & $\begin{array}{c}\omega_{\mathrm{r}} \\
(\mathrm{rad} / \mathrm{s})\end{array}$ & $\begin{array}{c}\mathrm{t} \\
(\mathrm{mm})\end{array}$ & $\begin{array}{c}\mathrm{a}_{\mathrm{p}} \\
(\mathrm{mm})\end{array}$ & $\begin{array}{c}\mathrm{b} \\
(\mathrm{mm})\end{array}$ & $\begin{array}{c}\mathrm{t}_{\mathrm{c}} \\
(\mathrm{mm})\end{array}$ & $\begin{array}{c}\mathrm{b}_{\mathrm{c}} \\
(\mathrm{mm})\end{array}$ \\
\hline 10 & 2.6 & 3.2 & 0.05 & 0.05 & 1.4 & 0.05 & 1.50 \\
\hline 15 & 3.9 & 4.8 & 0.05 & 0.05 & 1.4 & 0.05 & 1.45 \\
\hline 20 & 5.2 & 6.4 & 0.05 & 0.05 & 1.4 & 0.05 & 1.397 \\
\hline 25 & 6.5 & 8.0 & 0.05 & 0.05 & 1.4 & 0.05 & 1.350 \\
\hline
\end{tabular}

Table D-2: Mechanical and thermal parameters in rotary tool turning.

\begin{tabular}{|c|c|c|c|c|c|c|}
\hline $\begin{array}{c}\mathrm{V}_{\mathrm{w}} \\
(\mathrm{m} / \mathrm{min})\end{array}$ & $\begin{array}{c}\mathrm{F}_{\mathrm{c}} \\
(\mathrm{N})\end{array}$ & $\begin{array}{c}\mathrm{F}_{\mathrm{t}} \\
(\mathrm{N})\end{array}$ & $\begin{array}{c}\mathrm{F}_{\mathrm{f}} \\
(\mathrm{N})\end{array}$ & $\begin{array}{c}\mathrm{F} \\
(\mathrm{N})\end{array}$ & $\begin{array}{c}\mathrm{q}_{\mathrm{f}} \\
\left(\mathrm{W} / \mathrm{mm}^{2}\right)\end{array}$ & $1-\mathrm{R}_{\mathrm{e}}$ \\
\hline 10 & 74 & 100 & 22 & 78 & 51.6 & 0.215 \\
\hline 15 & 85 & 150 & 28 & 123 & 112.7 & 0.177 \\
\hline 20 & 92 & 188 & 30 & 158 & 182.4 & 0.152 \\
\hline 25 & 90 & 200 & 30 & 170 & 234.2 & 0.134 \\
\hline
\end{tabular}




\section{REFERENCES}

E. J. A. Armarego, V. Karri and A. J. R. Smith, 1994, Fundamental studies of driven and self-propelled rotary tool cutting processes-I. Theoretical investigation, International Journal of Machine Tools and Manufacture, 34, No. 6, 785-801.

E. J. A. Armarego, V. Karri and A. J. R. Smith, 1994, Fundamental studies of driven and self-propelled rotary tool cutting processes-II. Experimental investigation, International Journal of Machine Tools and Manufacture, 34, No. 6, 803-815.

G. Boothroyd, 1989, Fundamentals of metal machining and machine tools. New York: McGraw-Hill Book Co.

H. S. Carlsaw, J. C. Jaeger, 1959, Conduction of heat in solids. Oxford 2nd edition, U.K.: Oxford University Press.

P. Chen, 1992, Cutting temperature and forces in machining of high-performance materials with self-propelled rotary tool, JSME International Journal, Series III, Vol. 35, No. $1,180-185$.

P. Chen, 1992, High-Performance Machining of $\mathrm{SiC}$ whisker-reinforced aluminium composite by self-propelled rotary tools, Ann. CIRP 41, 59-62.

U. A. Dabade, S. S. Joshi, N. Ramakrishnan, 2003, Analysis of surface roughness and chip cross-sectional area while machining with self-propelled round inserts milling cutter, Journal of Materials Processing Technology, 132, pp. 305-312.

P. Gilormini, 1982, Contribution à la modélisation de la formation du copeau en usinage des métaux, Thèse, Ecole Nationale Supérieure des Mines de Paris.

S. S. Joshi, N. Ramakrishnan, H. E. Nagarwalla, P. Ramakrishnan, 1999, Wear of rotary carbide tools in machining of Al/SiCp composites, Wear, 230, 124-162.

H. A. Kishawy, A. G. Gerber, 2001, A model for the tool temperature during machining with a rotary tool, ASME, International Mechanical Engineers Congress and Exposition, New York, NY, IMECE2001/MED-23312, 1-8.

H. A. Kishawy, J. Wilcox, 2003, Tool wear and chip formation during hard turning with self-propelled rotary tools, International Journal of Machine Tools and Manufacture.

S. Lei and W. Liu, 2002, High-speed machining of titanium alloys using the driven rotary tool, International Journal of Machine Tools and Manufacture, 42, 353-661. 
E. G. Loewen, M. C. Shaw, 1954, On the analysis of cutting-tool temperatures, Trans. ASME, 217-231.

M. K. Medaska, 1998, The measurement of temperatures and forces in turning operation with cutting fluid, Thesis, Georgia Institute of Technology.

M. N. Ozisik, 1994, Finite difference methods in heat transfer, CRC Press, Inc.

S. V. Patankar, 1980, Numerical heat transfer and fluid flow, Hemisphere, McGraw-Hill.

M. C. Shaw, 1984, Metal cutting principles, Oxford University Press.

M. C. Shaw, P. A. Smith and N. H. Cook, 1952, The rotary cutting tool, Trans. ASME. 74, 1065-1076.

J. F. Thompson, Z. U. Warsi, C. W. Mastin, 1982, Boundary-fitted coordinate systems for numerical solution of partial differential equations, 1-108, Elsevier Science Publisher.

K. J. Trigger, B. T. Chao, 1951, An analytical evaluation of metal cutting temperatures, Trans. ASME, 57-58.

P. K. Venuvidod, W. S. Lau and P. N. Reddy, 1981, Some investigations in machining with driven rotary tools, Trans. ASME, 103, 469-477.

P. K. Venuvinod, W. S. Lau, P. N. Reddy, 1983, On the formation of a fluid film at the chip tool interface in rotary machining, Ann. CIRP 32 (1), 59-64.

C. Wuyi, C. Xing, Z. Guojin, G. Zuduan, 1991, High speed machining of hardened steel using CBN tipped rotary cutting tools, Transformation of science and technology into productive power, proceedings of he 11th International Conference on Production Research (ICPR), 23-27.

Y. Zhang, J. Wilcox, H. A. Kishawy, 2003, An assessment of carbide self-propelled rotary tools during machining hardened steel, Trans. of NAMRI/SME, XXXI, 185-192. 